University of Louisville

ThinkIR: The University of Louisville's Institutional Repository

\title{
Examining the relationship between college football season ticket holders' service personal values and their behavioral intentions : the moderating effect of team identification.
}

Gary Peng-Liang Tan

University of Louisville

Follow this and additional works at: https://ir.library.louisville.edu/etd

\section{Recommended Citation}

Tan, Gary Peng-Liang, "Examining the relationship between college football season ticket holders' service personal values and their behavioral intentions : the moderating effect of team identification." (2011). Electronic Theses and Dissertations. Paper 1416.

https://doi.org/10.18297/etd/1416

This Doctoral Dissertation is brought to you for free and open access by ThinkIR: The University of Louisville's Institutional Repository. It has been accepted for inclusion in Electronic Theses and Dissertations by an authorized administrator of ThinkIR: The University of Louisville's Institutional Repository. This title appears here courtesy of the author, who has retained all other copyrights. For more information, please contact thinkir@louisville.edu. 


\title{
EXAMINING THE RELATIONSHIP BETWEEN COLLEGE FOOTBALL SEASON TICKET HOLDERS' SERVICE PERSONAL VALUES AND THEIR BEHAVIORAL INTENTIONS: THE MODERATING EFFECT OF TEAM IDENTIFICATION
}

\author{
By \\ Gary Peng-Liang Tan \\ B.S., Central Michigan University, 2001 \\ M.A., Central Michigan University, 2003 \\ M.S., Central Michigan University, 2006
}

\begin{abstract}
A Dissertation
Submitted to the Faculty of the

School of Interdisciplinary and Graduate Studies of the University of Louisville In Partial Fulfillment of the Requirements for the Degree of

Doctor of Philosophy

College of Education and Human Development

University of Louisville

Louisville, Kentucky
\end{abstract}

August 2011 
Copyright 2011 by Gary P. Tan

All rights reserved 



\section{EXAMINING THE RELATIONSHIP BETWEEN COLLEGE FOOTBALL SEASON TICKET HOLDERS' SERVICE PERSONAL VALUES AND \\ THEIR BEHAVIORAL INTENTIONS: THE MODERATING \\ EFFECT OF TEAM IDENTIFICATION}

\section{By}

Gary Peng-Liang Tan

B.S., Central Michigan University, 2001

M.A., Central Michigan University, 2003

M.S., Central Michigan University, 2006

A Dissertation Approved on

June 24, 2011

by the following Dissertation Committee:

T. Chris Greenwe1l, Dissertation Director

Kary A. Hums

Anita M. Moorman

John' L. Keedy

Amy S. Hirschy 


\section{DEDICATION}

This dissertation is dedicated to my parents

Mr. Tan Swee Heong

and

Mrs. Lim Joo Kee

who have been with me through

the thick and thin of my education endeavor. 


\section{ACKNOWLEDGMENTS}

In 1861, Yale Graduate School of Arts and Sciences conferred the first Ph.D.

degree in North America to a scholar named James Morris Whiton (Liberty University, 2008). One hundred fifty years later, I have the opportunity and privilege to be on the path to join a league of extraordinary individuals devoting their life to generate knowledge for the society. My dream of earning a doctorate degree started in Michigan, and it has gone through Kentucky and ended in Florida. Over the past five years, there are many individuals that came, left, and stayed in my life. Mummy, Papa, Betty, Tony, Sonny, Edmund, and Sheanny thank you for sticking with me through the thick and thin of my life. I am who I am today because all of you consistently shower me with unconditional love and faith, even at times when I have doubt about my dream. All of you have taken turns to put a smile on my face while I am going through the toughest journey in my life. Each and every one of you helps me turn the "impossible into the inevitable" and my doctoral degree is dedicated to all of you.

I want to thank my dissertation chair, Dr. Chris Greenwell, who has faith in me despite not producing anything for two years after I have successfully completed my comprehensive exam. Dr. Greenwell showed me the compassion for knowledge and taught me the virtue of perseverance. The lessons I learned from Dr. Greenwell will be passed down to the next generation of college students. Thank you Dr. Mary Hums for listening to my countless complaints about the world is not fair, and relentlessly convey me that something good never come easy and keep fighting every day. Dr. John Keedy, 
whom I have a class with every single semester of my doctoral career at the University of Louisville, and showed me the beauty of qualitative research. Dr. Keedy met me as an inspired a new doctoral student, a doctoral student who was at the lowest point of his doctoral career, and a doctoral student breathing air full of confidence. Thank you Dr. Keedy for seeing the talents in me, when only a number of people in my life believe I am worthy of a conversation. Finally, Professor Anita Moorman, Dr. Amy Hirschy, Dr. Cathy Akens, and Gisela Vega, thank you for taking a great deal of time and focus to read my dissertation. Your meticulous feedback made my dissertation comes alive.

I also want to also thank special group of colleague and friends at Central Michigan University, University of Louisville, and Florida International University. Specifically, Jose Rodriguez who have been my best friend during my stay at the University of Louisville. Thank you Jose for "I have a wish speech at UTA 101". When all I can see in front of me are road blocks, your wish of seeing me graduate with a doctoral degree has inspired me to relentlessly pursue my dream. You made me believed that everything happened for a reason, but sometimes the reason may not be obvious to me, and it alright to live with the unknown. In addition, thank you Pinkie Smyser for all the complimentary counseling sessions and laughter at the University of Louisville Housing and Residential Life Office. Without your support, I would not be writing this acknowledgement section today.

A special thank you goes out to Maria "Fefi" Fernandez, who has been one of my biggest emotional supporters at Florida International University. You seen me smile, you seen me struggle, you seen me in tears, and most importantly you know when to give me a big hug when I needed one. You taught me the importance of being inspired by others 
and to inspire others, and adversities build character. My success today is a testament of unconditional support and confidence you have gave me, since the first day we started working together.

Finally, I would like to extend my deepest appreciation to Dr. Paul Natke, Dr. Philip Thompson, Dr. Scott Smith, Luanne Goffnett, Prachaya Vatthaisong, Tan Seong Chun, Pam Curtis, Hannah Piechowski, Ron Thompson, Lynn Hendricks, Adam Schwarz, Lavern Morant, Daniel Jordan, Filomena Martin, and all the professionals that I have the privilege and opportunity to call colleague and friend. All of you have impacted my life, from the moment I apply to doctoral programs to the moment I stand on the stage to receive my doctoral degree. 


\section{ABSTRACT \\ EXAMINING THE RELATIONSHIP BETWEEN COLLEGE FOOTBALL SEASON TICKET HOLDERS' SERVICE PERSONAL VALUES AND \\ THEIR BEHAVIORAL INTENTIONS: THE MODERATING EFFECT OF TEAM IDENTIFICATION}

\section{Gary Peng-Liang Tan}

June 24, 2011

Recently, some college football programs have experienced unsustainable attendance growth, increases in revenue discrepancies, stagnant "revenue growth", and increased operating costs (Brown, 2009; Fulks, 2009; Fullerton \& Morgan, 2009; Jackson, 2005; NCAA, 2009, 2010). These problems can be examined from customer service, social identification, and consumer behavior perspectives (Curtin, 1982; Katona, 1974; Wann \& Branscombe, 1993; Zeithaml, 1988). This study's research purposes are to understand service personal values antecedents and outcomes, and team identification's moderating effect on the relationship between service personal values, and both consumption satisfaction perceptions and behavioral outcomes. A sample of college football season ticket holders at a large public university in Southeastern United States completed an online survey. Factorial multivariate analysis of variance (MANOVA), multiple regression analysis, and hierarchical regression analysis were used to analyze the data.

The findings of this study indicated college football season ticket holders' team identification moderated the relationship between their service value to social recognition (SVSR), and both consumption satisfaction and behavioral intentions. College football 
season ticket holders' with low team identification level are more likely to depend on SVSR to formulate their consumption satisfaction perceptions and behavioral intentions, compared to college football season ticket holders' with high team identification level. Antecedents of college football season ticket holders' service personal values include number of household members, gender, university affiliation, number of years holding season tickets, and ethnicity. 


\section{TABLE OF CONTENTS}

PAGE

ACKNOWLEDGEMENTS .................................................................... iv

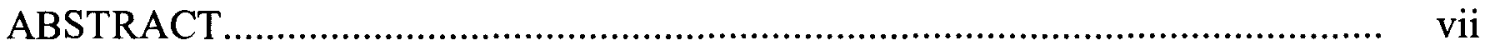

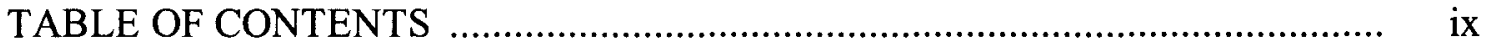

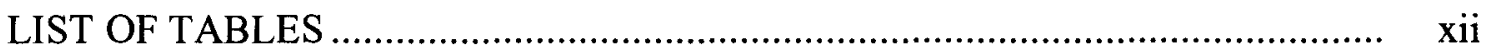

\section{CHAPTER}

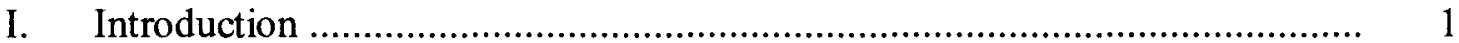

Research Problem ......................................................................... 2

Sport Consumption ...................................................................... 4

Service Personal Values..................................................................... 5

Team Identification..................................................................... 7

Purpose of the Study .................................................................... 10

Justification for the Study ............................................................. 11

Significance of the Study .................................................. 14

Research Questions......................................................................... 17

Delimitations .......................................................................... 19

Limitations ............................................................................ 19

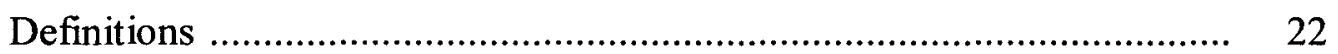

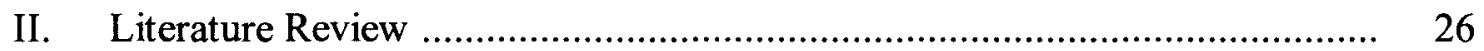

Service Personal Values ..................................................................... 28

Historical Development of Personal Values ............................. 29

Personal Values Measurement Scales ....................................... $\quad 35$

Sport Personal Values Literature .......................................... 45

Service Personal Values Summary ........................................... 49

Team Identification ....................................................................... 53

Historical Background of Team Identification ......................... 54

Sport Fan Team Identification ............................................. 57

Relationship between Team Identification and Sport

Consumption ............................................................. 62

Team Identification Summary ............................................ 66

Sport Consumption .................................................................... 68

Sport Consumer Decision Making Process .............................. 69

Sport Consumer Behavioral Intentions .................................... 77

College Football .................................................................. 79 
Sport Consumption Summary .................................................. 81

Summary of Literature Review ................................................................. 83

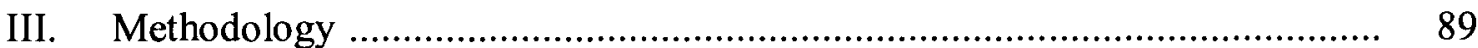

Research Study Purpose ............................................................... $\quad 89$

Research Questions ................................................................. 90

Study Design ........................................................... 92

Research Study Target Variables ........................................................... 93

Demographic Questionnaire ................................................... 93

Team Identification ................................................................. 94

Customer Satisfaction .............................................................. 95

Consumer Behavioral Intentions .............................................. 96

Service Personal Values ........................................................... 97

Service Personal Values Dimensions ............................... $\quad 97$

Field Study and Pilot Study ............................................................. 99

Research Participants ...................................................................... 100

Data Collection Procedure .............................................................. 101

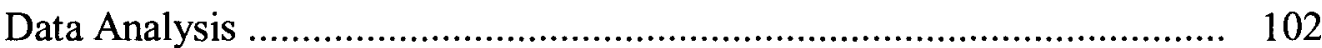

Factorial Multivariate Analysis of Variance ................................ 102

Multivariate Analysis of Variance Assumptions ............... 103

Multiple Regression Analysis ................................................. 104

Hierarchical Regression Analysis ............................................ 105

Regression Analysis Assumptions .................................. 106

Data Analysis Summary …………............................................ 107

Methodology Summary .................................................................. 111

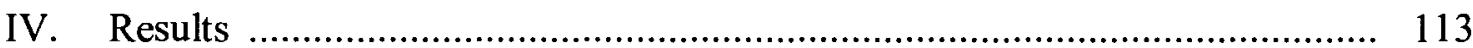

Field Test and Pilot Study Results ................................................... 113

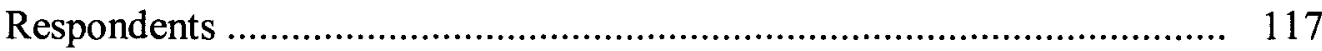

Response Rate ...................................................................... 117

Respondents' Demographic Profiles ....................................... 118

Scale Reliability ........................................................................... 122

Results for Research Question 1 .................................................... 124

Target Variables' Descriptive Statistics and Zero-Order Correlations ............................................................ 132

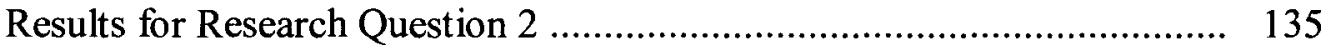

Results for Research Question 3 ................................................ 138

Results for Research Question 4 .................................................... 140

Results for Research Question 4(a) ............................................ 140

Results for Research Question 4(b) ........................................ 141

Results for Research Question 4(c) .......................................... 141

Results for Research Question 5 ......................................................... 145

Results for Research Question 5(a) ........................................... 145

Results for Research Question 5(b) ............................................ 145

Results for Research Question 5(c) .......................................... 146

Data Analysis Summary................................................................. 149 


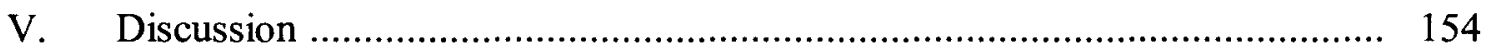

Main Findings and Implications ................................................... 158

Demographic Profiles and Service Value to Peaceful Life ........... 158

Demographic Profiles, Service Value to Social Recognition, and Service Value to Social Integration ............................ 159

Service Value to Social Recognition and Consumption Satisfaction Perceptions .............................................. 163

Service Value to Social Recognition, Service Value to Social ........

Integration, and Behavioral Intentions .............................. 165

Team Identification and Consumption Satisfaction Perceptions .... 167

Team Identification and Behavioral Intentions ............................ 169

Suggestions for Future Research ...................................................... 170

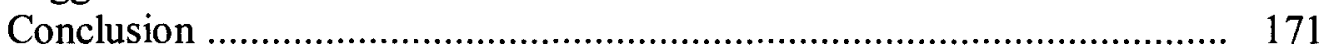

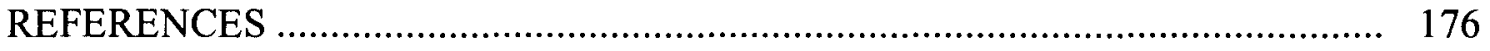

APPENDICES .................................................................................... 190

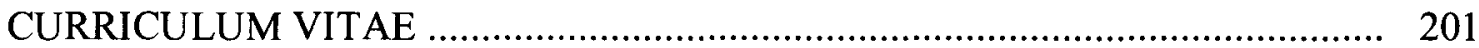




\section{LIST OF TABLES}

$\begin{array}{ll}\text { TABLE } & \text { PAGE }\end{array}$

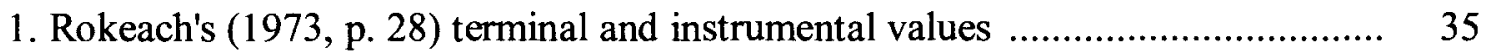

2. Service Personal Values Measurement Scale Summary .............................. 49

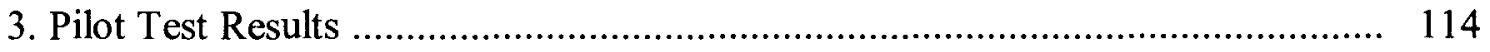

4. Demographic Profiles of Respondents ….................................................. 118

5. Scale Reliability Results .................................................................. 121

6. Levene Test Results for RQ1 .............................................................. 124

7. Means, Standard Deviations, and Intercorrelations of All Variables ................. 132

8. Correlations of Consumption Satisfaction with Service Personal Values

Dimensions ……....................................................................... 135

9. Correlations of Behavioral Intentions with Service Personal Vales

Dimensions

10. Results of Moderated Regression Analyses SERPVAL Dimensions and

TID on Consumption Satisfaction Perceptions ................................... 141

11. Results of Moderated Regression Analyses SERPVAL Dimensions and

TID on Behavioral Intentions ....................................................... 145

12. Summary of RQ (1) Findings ......................................................... 149

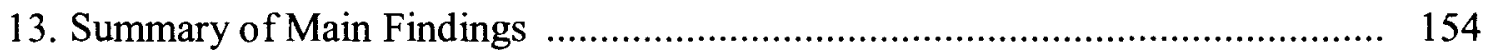




\section{CHAPTER I}

\section{INTRODUCTION}

A total of 628 schools competed in four divisions (i.e., Division I - Football Bowl Series, FBS, Division I - Football Championship Series, FCS, Division II, and Division III) during the 2009/2010 college football season (ESPN, 2010). College football was the highest revenue generating college sport in United States, and earning $311 \%$ more annual total revenue than the second place sport, men's college basketball in 2008 (Fulks, 2009). Research studies related to college football consumption reported some college football programs have limited resources to promote their services (Fulks, 2009; Znidar, 2007). As such, those college football programs need to channel their resources toward customer service initiatives and target consumer groups providing them with the highest return on their marketing investment (Mullin, Hardy, \& Sutton, 2000).

College football season ticket holders are considered one of the highest and most consistent revenue contributors for intercollegiate athletic programs (Fulks, 2005a, 2009; Young, 2001). In 2008, ticket sales accounted for $26 \%$ of generated revenue (i.e., the highest generated revenue source) for NCAA Football Bowl Subdivision (FBS) schools (Fulks, 2009). The target population for this study is college football season ticket holders at a college football program with limited resources to promote their services.

Many of the problems related to college football operations and competitions such as unsustainable attendance growth, increased in revenue discrepancies, stagnant in "revenue growth", and increased in operating costs can be examined from consumer 
behavior perspective (Curtin, 1982; Katona, 1974). Consumer behavior research studies reported customer service and social identification theories explained consumer behaviors (Cronin, Brady, \& Hult, 2000; Lavarie \& Arnett, 2000; Matsuoka, Chelladurai, \& Harada, 2003). For example, several researchers suggested (Cronin et al., 2000; Lages \& Fernandes, 2005; Kahle \& Homer, 1985; Lavarie \& Arnett, 2000; Madrigal, 1995, 2001; Matsuoka et al., 2003; Rokeach, 1973): (a) individuals' service personal values are correlated to their team identification levels, (b) individuals' service personal values and team identification together explained their consumption satisfaction perceptions and behavioral intentions, (c) individuals' consumption satisfaction explained their behavioral intentions, and (d) individuals' team identification may moderate the relationship between service personal values, and consumers' satisfaction perceptions and behavioral intentions. This study conceptual framework is based on consumer behavior, service personal values, and social identification theories. This study seeks to better understand customer satisfaction and behavior among college football season ticket holders so that marketing efforts are able to maximize the revenue potential. Despite being the highest revenue generating college sport in United States (U.S.), several problems are associated with college football marketing.

\section{Research Problem}

The average net profit for all Division I-A programs increased by $54 \%$ from 2004 to 2008 (Fulks, 2009), but only three (i.e., Big Ten, Big East, and Mountain West) of the eleven FBS conferences managed to increase their average football programs' attendance from 2008 to 2009 (NCAA, 2010). Fulks (2010, p. 8) reported "there was an $5.8 \%$ increase in generated revenues for the median FBS institutions from 2008 to 2009". 
College football attendance has continued to increase over the past few decades (Johnson, 2009), but the recent economic slowdown has negatively impacted consumers' sport spending behavior (Fullerton \& Morgan, 2009). Overall college football attendance decreased in the 2009/2010 season (NCAA, 2010). These inconsistencies in college football attendance can lead to unsustainable growth in college football revenue, which can be a problem for college sport administrators conducting budget planning. For example, college football administrators planning to build a new or expand an existing stadium may have difficulty justifying their actions, because of unsustainable growth in attendance.

A large discrepancy emerged between the conference with the highest and the conference with the lowest average attendance (NCAA, 2009). For example, the Southeastern Conference (SEC) members had the highest average attendance (i.e., 76,288) in the 2009/2010 college football season, and Mid-American Conference (MAC) members had the lowest average attendance (i.e., 15,317) in the 2009/2010 college football season (NCAA, 2009). The gap continued to grow from 2006 to 2008 (Brown, 2009). If this discrepancy in overall average college football attendance continues to increase, it can transition into increasing gap in overall revenue generated between the conference with highest average attendance and the conference with lowest average attendance. Fulks (2010) reported total expenses for FBS institutions increased at a faster rate than generated revenues from 2004 to 2009 . This increased gap in overall revenue generated from college football operations can jeopardize the ability of college football programs with low or negative revenues to continue competing in college football. Most university athletic programs' revenues are reaching their maximum potential 
or "hitting the ceiling", and are also facing stiff competition for sport consumers' spending, from other university athletic programs and professional sports (Fulks, 2009). From the operating costs aspect, some of the university athletic programs relying on direct institutional support in the past may be losing the privilege in the future (Jackson, 2005). Recently, universities across the U.S. are facing diminishing state funding for higher education (Jackson, 2005), and several universities (e.g., California State University - Fullerton, James Madison University, Ohio University, University of New Orleans, and University of Northern Iowa) cut some of their sport teams in order to cope with the declined state funding on higher education or to keep football program (Znidar, 2007). The stagnation in "revenue growth" combined with increased operating costs can impact some college football programs' ability to compete in the future. This study seeks to develop better understanding the relationship between service personal values, customer satisfaction, and consumer behavior among college football season ticket holders, so that college football marketers are able to maximize their college football programs' revenue potential.

\section{Sport Consumption}

Purchasing a college football season ticket is considered a major sport consumption action for college football consumers because it involves extensive financial, psychological, and physical commitments. For instance, it is a common practice for university athletic departments to require college football consumers to donate to the university's scholarship fund before they can purchase college football season tickets (e.g., University of Florida, 2010; University of Georgia, 2010; University of Miami, 2010). Potential college football season ticket holders may utilize extensive an 
decision making process to evaluate their purchase decision (Lamb, Hair, \& McDaniel, 2004), and one of the critical assumptions for using an extensive decision making process is that consumers rely extensively on their personal values to make their final consumption decision (Zeithaml, 1988).

\section{Service Personal Values}

Service personal values are defined as "the service's capacity to meet or reflect the individual's personal values" (Lages \& Fernandes, 2005, p. 1564). Zeithaml (1988) developed a means-end chain model to explain consumer behavioral outcomes. The means-end chain model suggested consumers generally go through four levels of cognitive abstraction (i.e., service attributes, service quality, service value, and service personal values) to assess a service, before making their final consumption decision (Zeithaml, 1988). Cognitive abstraction is the act of reducing concrete content information through individual thought process (Lages \& Fernandes, 2005). Zeithaml (1988) suggested service personal values is the highest consumers' cognitive abstraction level in the means-end chain model, followed by service value, service quality, and service attributes, and consumers' service personal values impacted their consumption satisfaction perceptions and behavioral intentions.

Lages and Fernandes (2005, p. 1565) reported service personal values include: (a) Service Value to Peaceful Life (SVPL) and it is defined as "if a service promotes a peaceful life, brings or improves tranquility, safety and/or harmony, then its user recognizes the value of this service", (b) Service Value to Social Recognition (SVSR) and it is defined as "individuals consider whether the service aids in gaining respect from others, social recognition and status, as well as whether it allows achieving a more 
fulfilled and stimulating life, which might then be revealed to others", and (c) Service Value to Social Integration (SVSI) and it is defined as "if the consumer perceives that a service strengthens friendships, provides the possibility of becoming more integrated in the group, or promotes better relationships at the social, professional or family levels, then the service will contribute to social integration, and naturally the individual will recognize personal value in the service".

Sport consumer behavior theory suggests sport consumers' behavioral intentions (i.e., behavioral component) are affected by their consumption satisfaction (i.e., affective component), and in turn, sport consumers' consumption satisfaction is affected by their cognitive processes such as customer service cognitive abstraction (Cronin et al., 2000; Fishbein \& Azjen, 1975; Greenwell, Fink, \& Pastore, 2002; Kelley \& Turley, 2001; Lutz, 1977; McDonald, Sutton, \& Milne, 1995; Wakefield \& Blodgett, 1996). Sport marketing researchers can utilize service personal values to explain sport consumer behavior (Kahle, Duncan, Dalakas, \& Aiken, 2001; Quester, Beverland, \& Ferrelly, 2006; Shao, 2002). It is critical for sport marketing researchers and practitioners to develop a more comprehensive understanding of sport consumers' service personal values, because they can utilize sport consumers' service personal values to create effective marketing plans (Kahle et al., 2001).

Several sport marketing research studies identified sport consumers' demographic profiles as important predictors of their service personal values (Kahle, 1983; Kahle, et al., 2001; Quester et al., 2006; Shao, 2002; Wang, Rao, \& D'Auria, 1994), but none of those studies examined college football season ticket holders. Young (2001) and Fulks (2009) suggested college football season ticket holders are different from regular college 
football consumers, because they are financially, emotionally, and psychologically invested (i.e., dedicated) to their team's success (Mullin et al., 2000; Young, 2001). College football season ticket holders' dedications toward their team success may stimulate them to use service personal values to construct their final consumption decision (Lamb et al., 2004). This study examines the relationship between college

football season ticket holders' service personal values and demographic profiles. Several researchers discovered individuals' service personal values correlated to their team identification levels (Kahle, 1983; Maslow, 1959; Wang, et al., 1994). Wann and Branscombe's (1990) and Trail and James' (2001) team identification studies provided additional theoretical background for this study.

\section{Team Identification}

Team identification is defined as "the sense of oneness with or belongingness to a team" (Matsuoka et al., 2003, p. 246) or the extent to which a fan feels a psychological comnection to his or her team (Wann \& Branscombe, 1993). Wann and Branscombe (1990) suggested team identification levels explained sport fans' tendencies to become fair-weather fans or die-hard fans (i.e., sport fans' behavior). Several research studies reported team identification explained most of the variance in sport consumers' satisfaction and behavioral intentions (Lavarie \& Arnett, 2000; Matsuoka et al., 2003; Van Leeuwen, Quick, \& Daniel, 2002). Team identification has generally been treated as one of the antecedents of sport consumers' consumption satisfaction perceptions or behavioral intentions (Lavarie \& Arnett, 2000; Trail, Anderson, \& Fink, 2000), and team identification has not been extensively utilized as a moderator to explain the relationship between sport customer service constructs, and satisfaction perceptions and behavioral 
intentions (Madrigal, 2001).

Social identity theory suggests sport fans' team identification impacts affective, cognitive, and behavioral outcomes (Sutton, McDonald, Milne, \& Cimperman, 1997; Trail et al., 2000; Wann \& Branscombe, 1993). Sport marketing research studies indicated team identification is considered one of the antecedents of sport consumers' satisfaction perceptions or behavioral intentions. For example, college football fans' university affiliation, prestige perception, and college football domain involvement predicted and explained their team identification level (Gwinner \& Swanson, 2003). Domain involvement refers to personal interest in a particular sport rather than a particular sport team or sport teams (Gwinner \& Swanson, 2003). In turn, college football fans' identification level predicted and explained their consumption satisfaction and behavioral intentions (Gwinner \& Swanson, 2003).

Baron and Kenny (1986) argued to advance a theory's research and practical implications, future researchers need to move beyond the basic research question (e.g., the relationship between service personal values and customer satisfaction, or the relationship between customer satisfaction and behavioral intentions). Frazier, Tix, and Barron (2004, p. 115) suggested "one way to do move beyond the basic research question is by examining the moderators' and mediators' effects", and Aguinis, Boik, and Pierce (2001) implied the discovery of critical moderators between the relationship of predictor and explanatory variables signifies the sophistication and maturity of a study field.

Wann and Branscombe (1993) suggested individuals' sport consumption decision making process (i.e., cognitive component) differed by team identification level, and they reported highly identified sport fans were more likely to attend more games and spend 
more for tickets compared to sport fans with low team identification levels. Individuals' self-expression behavior and tendencies to identify with sport teams moderate the relationship between their consumption decision making process and behavior (Madrigal, 2001). The current study advances the theory development of sport consumer behavior research using team identification as a moderating variable rather than an exogenous variable (i.e., an antecedent) to customer satisfaction and behavioral intentions. This study investigates the moderating effect of team identification on college football season ticket holders' service personal values and their behavioral intentions.

In conclusion, the service personal values construct is considered the most important cognitive abstraction in consumers' customer service cognitive abstraction (Lages \& Fernandes, 2005; Vinson, Scott, \& Lamont, 1977; Zeithaml, 1988), and consumers' service personal values are impacted by their demographic profiles such as number of household members, gender, ethnicity, household income, alumni status, and number of years holding season tickets (Kahle et al., 2001; Quester et al., 2001). The independent variable for this study is service personal values (i.e., Service Value to Peaceful Life, SVPL, Service Value to Social Recognition, and Service Value to Social Integration, SVSI). The dependent variables for this study are behavioral intentions and consumption satisfaction perceptions. The moderating variable for this study is team identification. Figure 1 demonstrates the conceptual framework for this study. This study's finding will help college football administrators facing unsustainable attendance growth, increased in revenue discrepancies, stagnant "revenue growth", and increased operating costs, because it explores multiple facets of consumer decision making process (i.e., cognitive and affective components). 
Figure 1

Conceptual Framework for this Current Study

\begin{tabular}{|c|c|c|}
\hline $\begin{array}{l}\text { Consumers' } \\
\text { Demographic } \\
\text { Profiles }\end{array}$ & $\begin{array}{c}\text { Independent Variables } \\
\text { (e.g., Service Personal } \\
\text { Values) }\end{array}$ & $\begin{array}{l}\text { Dependent Variables (e.g., } \\
\text { Consumption Satisfaction } \\
\text { and Behavioral Intentions) }\end{array}$ \\
\hline & $\begin{array}{l}\text { Modera } \\
\text { (e.g., Tea }\end{array}$ & $\begin{array}{l}\text { riables } \\
\text { (fication) }\end{array}$ \\
\hline
\end{tabular}

\section{Purpose of the Study}

Service personal values are considered one of the most important constructs predicting and explaining consumers' consumption satisfaction perceptions and behavioral intentions (Lages \& Fernandes, 2005; Vinson et al., 1977; Zeithaml, 1988). The success of sport organizations may depend on their ability to satisfy consumers' service personal values (Kahle et al., 2001; Quester et al., 2006; Shao, 2002). Service personal values are correlated to consumers' demographic profiles (Kahle et al., 2001, Lages \& Fernandes, 2005, Lamb et al., 2004), and it is the final level of consumers' customer service cognitive abstraction possessing more individualized characteristics and considered a more sophisticated structure compared to service attributes, service quality, and service value (Lages \& Fernandes, 2005; Zeithaml, 1988). Sport consumers' team identification level impacts their consumption satisfaction perceptions and behavioral intentions (Lavarie \& Arnett, 2000; Matsuoka et al., 2003; Wann \& Branscombe, 1993), and team identification moderates the relationship between sport consumers' customer service cognition abstraction, and affective and behavioral outcomes (Madrigal, 2001). 
Three research purposes have been developed to solve the research problems for this study: (a) to understand the relationship between college football season ticket holders' demographic profiles and their service personal values dimensions (i.e., service value to peaceful life, SVPL, service value to social recognition, SVSR, and service value to social integration, SVSI), (b) to understand the relationship between college football season ticket holders' service personal values dimensions (i.e., SVPL, SVSR, and SVSI), and both consumption satisfaction perceptions and behavioral intentions, and (c) to understand the moderating effect of college football season ticket holders' team identification level on the relationship between their service personal values dimensions (i.e., SVPL, SVSR, and SVSI), and both consumption satisfaction perceptions and behavioral intentions.

\section{Justification for the Study}

Sport marketing research studies suggest season ticket holders make up an important group for sport organizations (Pan \& Baker, 2005; Young, 2001). College football season ticket holders provide intercollegiate athletic departments with a consistent stream of revenue (Fulks, 2009; Young, 2001). Previous research studies related to college football season ticket holders (e.g., Pan \& Baker, 2005; Price \& Sen, 2003) predominantly focused on using game specific variables or variables outside of sport marketers control (e.g., quality of opponents, quality of home team players, game day weather, etc.) to explain the college football season ticket holders' behaviors, and previous college football findings may not possess strong practical implications for sport marketers. The current study examines college football season ticket holders' service personal values and provides suggestions for college football sport marketers to 
incorporate service personal values into promotional themes and marketing plans.

Funk et al. (2003) suggested future sport marketing researchers need to analyze the sport consumer decision making process from multiple facets (i.e., cognitive, affective, and behavior), use multiple multi-disciplinary theories, and develop holistic lines of research. Several personal values researchers implied future researchers need to further explore the values-attitudes-behaviors hierarchy in different market contexts (Homer \& Kahle, 1988; Vinson et al., 1977). This study fills the gap in the sport consumer behavior literature by focusing on variables (e.g., service personal values and team identification) allowing sport marketers to develop marketing plans to change college football consumer behavior (Lamb et al, 2004; Matsuoka et al., 2003). Sport marketers can develop marketing plans and target their promotional messages based on college football season ticket holders' service personal values, team identification levels, and consumption satisfaction perceptions.

Service personal values have been identified as the most important factor in the means-end chain approach (Lages \& Fernandes, 2005; Vinson et al., 1977; Zeithaml, 1988). Consumers rely considerably on their personal values in the purchase decision making process (Lages \& Fernandes, 2005; Lamb et al, 2004; Vinson et al., 1977), and college football season ticket purchases involve an extensive purchase decision making process (Lamb et al., 2004; Young, 2001). Given the information, this study includes four research questions to examine the relationship between college football season ticket holders' service personal values, consumption satisfaction perceptions, and behavioral intentions.

Several sport marketing researchers (e.g., Kahle et al., 2001; Quester et al., 2002) 
suggested sport consumers' demographic profiles are important predictors of their service personal values. Currently, some college football marketers may possess limited resources to promote their services (Fulks, 2009), and they need to channel their resources to promote customer service initiatives (i.e., service personal values) for the customer group (i.e., season ticket holders), providing them with the highest return on promotions. Service personal values have not been linked to college football season ticket holders' behavioral intentions despite their usefulness in explaining consumer behavior (Kahle et al., 2001; Quester et al., 2006). Therefore, this study includes six research questions to examine the relationship between college football season ticket holders' demographic profiles and service personal values dimensions (i.e., service value to peaceful life, SVPL, service value to social recognition, SVSR, and service value to social integration, SVSI).

Team identification has been recognized as one of the variables explaining and predicting the relationship between sport consumers' consumption satisfaction perceptions and behavioral intentions (Cronin et al., 2000; Lavarie \& Arnett, 2000). In the past, sport marketing researchers (e.g., Matsuoka et al, 2003; Wann \& Branscombe, 1993) typically utilized team identification as a mediator rather than a moderator. Social science researchers argued to advance a theory's research and practical implications, future researchers need to progress beyond simple analysis of the relationship between two variables (Baron \& Kenny, 1986; Frazier et al., 2004). A review of sport marketing research studies showed a lack of literature examining the moderating effect of team identification on the relationship between college football season ticket holders' customer service expectations and their behavioral intentions, despite the ability of team 
identification levels to change consumer behavior (Madrigal, 2000, 2001; Wann \& Branscombe, 1990,1993). The current study utilized six research questions to examine to examine the moderating effect of team identification on the relationship between college football season ticket holders' service personal values (SVPL, SVSR, and SVSI) and consumption behavior (i.e., consumption satisfaction perceptions and behavioral intentions). In conclusion, this study attempted to solve college football marketing problems using a combination of appropriate marketing (i.e., service personal values) and sport grounded theories (i.e., team identification).

Significance of the Study. This study presents several contributions to the field of sport marketing. In the current tough economic environment, sport consumers are conscientious with their sports related spending (Fullerton \& Morgan, 2009; Rudy, 2008). For instance, while overall college football attendance reached a new record high (i.e., $48,839,003$ ) in the $2008 / 2009$ season (Johnson, 2009), overall college football attendance dropped to $48,284,673$ in $2009 / 2010$ season (NCAA, 2010). The inconsistency in college attendance can cause a problem for sport administrators conducting budget planning. There is a need for future sport marketing researchers to develop marketing strategies utilizing sophisticated customer service and sport marketing constructs (e.g., service personal values and team identification) designed to foster consistent college football attendance growth.

Funk et al. (2003) suggested future sport marketing researchers also need to: (a) explore sport consumer behavior from multiple consumer decision making aspects, (b) develop holistic research lines, and (c) collect data in naturalistic settings. This study seeks to explore factors influencing college football season ticket holders' behavioral 
intentions using their service personal values, consumption satisfaction evaluation, and team identification level. It is anticipated that several theoretical and managerial implications will emerge from the findings.

Funk et al. (2003) implied future sport consumer behavior researchers need to focus on developing research that can generate more research questions rather than just publicizing results. Both service personal values and team identification are considered strong and consistent predictors for consumers' satisfaction evaluations (Homer \& Kahle, 1988; Matsuoka et al., 2003), but the relationship between college football season ticket holders' team identification level and consumers' satisfaction evaluations has not been widely explored. The findings from this study can attempt to stimulate more research questions related to the relationship between college football season ticket holders' identification level and service personal values. Consumers possess a small set of personal values (Kahle, 1983; Rokeach, 1973; Schwartz, 1992) and consumers' service personal values are consistent over time (Lages \& Fernandes, 2005). The findings related to the relationship between service personal values and team identification can help college football researchers and practitioners initiate marketing strategies to build long term customer relationships.

Funk et al. (2003) recommended future sport consumer behavior researchers to focus on developing research studies investigating ways to link different neighboring concepts to explain sport consumer behaviors. This study utilizes service marketing and social identity theories to explain sport consumers' affective (i.e., consumption satisfaction perceptions) and behavioral (i.e., behavioral intentions) outcomes. The findings from this study can serve as building blocks for future sport marketing 
researchers intending to develop a model investigating causal relationships between sport consumers' service personal values, team identification, customer satisfaction, and behavioral intentions. For example, future sport marketing researchers can utilize either structural equation modeling or qualitative techniques to analyze causal relationships between sport consumers' service personal values, team identification, customer satisfaction, and behavioral intentions. The causal relationship findings have the potential to help sport researchers develop a sport-focused consumer behavior theory (Chalip, 2006). This study focuses exclusively on college football season ticket holders, and future sport marketing researchers can utilize the conceptual framework of this study to analyze season ticket holders' consumption behaviors in other sport contexts (e.g., college basketball, professional football, professional baseball, and professional basketball season ticket holders).

A comprehensive understanding of the relationship between college football season ticket holders' service personal values, team identification levels, consumption satisfaction perceptions, and behavioral intentions may help college football marketers increase their customer retention rate and profitability (Mittal, Anderson, Sayrak, \& Tadikamalla, 2005). College football season ticket holders' service personal values and team identification levels can also serve as benefit segmentation bases for college football marketers. Benefit segmentation is the customer grouping process based on the benefits they seek from product or service consumption (Lamb et al., 2004). Benefit segmentation allows sport marketers to devise appropriate marketing strategies to satisfy their consumers' consumption benefits.

Sport organizations' employees play a key role in the service delivery process 
(Lamb et al, 2004; Parasuraman, Zeithaml, \& Berry, 1985). It is important for sport organizations to develop marketing activities sharing the same values as their customers and recruit, hire, and train their employees (i.e., players, coaches, managers, and support staff). For example, if most of a sport organization's customers possessed the service value of social integration, then the sport organization can focus building the marketing plan (e.g., promoting the importance of social gathering to strengthen family ties at sporting events) around the service value of the social integration dimension.

\section{Research Questions}

This study asked the following research questions to accomplish the three research purposes of this study:

$R Q 1(a)$ : Does college football season ticket holders' number of household member(s) correlate to their service personal values dimensions (i.e., service value to peaceful life or SVPL, service value to social recognition or SVSR, service value to social integration or SVSI)?

$R Q 1$ (b): Does college football season ticket holders' gender correlate to their service personal values dimensions (i.e., SVPL, SVSR, and SVSI)?

$R Q 1(c)$ : Does college football season ticket holders' ethnicity correlate to their service personal values dimensions (i.e., SVPL, SVSR, and SVSI)?

$R Q 1$ (d): Does college football season ticket holders' annual household income, correlate to their service personal values dimensions (i.e., SVPL, SVSR, and SVSI)?

RQI (e): Does college football season ticket holders' alumni status correlate to their service personal values dimensions (i.e., SVPL, SVSR, and SVSI)? 
$R Q 1(f)$ : Does college football season ticket holders' number of years holding season tickets correlate to their service personal values dimensions (i.e., SVPL, SVSR, and SVSI)?

RQ2: Which dimensions of the college football season ticket holders' service personal values (i.e., SVPL, SVSR, and SVSI) are significant in explaining and predicting their consumption satisfaction perceptions?

RQ3: Which dimensions of the college football season ticket holders' service personal values (i.e., SVPL, SVSR, and SVSI) are significant in explaining and predicting their behavioral intentions?

$R Q 4(a):$ How do college football season ticket holders' levels of team identification moderate the relationship between their service value to peaceful life and consumption satisfaction perceptions?

$R Q 4(b):$ How do college football season ticket holders' levels of team identification moderate the relationship between their service value to social recognition and consumption satisfaction perceptions?

$R Q 4(c):$ How do college football season ticket holders' levels of team identification moderate the relationship between their service value to social integration and consumption satisfaction perceptions?

$R Q 5(a):$ How do college football season ticket holders' levels of team identification moderate the relationship between their service value to peaceful life and behavioral intentions?

$R Q 5(b):$ How do college football season ticket holders' levels of team identification moderate the relationship between their service value to social recognition and behavioral 
intentions?

$R Q 5(c)$ : How do college football season ticket holders' levels of team identification moderate the relationship between their service value to social integration and behavioral intentions?

\section{Delimitations}

This study contained several delimitations. First of all, this study only examines college football consumers because the major purpose of this study is to examine the moderating effect of college football season ticket holders' team identification level on the relationship between service personal value and consumer behavior (i.e., satisfaction and behavioral intentions). The purpose of this study is not to examine the relationship between sport consumers' service personal values in different sport contexts. Sport marketing research studies on service personal values have not been extensively conducted in any other sports (Kahle et al., 2001; Quester et al., 2006; Shao, 2002). Other college or professional sports may benefit from understanding sport consumers' service personal values. In such cases, this study could serve as the precedent for future sport service personal values research studies.

Secondly, making college football season ticket holders the only target group is another delimitation of this study. College football season ticket holders provide a consistent stream of revenue for college football programs (Young, 2001), and one of the ways sport marketers can increase ticket sales is to sell season tickets. Future sport marketing research studies can utilize the conceptual framework from this study to study sport consumers in different sport contexts, and sport marketers can use the survey in this create service personal values market segmentation bases. 


\section{Limitations}

One of the limitations of this study is the ability to generalize this study's findings to all college football teams. The data were collected at a large Southeastern public university, and may not represent college football season ticket holders at other institutions. Kahle, Liu, and Watkins (1992) conducted a study to investigate consumers' personal values across United States (U.S.) regions and discovered consumers' personal values differ significantly across U.S. regions. Shao (2002) and Wang et al. (1994) discovered significant differences among U.S. and Asian consumers' personal values. If this study was to be conducted at other institutions in different United States regions or countries, the results may be different.

The college football team where the data were collected has a short program history. The college football program in this study joined NCAA Division I-A college football competition (i.e., currently known as Football Bowl Series) less than ten years ago. Previous research studies reported consumers' involvement impacted their identification level (Lavarie \& Arnett, 2000; Sutton et al., 1997; Wann \& Branscombe, 1993). Short team history or lack to team traditions may lead to inaccurate measurement of college football season ticket holders' team identification level, and sport marketers need to apply care while deciphering the findings and implications of this study. The selection of the target population can also be one the limitations of this study. This study focuses on college football season ticket holders, because they provide college football teams and marketers with the most consistent stream of income (Young, 2001). The findings from this study may not represent all college football consumers' service personal values, consumption satisfaction perceptions, behavioral intentions, and team 
identification level. Sport marketers and researchers need to apply careful considerations while interpreting the implications of this study.

The decision to utilize the service personal values (SERPVAL) scale developed by Lages and Fernandes (2005) is also another limitation of this study. The SERPVAL scale has only been previously utilized by Thuy and Hau (2010), despite possessing strong content and construct reliability and validity (Lages \& Fernandes, 2005). This study's researchers conducted a field study and a pilot study, and came up with a modified version of SERPVAL scale. The SERPVAL scale reliability analysis showed the pilot study results (i.e., SVPL $\alpha=.851$, SVSR $\alpha=.854$, and SVSI $\alpha=.833$ ) are generally better than actual survey results (i.e., SVPL $\alpha=.809$, SVSR $\alpha=.862$, and SVSI $\alpha=.814$ ), but all the reliability findings for this study suggested Lages and Fernandes' SERPVAL scale and modified SERPVAL scale for this study are considered a "good" scale (Nunnelly, 1970).

Individuals' personal values are generally consistent over time, but personal values can change due to life changing events (e.g., birth of a child, death in the family, or natural disasters). Sport marketers need to recognize changes in their customers' personal values and plan marketing activities accordingly to meet their customers' service personal values (Kahle et al., 2001). For instance, the New Orleans Saints focused their promotional activities around service values to social integration after Hurricane Katrina (e.g., Drew Brees, New Orleans Saints' quarterback, visited families impacted by Hurricane Katrina to promote a sense of community).

The use of behavioral intentions rather actual purchase behavior as dependent variable is another limitation of this study. Sport consumers' final purchase decision may 
be different from their behavioral intentions, despite previous research studies indicating behavioral intentions as a valid and reliable predictor of actual purchase behavior (Cornwell \& Coote, 2005; Fishbein \& Azjen, 1975; Zeithaml et al., 1996). This study utilizes only one customer service component (i.e., service personal values) rather than all customer service components proposed by Zeithaml (1988), and the variance explained in both college football season ticket holders' consumption satisfaction perceptions and behavioral intentions may be limited. Sport marketers and researchers need to interpret the findings and implications of this study with considerations.

\section{Definitions}

Basking-in-reflected-glory (BIRG): A self-serving cognition theory describing individuals' decisions associating themselves with successful others so that the successful others' success becomes their own (Cialdini et al., 1976)

Behavioral Intentions: The "indicators that signal whether customers will remain with or defect from the company" (Zeithaml, Berry, \& Parasuraman, 1996, p. 33).

Consumer Behavior: The "processes a consumer uses to make purchase decisions, as well as to utilize and dispose of purchased goods or services, it also includes factors that influences purchase decisions and product use" (Lamb et al., 2004, p. 142).

Customer Sacrifice: "What is given up or sacrificed to acquire a service" (Zeithaml, 1988, p. 10).

Customer Service: The "management strategy that focuses on meeting customer expectations" (Wagenheim \& Reurink, 1991, p. 263) and this strategy can be applied to both product and service based companies. 
Customer Satisfaction: The "feeling that a product has met or exceeded the customer's expectations" (Lamb et al., 2004, p. 11).

Cutoff-reflected-failure (CORF): Some individuals tend to distance themselves away from others who are unsuccessful to avoid negative association and preserve their selfimage (Snyder, Higgins, \& Stucky, 1983, Snyder, Lassegard, \& Ford, 1986).

National Collegiate Athletic Association, NCAA: A voluntary organization through which the nation's colleges and universities govern their athletics programs. It is comprised of institutions, conferences, organizations and individuals committed to the best interests, education and athletics participation of student-athletes (NCAA, 2008). Service Marketing: The "marketing of activities and processes rather than object" (Solomon, Surprenant, Czepiel, \& Gutman, 1985, p. 106).

Service Attributes: The intrinsic and extrinsic benefits or properties (e.g., prestige, cost, reliability, exclusivity, availability, etc.) consumers gain from using a process or performance rather than a good (Lovelock, 1991; Young \& Feigin, 1975, Zeithaml, 1988).

Service Quality: The "consumer's overall impression of the relative inferiority or superiority of the organization and its services" (Bitner \& Hubbert, 1994, p. 77). Service Value: The "consumers' overall assessment of a product utility based on perceptions of what is received and what is given" (Zeithaml, 1988, p. 14). Service Personal Values: The "service's capacity to meet or reflect the individual's personal values" (Lages \& Fernandes, 2005, p. 1564). 
Service Value to Peaceful Life: "If a service promotes a peaceful life, brings or improves tranquility, safety and/or harmony, then its user recognizes the value of this service" (Lages \& Ferenandes, 2005, p. 1565).

Service Value to Social Recognition: "Individuals consider whether the service aids in gaining respect from others, social recognition and status, as well as whether it allows achieving a more fulfilled and stimulating life, which might then be revealed to others" (Lages \& Ferenandes, 2005, p. 1565).

Service Value to Social Integration: "If the consumer perceives that a service strengthens friendships, provides the possibility of becoming more integrated in the group, or promotes better relationships at the social, professional or family levels, then the service will contribute to social integration, and naturally the individual will recognize personal value in the service" (Lages \& Ferenandes, 2005, p. 1565).

Social Identification Theory: The tendency of the in-group (i.e., us) to discriminate against an out-group (i.e., them) to boost self-image. Social identity theory composed of three processes: (a) social categorization, (b) social identification, and (c) social comparison (Tajfel \& Turner, 1979).

Social Categorization: Individuals categorize people (i.e., including themselves) in order to understand the social environment (Tajfel \& Turner, 1979). Social Identification: Individuals embrace the group identity they categorized themselves belonging to (Tajfel \& Turner, 1979). 
Social Comparison: Once individuals have categorized and identified themselves as part of a group, they tend to compare their group with other groups (Tajfel \& Turner, 1979).

Team Identification: "The sense of oneness with or belongingness to a sport team"

(Matsuoka et al., 2003, p. 246) or the extent to which a fan feels a psychological connection to his or her team (Wann \& Branscombe, 1993). 


\section{CHAPTER II}

\section{LITERATURE REVIEW}

Football is the highest revenue generating sport among intercollegiate sports (Fulks, 2009), but there are several problems associated with college football competition. For example, only three (i.e., Big Ten, Big East, and Mountain West) out of the eleven FBS conferences managed to increase their average football programs' attendance from 2008 to 2009 (NCAA, 2010), and overall college football attendance decreased for the first time in several decades due to the economic downturn in 2009 (Fullerton \& Morgan, 2009, Johnson, 2009, NCAA, 2010). These inconsistencies in attendance growth can lead to unsustainable growth in college football revenue. The gap between the highest and the lowest revenue generating college football conferences continues to grow (NCAA, 2009). Fulks (2009) noticed most university athletic programs' revenues are reaching maximum potential, and direct institutional supports are declining. The stagnant in "revenue growth" and increased in operating costs can impact college football team's ability to compete in the future.

Problems related to college football operations and competitions such as unsustainable attendance growth, increased in revenue discrepancies, stagnant in "revenue growth", and increased in operating costs are tied to consumers' consumption behaviors (Curtin, 1982; Katona, 1974). A review of research studies related to college football suggested customer service impacts consumer behaviors (Cronin et al., 2000; Robinson, Trail, Dick, \& Gillentine, 2005). Ziethaml (1988) proposed one of the most 
notable research studies related to customer service. Zeithaml (1988) proposed meansend chain approach suggesting consumers store information related to service or product consumption at four cognitive abstraction levels. Cognitive abstraction is the act of reducing concrete content information through individual thought process (Lages \& Fernandes, 2005). Zeithaml (1988) suggested the highest consumer service cognition abstraction level is service personal values, and it is followed by service value, service quality, and service attributes.

Service personal values are critical elements in consumers' cognitive structure, because consumers' service personal values predict and explain their affective and behavioral responses (Homer \& Kahle, 1988, Madrigal \& Kahle, 1994, Zeithaml, 1988). Consumers going through extensive decision making process rely on the interactions between service personal values stored in their cognitive structure (Lamb et al., 2004). Consumers' service personal values' interactions play a key role in predicting and explaining their consumption behavior (Kahle, 1983; Lages \& Fernandes, 2005; Rokeach, 1973). Consumers' service personal values are more reliable and consistent in explaining and predicting consumer perceptions toward service delivery compared to all the other "lower level" means end chain's variables such as service value, service quality, and service attributes (Zeithaml, 1988).

A number of sport marketing research studies investigated the relationship between consumers' service personal values, affective, and behavioral structures, and they discovered service personal values is a critical component impacting sport consumers' consumption satisfaction perceptions and behavioral intentions (Kahle et al., 2001; Quester et al., 2006; Shao, 2008). Service personal values dimensions (e.g., service 
value to peaceful life, SVPL, service value to social recognition, SVSR, and service value to social integration, SVSI) have not been linked with college football consumer behaviors, despite their usefulness to predict and explain sport consumer behaviors (Kahle et al., 2001; Quester et al., 2006). One research purpose for this study is to utilize service personal values to predict and explain college football season ticket holders' behaviors.

This literature review chapter has several objectives: (a) examine the historical development of service personal values and its relationship with the sport consumer behavior, (b) identify the nature of relationship between service personal values, team identification, and sport consumer behavior, and (c) determine the key consumer behavioral outcomes of service personal values. The literature review chapter is organized in the following sections: (a) service personal values, (b) team identification, and (c) sport consumption.

\section{Service Personal Values}

Marketing researchers' and practitioners' interest in customer service issues grew as a consequence of increased economic importance of the service industry and increased value-added produced by customer service to physical goods (Cronin, 2003). Zeithaml's (1988) means-end chain approach is one of the most comprehensive research studies simultaneously investigating multiple customer service elements impact on consumer decision making process and behavioral outcomes (Cronin et al., 2000; Kwon, Trail, \& James, 2007; Lages \& Fernandes, 2005; Westerbeek \& Shilbury, 2003). Zeithaml (1988) assumed there were several customer service elements (i.e., the means) impacting consumers' purchasing decisions (i.e., the end), and she discovered consumers underwent 
four levels of cognitive abstraction prior to making their final product or service consumption decision: (a) attributes, (b) quality, (c) value, and (d) personal values. Zeithaml (1988) stressed future service marketing studies needed to focus on consumer perceptions rather than objective reality of consumers.

Ziethaml (1988) claimed consumers' perceptions toward service or product consumption existed in hierarchical format with the higher level of cognitive abstraction (i.e., service personal values) dominating the lower level of abstractions (i.e., service value, service quality and service attributes). Consumers engage in extensive decision making processes (i.e., using higher level of cognitive abstraction such as service value pr service personal values) when purchasing an unfamiliar, expensive, or infrequent purchase product of service (Lamb et al., 2004). For example, a consumer purchasing a cup of coffee may only consider the attributes (e.g., taste, origin, caffeine level, etc.) of the coffee. Meanwhile, a consumer purchasing a life insurance may go through higher levels of cognitive abstraction (i.e., insurance agent's service quality, the price of the insurance, matching personal values with insurance companies' values). A college football season ticket is considered an expensive and infrequent purchase item (Young, 2001). This study focuses on using service personal values to analyze college football season ticket holders' decision making process and behavior.

Historical Development of Personal Values. The study of human personal values originated from sociology. Sociologists such as Eduard Spranger, William Thomas, and Florian Znaniecki investigated Polish immigrants' social issues using social values in the late 1920s (Agle \& Caldwell, 1999). In between 1918 and 1920, Thomas and Znaniecki published a series of five qualitative studies entitled 'The Polish Peasant 
in Europe and America: A Classic Work in Immigration History', sparking new discussions among social scientists about a type of community psychology called social values (Zaretsky, 1996). Thomas and Znaniecki attempted to explain the Polish immigrants' social problems in Europe and the U.S. by examining the relationship between individuals and society surrounding them (Zaretsky, 1996), and they found the psychology of the Polish immigrants was identical to the interaction of an old community with a modern and complex form of society (Zaretsky, 1996). Spranger categorized human beings exclusively on the entities they value, and classified human beings into six major categories based on the group of their value orientations: theoretical, economic, aesthetic, social, political, and religious (Agle \& Caldwell, 1999; Jalilvand, 2000). Thomas, Znaniecki, and Spranger human values findings formed the theoretical foundation for the personal values theory development.

In the 1950 s, several social scientists analyzed micro social issues using the human value theory proposed by Spranger, and Thomas and Znaniecki. Stigler (1950) developed economics utility theory using human values theory, and his contributions to the field of microeconomics included expanding the understanding of marginal utility and consumer sacrifice theories. Parsons and Shils (1951) utilized the human values theory to develop the conceptual framework and classification system theory of human actions. Stigler (1950), and Parson and Shils (1950) findings paved the way for future social scientists (e.g., Bronowski, 1956; Maslow, 1959) to create more coherent human behavior theory.

Bronowski's (1956) research study emphasized the importance of human values theory and his findings demonstrated several differences between physical science and 
social science research. Bronowski (1956) suggested human are different from physical science elements because human beings actions have purposes and goals, and he argued social scientists utilizing physical science approaches to analyze human studies often failed to distinguish between the means and the ends of human actions. Bronowski (1956) claimed there were times an individual may not even fully understand the purposes (i.e., the ends) of his or her actions. Thus, there is a need for future social scientists to conduct research on human actions using human values theory (Branowski, 1956).

Building upon Branowski's (1956) findings, Maslow (1959) provided a new social science conceptual framework entitled "humanistic psychology." The main difference between Maslow's (1959) research study compared to other social scientists' research studies on human values was Maslow (1959) utilized an empirical, dynamic, naturalistic, and scientific descriptive of human beings rather than theoretical descriptive of human beings. Maslow's (1959) suggested human behavior as having the state of being (actuality) and the state of becoming (potentiality), based on empirical evidence he gathered from two stages of human cognition (i.e., peak experiences or altered states of consciousness, and states of being cognition to create a new idea of human beings and their mental health). Maslow (1959) suggested human actions were not entirely selfdefining, rather their actions contained certain end-state in minds. The end-states or terminal values are waited to be discovered and actualized by the individual. Maslow (1959) implied these values can either be good or bad depending on how an individual decides to develop them into one's identity.

Maslow (1968) connected the humanistic psychology findings to his previous research on human hierarchy of needs (Maslow, 1943). Maslow (1968) suggested human 
value reflected an individual's reasoning of what is the most important element in his or her life and human value is a critical construct determining an individual's ultimate goal (i.e., self actualization in Maslow's hierarchy of needs). Maslow (1968) created a list of 'B Values' or "being values" explaining human self actualization.

Maslow's (1959) findings inspired a new generation of personal values researchers in the 1960 's. Personal values studies expanded from social science to business academic disciplines such as management and organizational development. The main research focus during 1960's shifted from theoretical development of personal values to operationalizing personal values construct (Agle \& Caldwell, 1999).

Allport, Vernon, and Lindzey (1960) led the task operationalizing the personal values concept, and they created a survey instrument to measure personal values based on the theoretical framework developed by Eduard Spranger (Agle \& Caldwell, 1999). Allport et al. (1960) argued personal values need to be measured using the propriate functioning theory. The propriate functioning theory assumed most human behaviors were motivated by something other than the human tendency to satisfy biological needs (i.e., opportunistic functioning).

Human behavior was most likely motivated by the function of self-expression (Allport et al., 1960). They designed a survey instrument to measure and explain the relative importance of the human being's value orientations (i.e., theoretical, economics, aesthetic, social, political, and religious). Allport et al. (1960) findings supported Maslow's $(1943,1968)$ implications, recognizing the need for future social science studies to focus more on developing the personal values theory using the hierarchy of human motivations. 
Kluckhohn and Strodtbeck (1961) offered social scientists another important instrument (i.e., value orientations method, VOM) to evaluate individual's personal values. VOM allowed social science researchers to assess cultural differences in a society using the personal values theory, and it involves a two-step process: (a) value orientations survey, and (b) value orientations model. The value orientations survey classifies human value orientations into five common human concern categories: (a) character of human nature, (b) human relationship to nature, (c) human sense of time, (d) human activity, and (e) social relations. Kluckhohn and Strodtbeck (1961) also postulated those values driving human behavior can be derived from the interactions among three components in the individuals' decision making process: (a) cognitive (i.e., the way an individual deliberates about the issue), (b) affective (i.e., the way an individual feels about the issue), and (c) directive (i.e., the make-up of an individual biological disposition). Kluckhohn and Strodtbeck (1961) developed the values orientation model based on four assumptions: (a) there are five human concerns for which all human beings must come up with solutions, (b) there are limited and systematic solutions to human concerns, (c) the solutions to human concerns vary among individuals because of the differences in individuals' values orientation, and (d) all the value orientations continually exist in every individuals and societies, but the hierarchy of human concerns solution between the society and individuals residing in it may change. Kluckhohn and Strodtbeck (1961) concluded the human concern solutions hierarchy allows social scientists to profile the primary and secondary value orientations for an individual and his or her society. The value orientations model can assist future personal values researchers to predict an individual's affective and behavioral responses. 
England (1967) developed the Personal Values Questionnaire (PVQ) measuring managers' personal and managerial values for organizational theory researchers, and he assumed an individual's personal values structure was a comparatively stable conceptual framework predicting the nature of an individual's behavior. England (1967) suggested future personal values researchers need to utilize PVQ to evaluate manager decisionmaking patterns. Agle and Caldwell (1999) discovered PVQ served as the standard measurement scale for a number of future organizational theorists (e.g., Akaah \& Lund, 1994, Leidtka, 1989, Lusk \& Oliver, 1974) investigating the relationship between managers' personal values, ethnicity, gender differences, and professional aspirations. England (1967) conducted additional personal values research studies focused on analyzing personal values impact on managers' strategic decision-making capabilities (England \& Lee, 1971, Whitely \& England, 1980).

In conclusion, human values theory development moved from the theory development within the macro perspectives (i.e., society) in the 1910 s to the micro perspective (i.e., individual) measurement scale construction in the 1960s (Agle and Caldwell, 1999). Human values theory research studies expanded exponentially with the creation of several personal values measurement scales such as VOM and PVQ (Agle \& Caldwell, 1999). It is vital for future personal values researchers to understand the importance of measurement scale in the advancement of personal values theory development. Allport et al. (1960), Kluckhohn and Strodtbeck (1961), and England (1967) made significant contributions toward the development of personal values measurement scale, and they paved the way for the seminal research study in personal values conducted by Milton Rokeach (Agle \& Caldwell, 1999). 
Personal Values Measurement Scales. Rokeach (1973) created the Rokeach Value Survey (RVS) to measure individual's personal and social values. Rokeach (1973, p. 5) defined a value as "an enduring belief that a specific mode of conduct or end-state of existence is personally or socially preferable to an opposite or converse mode of conduct or end-state of existence. A value system is an enduring organization of beliefs concerning preferable modes of conduct or end-states of existence along a continuum of relative importance". Rokeach (1973) developed the RVS based on five assumptions: (a) individuals possessed a relatively small total number of values, (b) all individuals possessed the same values to different degrees, (c) values were organized into value systems (i.e., terminal and instrumental), (d) human values antecedents included culture, society and institutions, and personality, and (e) the outcomes of human values analysis will be manifested in almost all the phenomena social scientists considered worth evaluating and understanding. Rokeach (1973) suggested values contained three components (i.e., cognition, affection, and behavioral) based on his definition and assumptions, and he claimed a value can signify a socially or personally preferred preference and any socially preferred value or values may be utilized as norms encouraging the society members to conform. Rokeach's (1973) values conceptual framework was similar to Kluckhohn and Strodtbeck (1961) values conceptual framework.

Rokeach (1973) proposed there were two categories of values (i.e., 18 terminal values and 18 instrumental values). Table 1 shows Rokeach's terminal and instrumental values. Rokeach (1973) suggested terminal values represented individual's desired endstates of existence and instrumental values represented individual's modes of conduct 
related to morality or competence. Rokeach (1973) postulated terminal and instrumental values were two sets of separate but interrelated schemes, and Rokeach (1973, p. 12) explained "... wherein all the values concerning modes of behavior are instrumental to the attainment of all the values concerning end-states". For example, an individual with a sense of accomplishment (i.e., terminal values) may utilize ambitious (i.e., instrumental values) to achieve his or her terminal values. Rokeach (1973) suggested personal values can be used as the criterion to change individual's behavior. For instance, when an individual is confronted with an extensive decision making process, the individual's set of personal values will be activated. In turn, those personal values assist the individual in making the decision. 
Table 1

Rokeach's (1973) 18 Terminal Values and 18 Instrumental Values

Terminal Values:

Instrumental Values:

End-States of Existence Preferable Modes of Conduct

A comfortable life Ambitious

An exciting life

Broadminded

A sense of accomplishment

Capable

A world at peace

Cheerful

A world of beauty

Clean

Equality

Courageous

Family security

Forgiving

Freedom

Helpful

Happiness

Honest

Inner harmony

Imaginative

Mature love

Independent

National security

Intellectual

Pleasure

Logical

Salvation

Loving

Self-respect

Obedient

Social recognition

Polite

True friendship

Responsible 
Rokeach (1973) concluded short-term values and value systems help guide an individual's daily decision-making process. He also suggested personal values possessed several compelling motivational components. For example, the long term impact of values and value systems served as a function for Maslow's (1943) higher levels of human hierarchy of needs (i.e., self actualization and ego needs). Individuals ranked the importance of each value and constructed a hierarchy of values, and the hierarchy of values then guided individuals' short term and long term behaviors. This study reviews Vinson et al.'s (1977) research study to gain comprehensive understanding the relationship between personal values and consumer behavior.

Vinson et al. (1977) noticed previous marketing researchers recognized the importance of attitudes and attitude change, but they discovered attitudes and attitude change explained only a small portion of variance in consumer behavior. Vinson et al. (1977) claimed the role of personal values in marketing and consumer behavior has not been widely researched despite the significant impact the personal values construct has on the individuals' behavior, and they utilized personal values construct as an explanatory variable and conceptualized a value model to explain consumer behavior.

Vinson et al. (1977) developed the value model based on the assumption that individual values can be categorized into three cognitive abstraction levels: (a) dozens of global or generalized personal values, (b) hundreds of domain-specific values, and (c) thousands of products attributes evaluations. For example, an individual purchasing a car may possess dozens of global or generalized values (e.g., exciting life, equality, selfrespect, etc.), hundreds of domain-specific values (e.g., durable, non-polluting, easy to repair, etc.), and thousands of product attributes evaluations (e.g., advanced engine 
system, luxurious interior, high gas mileage, etc.). Those three cognitive abstraction levels were arranged in a hierarchical network and formed the individual's belief system.

Vinson et al. (1977) argued the personal values construct is a function of sociocultural, economic, and family environment, and they proceeded to explain the relationship between individual's belief system and the central-peripheral dimension. They asserted global values were more centrally held compared to domain-specific values and product attributes evaluations were the least centrally held in the individual belief system. Vinson et al. (1977) proposed an individual's preference for products and brands is a function of the difference in individual's value orientations, they measured Rokeach's (1973) global values and domain-specific values using several seven-point Likert-type scales rather than using the Rokeach's (1973) RVS (i.e., an ordinal scale), because an ordinal scale is less informative and lacks predictive capability compared to interval or ratio scales (Clawson \& Vinson, 1978).

Vinson et al. (1977) collected the value orientations and attitudinal data from consumers residing at two culturally distinct regions (i.e., traditional and liberal) in the U.S., and they discovered the two groups are significantly different in their global values, domain-specific values, and product attributes evaluations. Those differences were explained consumers' product choices and social issues perceptions. Vinson et al. (1977) concluded personal values were centrally held cognitive abstraction capable of stimulating individual's motivation for behavioral responses, and they suggested an individual's personal values construct is an efficient and measurable variable suitable for market analysis and market segmentation initiatives. Vinson et al. (1977) implied marketers can use individual's personal values to develop product planning and 
promotional strategy, and their conclusion was later supported by Homer and Kahle's (1988) research findings. Homer and Kahle (1988) suggested values possessed internal and external dimensions influencing the consumer attitudes. In turn, the consumer attitudes influenced their behavior.

Vinson et al.'s (1977) findings suggested values had more influence on consumers' attitudes compared to consumers' behaviors and they proposed the values attitudes - behaviors hierarchy. Vinson et al.'s (1977) implied future researchers need to examine the values - attitudes - behaviors hierarchy in different market contexts (e.g., sports and communication industries), and it is important for future personal values researchers to further refine the Rokeach Value Survey. Next, this study reviews three other major research studies related to the personal values measurement scales development. Those research studies were: (a) Kahle's (1983) List of Values (LOV), (b) Schwartz's (1992, 1994) Values Scale (SVS), and (c) Lages and Fernandes' (2005) service personal values (i.e., SERPVAL) scale.

Kahle (1983) created the List of Values (LOV) to evaluate the Americans' values and LOV is based on Feather's (1975), Maslow's (1954), and Rokeach's (1973) values conceptual frameworks. Kahle (1983) utilized the social adaptation theory to explain individuals' ability to adapt themselves to different social roles, and he suggested individuals adapted themselves to social roles through values development and realization. Kahle (1983) modulated Rokeach Value Survey's terminal values into a smaller values subset, and he argued the LOV is generalizable across several critical life roles and circumstances, and primarily individual-oriented. LOV contains nine items and those items are sense of belongingness, excitement, fun and enjoyment in life, warm 
relationships with others, self-fulfillment, being well-respected, a sense of accomplishment, security, and self-respect.

Kahle's (1983) LOV scale implementation is a two-step procedure. Initially, the LOV focused on rating all those nine items from the list and then ranking of individuals' top two most important values from the list. Rokeach Values Survey (RVS) focused on individuals' ranking of all the terminal and instrumental values in the list, and Kahle (1983) argued the LOV is an easier instrument for personal values researchers to administer and respondents to complete compared to RVS, and he discovered many of the values in the RVS did not directly explain the consumer behavior. LOV overcame the Rokeach Value Survey lack of explanatory power by combining multiple RVS items (e.g., family security and national security) into a single item (i.e., security). Kahle (1983) included two new items to the LOV scale (i.e., sense of belonging and self-fulfillment), which did not exist in the RVS.

Kahle (1983) implied LOV items can be further clustered into two groups (i.e., internal control locus and external control locus), and he suggested internal control locus' values included self-fulfillment, fun and enjoyment in life, sense of accomplishment, and self-respect and the external control locus' values included sense of belonging, being well respected, and security. Kahle (1983) also suggested those individuals with strong internal control locus' values generally depend on inner strength (i.e., own ability) to solve their life's problem, and those individuals with strong internal control locus' values also deemed themselves to possess influence power and ability controlling outcome. In contrast, individuals with strong external control locus' values tend to depend heavily on luck and fate to overcome their life's problem. Kahle's (1983) LOV became the main 
measurement scale for several other research studies (e.g., Homer \& Kahle, 1988, Kahle, Rose, \& Shoham, 1999, Madrigal \& Kahle, 1994) exploring the relationship between personal values and consumer behavior.

At the same time, Schwartz (1992) developed another major personal values measure scale, and he created the Schwartz Values Scale (SVS) to measure individuals' personal values. SVS is based on Schwartz and Bilsky (1987) values assumptions, which assumed values are: (a) concepts or beliefs, (b) desirable end states or behaviors, (c) beyond specific situation, (d) steering individual's behavioral intentions, (e) ranked by relative importance, $(\mathrm{f})$ motivated individual's actions, $(\mathrm{g})$ functioned as individual's behavioral standards, and (h) acquired through individual's socialization and life learning experiences. Schwartz (1992) suggested 10 personal values constructs for SVS: (a) power, (b) achievement, (c) hedonism, (d) stimulation, (e) self-direction, (f) universalism, (g) benevolence, (h) tradition, (i) conformity, and (j) security. He derived SVS' values from three humans and societies' universal requirements and needs: (a) individuals as biological organisms, (b) individuals as organized social interaction, and (c) individuals as efficient groups function and survival. Schwartz (1992) suggested hedonism was derived from the individuals' and societies' need to have organized social interaction, and he argued values conflict or compatibility lead to attitudes and behavioral changes.

Schwartz (1992) created a circular value system describing higher order bi-polar values, and those values were organized by motivational similarities and oppositions. He suggested motivational values are continuous and values (e.g., stimulation and selfdirection) sharing same motivational orientation (i.e., openness to change) were placed next to each other's. On the contrary, the values situated on the opposite locations (i.e., 
bi-polar) within the circular values system demonstrated the conflict nature between values from different motivational orientations (e.g., self-enhancement vs. selftranscendence). Schwartz (1992) postulated hedonism is the only values construct with two motivational orientations (i.e., openness to change and self-enhancement).

Several other researchers (e.g., Burgess \& Steenkamp, 1999, Grunert \& Juhl, 1995, Wilson, 2005) utilized SVS to measure personal values construct in their studies, and they discovered the SVS possessed content and construct validity. Schwartz (1992) concluded personal values possessed enduring and desirable characteristics, and he implied personal values can serve as guiding principles for individuals' attitudes and behaviors. In conclusion, Rokeach Value Survey, List of Values, and Schwartz Value Scale have been major instruments chosen by personal values researchers over the past three decades. Recently, Lages and Fernandes (2005) introduced a new multi items personal values instrument (i.e., SERPVAL), and it was designed specifically for service marketing research study. SERPVAL is a Likert scale measuring a service provider ability to meet individual's service personal values.

Lages and Fernandes (2005, p. 1564) defined service personal values as "the customer's overall assessment of the use of a service based on the perception of what is achieved in terms of his own personal values", and they argued major advancement in service marketing can be accomplished through service marketing theories integration and measurement scale development. Lages and Fernandes (2005) developed the SERPVAL scale based on Zeithaml's (1988) means-end chain model and Rokeach (1973) Values Survey (RVS).

Lages and Fernandes (2005) conducted a pilot study with 30 mobile users to test 
the SERPVAL scale reliability (i.e., using Cronbach's alpha coefficient), and they discovered the SERPVAL scale possessed strong content reliability. Prior to the pilot study, the researchers submitted the survey questionnaire for the panel of experts review (i.e., to assess SERPVAL scale validity), and they discovered the SERPVAL possessed strong face and content validity. Lages and Fernandes (2005) implemented the SERPVAL scale and collected 386 responses from mobile telecommunications consumers using the convenience sampling technique. They proceeded to conduct exploratory and confirmatory factor analysis to assess the SERPVAL construct validity. The initial SERPVAL scale has 28 items, and after the confirmatory factor analysis, 12 items remained in the scale. Those 12 items loaded on three dimensions (i.e., peaceful life, social recognition, and social integration), and Lages and Fernandes (2005) discovered all three dimensions in the SERPVAL scale were significantly correlated to the customer satisfaction construct.

Lages and Fernandes (2005) concluded the Rokeach Value Survey (RVS) measured personal values construct in greater details compared to Schwartz Values Scale (SVS), and they implied service marketers can use the SERPVAL as organizational benchmarking and segmentation tools. For example, marketing practitioners can use SERPVAL scale to assess if their service delivery meets their customers' personal values expectations and comparing their organizations performance to industry best (i.e., using SERPVAL as a benchmarking tool). Marketing practitioners can also use SERPVAL scale to develop a sub-set market for their customers who shared the same service personal values (i.e., market segmentation), and create intentional marketing strategies to meet their customers' service personal values. Lages and Fernandes (2005) implied 
personal values may significantly impact sport consumers' satisfaction and behavioral intentions. A review of sport marketing research studies indicated several sport marketing research studies (Kahle et al., 2001; Quester et al., 2006; Shao, 2002) investigated the relationship between sport consumers' service personal values and consumption behavior. Next, this study examines research studies assessing the relationship between personal values and sport consumer behavior.

Sport Personal Values Literature. Kahle et al. (2001) is one of the earliest sport marketing researchers to examine the sport fans' values, and they responded to Vinson et al. (1977) and Homer and Kahle's (1988) research implication calling future personal values researchers to explore the values - attitudes - behaviors hierarchy in different market contexts. Kahle et al. (2001) argued one of the keys to successful sport organizations rested on the sport marketers' capability to understand and satisfy their sport customers' personal values. They assumed individuals' values are correlated with certain demographic profiles and explained consumer behaviors. Kahle et al. (2001) posited individuals' values segments and associated value chains can be explained using Kahle's (1983) List of Values. They suggested the value chains demonstrated the relationship among value segments, attitudes, activities, beliefs, and purchasing behaviors, and utilized List of Values to categorize and segment sport attendees' social values.

Kahle et al. (2001) collected data from attendees at two men's and two women's college basketball games and they discovered significant differences between the men's and women's college basketball fans' values (i.e., self-respect, self-fulfillment, security, and sense of belongingness). Kahle et al. (2001) reported camaraderie is a critical 
construct in the fan motivation variable, and they recommended sport marketers can utilize the personal values construct to guide their marketing plans. For instance, sport marketers can develop advertising and public relation campaigns highlighting sport consumers' personal values at different cognitive abstraction levels. Sport marketers can also develop family section seating for sport fans valuing warm relationships with others, or fan appreciation day for sport fans who valued sense of belongingness. Kahle et al. (2001) recommended sport fans can be segmented based on their personal values, an implication similar to the one proposed by Lages and Fernandes (2005). Kahle et al. (2001) encouraged future researchers to further explore other psychological aspects of fan behavior, and their findings steered several other sport marketing researchers (e.g., Shao, 2002, Quester et al., 2006) to focus on examining the relationship between values and sport consumption.

Shao (2002) conducted a cross-cultural study to explore cultural values impact on sport consumption preferences and behaviors, and she noted technological advancement (e.g., internet and satellite televisions) globalized the sport consumption and distribution. Shao (2002) reported sport organizations are facing global competition for sport consumers' disposable income, and there is a need for sport marketing researchers to develop a comprehensive understanding of sport consumer decision making process and behavior. Shao (2002) defined cultural values as a set of values commonly shared among members of a society, and cultural values help to create expectations for members living in the society. Shao (2002) also reported most of the sport marketing researchers predominantly focusing on using service quality and service attributes to explain sport consumers' needs and consumption satisfaction perceptions. She argued in order to 
advance the sport consumer behavior literature, it is imperative for sport marketing researchers to explore beyond the service quality domain. Shao (2002) decided to focus on using the sport consumers' psychological abstraction higher than service quality (e.g., service value or service personal values) to examine consumer behavior, and she examined the impact of cultural values on consumers' sport consumption preferences and frequencies in two cultural settings (i.e., American and Taiwanese).

Shao (2002) utilized Kahle's (1983) List of Value (LOV) to analyze American and Taiwanese sport consumers' values structure. She investigated American and Taiwanese's cultural values impact on their sport consumption preferences and frequencies, and the relationship between sport consumption preferences and frequency in both cultural settings. Shao (2002) discovered Americans and Taiwanese cultural values structures were significantly different, and both populations' cultural values jointly explained the variance in their sport consumption preferences and frequencies. Shao (2002) also discovered sport consumption preferences were significantly correlated to sport consumption frequency for both cultural settings, and she stressed the importance of recognizing and comprehending global sport consumers' cultural values'. Shao (2002) concluded cultural values have the potential to influence sport organizations' overall marketing success.

Quester et al. (2006) investigated sport consumers' personal values impact on extreme sports consumer's initial and ongoing brand choice within the extreme sports subculture. Quester et al. (2006) posited extreme sports consumers' core values and brand preferences were impacted by their ties to the extreme sports subcultures and responses to the subcultures' pressures (i.e., commercialization or mainstreaming). They argued 
consumers' personal values and socio-cultural contexts are important factors affecting sport organizations' brand building initiatives. Quester et al. (2006) reported individuals' values construct is a field well under-explored by sport marketing researchers, despite the effectiveness of personal values in marketing plan development. They also shared previous consumer values research (e.g., Shao, 2002; Vinson et al., 1977) tend to focus on shared community or cultural values rather than individuals' values impact on consumption and brand preference. Quester et al. (2006) argued personal values are better consumer behavior predictors and explanatory variables compared to cultural values. Based on Vinson et al. (1977) and Kahle et al. (2001) suggestions, Quester et al. (2006) argued there is a need for sport marketing researchers to evaluate subculture ties and pressure experienced impact on individuals' values and brand preference.

Quester et al. (2006) designed an exploratory qualitative research study to examine the sport consumers' core value impact on their: (a) subculture (i.e., extreme sports) attachment, (b) existing and enduring brand choice, and (c) subculture pressures responses (i.e., commercialization) and brand preference. They discovered four consumers' values explained extreme sport type's preference, brand preference, and commercialization responses. Those four consumers' values are freedom, belongingness, excellence, and connection. Quester et al. (2006) also discovered extreme sports consumers may simultaneously possess more than one core values, but extreme sports consumers' sport type preference was generally driven by only one core value. They suggested the extreme sports consumers initially ranked their values and then utilized the most important value to guide their consumption decision.

Quester et al. (2006) suggested consumers' extreme sports involvement (i.e., 
either core or peripheral) impacted their values orientation, and extreme sports consumers' core value influenced their brand choice and attitude to commercialization (i.e., extreme sports exposure to the general public). For instance, extreme sport consumers possessing freedom value selected anti-establishment brand, but they may stop consuming when the extreme sport became commercialized. Quester et al. (2006) concluded consumers' involvement, values, and sport commercialization impacted their brand definition. They implied a longitudinal study may help future personal values researchers to further clarify the relationship between consumer involvement dynamics and brand preferences. Quester et al. (2006) reported freedom-driven consumers described authenticity as the brand remaining truly to the sports, and they suggested future researchers need to define and expand the authenticity concept using a larger sample size.

Service Personal Values Summary. Understanding consumers' personal values is one of the most important steps in developing successful marketing plans and the ability of sport organizations to survive global competition rest on their ability to meet sport consumers' personal values (Homer \& Kahle, 1988; Madrigal \& Kahle, 1994; Westerbeek \& Shilbury, 2003; Vinson et al., 1977; Zeithaml, 1988). The study of individuals' personal values began in the field of social science (Agle \& Caldwell, 1999), and social scientists discovered personal values predicted and explained human actions (Branowski, 1956; Maslow, 1968). Individuals' actions possess end states or terminal values (Allport et al., 1960; Maslow, 1959; Rokeach, 1973; Zeithaml, 1988), and individual's personal or terminal values were shaped by their demographic profiles, cultures, and life experiences (Kahle et al., 2001; Lamb et al, 2004). The advancement of 
personal values research studies were stimulated by the creation of several personal values survey instruments (Agle \& Caldwell, 1999; Kahle, 1983; Lages \& Fernandes, 2005; Schwartz, 1992), and Rokeach's (1973) Values Survey (RVS) stimulated the utilization of personal values in marketing research (Agle \& Caldwell, 1999; Kahle et al., 2001; Shao, 2002; Quester et al., 2006). Table 2 presents a summary of major personal values measurement scales.

Several marketing research studies suggested consumers apply extensive decision making process when they are purchasing an expensive product or service (Lamb et al., 2004; Young, 2001; Ziethaml, 1988). Consumers applying extensive decision making process typically go through all four levels of cognitive abstraction before making their final consumption decision, and the highest level of consumer cognitive abstraction is 
Table 2

Service Personal Values Measurement Scale Summary

\begin{tabular}{|c|c|c|c|c|}
\hline Aoronym & RVS & LOV & SVs & SERPVAL \\
\hline Scale Name & Rokeach Value Survey & List of Values & Sctwart Values Scale & Service Personal Values \\
\hline Authors & Milton Rokeach & Lym R. Kahle & ShalomH Schwart & $\begin{array}{c}\text { Luis F. Lages } \\
\text { Joena C. Femandes }\end{array}$ \\
\hline Year of Creation & 1973 & 1983 & 1992 & 2005 \\
\hline Theoretical Foundation & $\begin{array}{c}\text { Florence R. Nudhiohn (1961) } \\
\text { Fred L Strodtbedk (1961) }\end{array}$ & $\begin{array}{l}\text { Abraham H Masiow (1954) } \\
\text { Miton Rokeach (1973) } \\
\text { Norman T. Feather (1975) }\end{array}$ & \begin{tabular}{|c|} 
ShalomH Sctwartz (1987) \\
Wolfgang Bilsky (1987)
\end{tabular} & $\begin{array}{l}\text { Mlton Rokeach (1973) } \\
\text { Lymn R. Kahle (1983) }\end{array}$ \\
\hline Field of Study & Social Psychology & Marketing & Merketing & Service Merketing \\
\hline \multirow[t]{2}{*}{ Number of Items } & $\begin{array}{c}18 \text { Terminal Values } \\
18 \text { Instrumental Values }\end{array}$ & 9 & 10 & 12 \\
\hline & Refer to Table 21 & $\begin{array}{c}\text { Self-Respect } \\
\text { Searity } \\
\text { Warm Relationship with Others } \\
\text { Self Fulfillment } \\
\text { A Sense of Accomplishment } \\
\text { Being Respected } \\
\text { A Sense of Belonging } \\
\text { Fun and Enioyment } \\
\text { Excitement }\end{array}$ & $\begin{array}{l}\text { Universalism } \\
\text { Benevolence } \\
\text { Conformity } \\
\text { Tradition } \\
\text { Security } \\
\text { Power } \\
\text { Adhievement } \\
\text { Hedonism* } \\
\text { Stimulation } \\
\text { Self-Direction }\end{array}$ & $\begin{array}{c}\text { Tranquility } \\
\text { Family Searity } \\
\text { Harmony and Stability in Life } \\
\text { Pleasureable Life } \\
\text { Respect from Others } \\
\text { Feeling that the World is More Agreeable } \\
\text { Social Recogrition } \\
\text { Status } \\
\text { Stimulating and Adventurous Life } \\
\text { Higher Intergration in My Group } \\
\text { Better Relationship with Others } \\
\text { Strengthen My Friendship Relationship }\end{array}$ \\
\hline Dimensions & $\begin{array}{c}2 \\
\text { Terminal Values (18) } \\
\text { Instrumental Values (18) }\end{array}$ & N/A & $\begin{array}{c}4 \\
\text { Self-Transœendance (2) } \\
\text { Self-Erhancement (2) } \\
\text { Openess to Change (2+*) } \\
\text { Conservation }\left(2+^{*}\right)\end{array}$ & $\begin{array}{l}3 \\
\text { Senvice Value to Peaceful Life, SVPL (4) } \\
\text { Service Value to Sodal Recognition, SVSR (5) } \\
\text { Service Value to Social Integation, SVI (3) }\end{array}$ \\
\hline
\end{tabular}


personal values (Lages \& Fernandes, 2005; Vinos et al., 1977; Ziethaml, 1988). Sport marketing research studies reported personal values have not been extensively utilize to explain and predict sport consumers (e.g., season ticket holders) going through extensive consumption decision making process, despite service personal values usefulness to predict and explain consumer decision making process (Kahle et al., 2001; Quester et al., 2006; Shao, 2002). This study utilizes personal values to explain sport consumers' consumption satisfaction perceptions and behavioral intentions.

The conceptualization of personal values can be explained using the social adaptation theory (Kahle, 1983), and Wang et al. (1994, p. 185) suggested "personal values are the most abstract type of social cognitions that function to facilitate adaptation to one's environment". Individuals' ethnic background, and social, economic, political and technological environments impacted their personal values (Kahle et al., 2001; Lamb et al., 2004; Wang et al., 1994). The first research purpose of this study is to seek comprehensive understanding of the relationship between college football season ticket holders' demographic profiles and their service personal values dimensions.

Multiple business and sport marketing research studies discovered personal values predicted and explained consumer behaviors (Kahle et al., 2001; Quester et al., 2006; Shao, 2002; Vinson et al., 1977). Previous marketing research studies demonstrated individuals' personal values are related to consumers' consumption satisfaction perceptions (Homer \& Kahle, 1988; Lages \& Fernandes, 2005) and behavioral intentions (England, 1967; Rokeach, 1973; Schwartz, 1992; Vinson et al., 1977). Personal values consist of relatively small set of variables, and they have been identified as stronger predictor and explanatory variables compared to attitudes variables (Rokeach, 1973; 
Shao, 2002; Vinson et al., 1977; Homer \& Kahle, 1988).

Kahle et al. (2001) suggested sport organizations success depends on their ability to understand and satisfy their customers' personal values, and they argued personal values were not widely utilized by the sport marketing researchers to investigate sport season ticket holders' behaviors, despite personal values ability to predict and explain consumers' consumption satisfaction perceptions and behavioral intentions. The second purpose of this study is to develop an understanding of the relationship between college season ticket holders' service personal values, consumption satisfaction perceptions, and behavioral intentions.

Individuals' socialization and life learning experiences impacted their personal values (Kahle, 1983). The conceptualization of personal values using social adaptation theory suggested, "a neo-Piagetian account of attitudes, values, and other social cognitions, implies that adaptive significance of information will determine its impact. Information based on salience may be processed, but its usefulness may be based on usefulness for adaptation" (Kahle \& Homer, 1985, p. 954). For example, if an individual perceives that a particular set of personal values has stopped to facilitate his or her social adaptation at a certain point, he or she will proceed to adopt another new set of personal values. Sport consumers' adaptation to the society (i.e., team identification level) impacts the relationship between their personal values, and consumption satisfaction perceptions and behavioral intentions (Madrigal, 2001; Madrigal \& Kahle, 1994). Next, this study examines research studies related to team identification.

\section{Team Identification}

Team identification refers to the extent to which a sport fan feels a psychological 
connection to his or her team (Wann \& Branscombe, 1993). Several researchers reported there is a relationship between individual's service personal values, social identification tendencies, and behavioral outcomes. For instance, Maslow (1959) suggested individual's end-states or terminal values are cognitive factors waiting to be discovered and actualized by the individual. These values can either be good or bad depending on how an individual decides to develop them into one's identity (Maslow, 1959). Allport et al. (1960) suggested the propriate functioning theory explained most human behaviors are motivated by their tendency for self-expression rather than the tendency to satisfy biological needs (i.e., opportunistic functioning).

Kahle (1983) and Madrigal (2001) suggested individuals' tendencies adapting themselves to social roles (i.e., team identification level) moderated the relationship between their values development and realization, and behavioral outcomes. This study focuses on the literature related to team identification, and the objectives of the team identification literature review are: (a) examining the historical development of team identification theory, (b) understanding sport fan team identification development, and (c) understanding the relationship sport fans' team identification level and consumption behavior.

Historical Background of Team Identification. Marketing literature revealed sport fans' team identification research studies emerged from the field of social psychology and team identification is based on social identity theory (Madrigal, 2000; Murrell \& Dietz, 1992; Wann \& Branscombe, 1990). Tajfel (1974) proposed a conceptual framework explaining intergroup behavior using social identity theory, and he defined social identity as the individuals' sense of who they are based on their group 
affiliation. Tajfel (1974) argued intergroup behavior should be studied from the "men in group" perspective rather than individual psychological aspects, and he stressed it is critical for psychologists to use social psychological variables to explain intergroup relationship.

Tajfel (1974) suggested individuals go through a series of cognitive processes when they are assessing other individuals' behaviors, and he noticed the "men in group" perspective suggested individuals initially categorize human beings into social categories (i.e., social categorization) to: (a) develop an understanding of others, (b) comprehend their own social environment, and (c) identify others. He added individuals develop an in-depth understanding about themselves through social identification process. Individuals define appropriate behaviors based on the group norms they identified and they may simultaneously affiliate with several groups. Tajfel (1974) suggested individuals continuously attempt to achieve satisfactory self-concept, pride, and selfesteem through the group affiliation, and he suggested individuals have to acquire a sense of belonging to a group and become an in-group member (i.e., social identification), before they can develop the dislike for an out-group.

Tajfel (1974) proposed individuals tend to compare their group with other groups (i.e., social comparison) after they have gone through social categorization and social identification processes. He suggested the individuals' group needs to perform better than other groups in order for them to maintain their self-esteem and one of social comparison outcome was prejudice. Tajfel (1974) concluded individuals go through three cognitive stages when they are assessing others' behavior. Those three cognitive stages are social categorization, social identification, and social comparison. Tajfel (1974) intergroup 
behavior conceptual framework served as the theoretical foundation for Tajfel and Turner's (1979) social identity theory. Social identity theory stated the in-group (i.e., us) discriminated against the out-group (i.e., them) to boost their self-image (Tajfel \& Turner, 1979).

Cialdini et al. (1976) developed another conceptual framework demonstrating individuals' attempt to enhance their public image. Cialdini et al. (1976) suggested individuals enhance their public image through public identification with successful others (i.e., a process called basking in reflected glory, BIRG), and they argued BIRG is a distinctive phenomenon because the individual who BIRG has no relationship with the other's success. Cialdini et al. (1976) conducted three experimental studies to examine the college football BIRG phenomenon. In the first experiment, they discovered university students are more likely to wear university apparel after the university's college football team victory. Cialdini et al. (1976) found students utilized the pronoun "we" more when expressing the college football team victory rather than loss in second and third experiments. They suggested the experiment participants' tendency to announce their connection with a positive source is strongest when their public identity was threatened, and individuals attempt to make connection with positive sources because they perceived others tend to evaluate positive sources the same way as they did. Cialdini et al. (1976) recognized individuals' BIRG tendency was an effort to acquire respect from those who understand the connection (i.e., the relationship between individuals and sport organizations).

Cialdini et al. (1976) concluded sport fans may perceive team's victories or defeats as personal successes or failures because sport fans' self-esteem perceptions were 
influenced by others' esteem perceptions of them, and they implied BIRG may be influenced by either interpersonal mediator (i.e., others' esteem perceptions) or intrapersonal mediator (i.e., personal satisfaction purpose). On the contrary, Snyder et al. (1983) suggested some individuals tend to distance themselves away from others who were unsuccessful or cutting off reflected failure (CORF). Individuals CORF to avoid negative association to preserve their self-image (Snyder et al., 1986). Cialdini et al. (1976), Tajfel and Turner (1979), and Snyder et al. (1983) findings provided theoretical foundations for other sport consumer behavior researchers attempting to develop the sport fans' team identification theory.

Sport Fan Team Identification. Wann and Branscombe (1990) is one of the earliest researchers to merge basking in reflected glory (BIRG) and cut off in reflected failure (CORF) concepts, and evaluated group identification impacts on individuals' tendencies to BIRG and CORF. Wann and Branscombe (1990) reported individuals associated themselves with successful others as an approach to boost their self-esteem (i.e., a phenomenon known as BIRGing), and they also reported some individuals also tend to distance themselves away from unsuccessful others as an approach to maintain their self-esteem (i.e., a phenomenon known as CORFing). Wann and Branscombe (1990) claimed sports spectators' identification levels moderated their BIRG and CORF tendencies, and they hypothesized team identification is an important factor changing spectators' behaviors and affects.

Wann and Branscombe (1990) developed a 2 (gender - male and female) X 3 (identification levels - low, moderate, and high) X 2 (BIRG and CORF) mixed factorial design to analyze individuals' identification level impact on their BIRG and CORF 
tendencies. They discovered individuals with high fan identification level are more likely to BIRG than CORF, and individuals with moderate or low fan identification level are more likely to CORF than BIRG. Wann and Branscombe (1990) suggested high identification fans are considered the "die-hard fans", and moderate and low identification fans are considered "fair weather fans".

Wann and Branscombe (1990) suggested fan identification levels can partially explain the fluctuations in sporting events attendance. They implied future research studies need to investigate the relationship between individuals' team identification and their perceptions of others practicing BIRG and CORF behavior. In addition, Wann and Branscombe (1990) also implied highly identified fans were more likely to demonstrate anger, hostility, aggression, depression and cognitive adjustments to cope with their team failure, compared to moderate and low identification fans. Wann and Branscombe's (1990) findings prompted other sport marketing researchers (e.g., Kahle et al., 1997; Murrell \& Dietz, 1992; Wann \& Branscombe, 1993) to further investigate team identification impact on sport consumers' behavior.

Murrell and Dietz (1992) analyzed the relationship between fan identification and team support (i.e., fan attendance and overall team evaluation), and they noticed most previous sport marketing research studies examining sport attendance suggested winning is the most important variable predicted and explained sport fans' demand. Murrell and Dietz (1992) argued previous sport marketing research studies failed to explain team with losing records and high attendance circumstances, or team with winning records and low attendance circumstances. They developed a model to explain sport fan support behavior using two social identity elements (i.e., collective esteem and in-group identification). 
Murrell and Dietz (1992) measured the dependent variable (i.e., fan support behavior) using three items (i.e., overall attendance, attitudinal support, and predicted success), and discovered sport fans' in-group identification predicted their attendance behavior and overall sport teams' evaluations (i.e., predicted players' successes). In addition, the sport fans' in-group identification also predicted team attitudinal support. Murrell and Dietz (1992) concluded individuals' perceived institutional status (i.e., individuals' public esteem) significantly predicted team support behavior, and their findings supported previous conclusions made by Cialdini et al. (1976), and Wann and Branscombe (1990). Murrell and Dietz (1992) implied future researchers need to focus on developing longitudinal research studies to assess the relationship between fan identification and team performance, and later on, Wann (1996) responded to Murrell and Dietz's (1992) research implication.

Wann and Branscombe (1993) argued there is a lack of valid and reliable instrument to measure sport fans' team identification, despite team identification ability to predict sport fans behavior. They developed the Sport Spectator Identification Scale (SSIS) to measure sport spectators' identification levels, and SSIS contained seven items forming a single composite sport spectator identification score. Wann and Branscombe (1993) suggested those seven items in SSIS measured: (a) the individuals' fan perceptions about their team, (b) the importance of winning, (c) the degree of spectators' team identification, (d) spectators' identification level, (d) the extent others viewed sports spectators' as a fan, (e) the sports spectators involvement levels (i.e., how closely sport spectators' following the progress of their team), (f) how often sports spectators wearing their team paraphernalia, and (g) the level of dislike sports spectators have against their 
principal rivals.

Wann and Branscombe (1993) discovered highly identified sport spectators are more likely: (a) possessing higher involvement level, (b) demonstrating ego-enhancing identification pattern by celebrating their team success publicly, (c) possessing more positive expectations regarding future team's performances, (d) spending more money and time on game attendance, and (e) believe their in-group members' possessed special qualities. Wann and Branscombe (1993) suggested sport spectators' future performance expectations differed by their identification levels. They also discovered SSIS is a valid and reliable instrument assessing spectator's team identification levels, and SSIS was utilized in several other research studies related to team identification. One of those research studies is Wann's (1996) seasonal changes in spectators' identification and involvement analysis. He responded to Murrell and Dietz's (1992) research implication indicating fan identification effect is impervious to competition outcomes.

Wann (1996) argued fan identification level is an important predictor of fan behavior (e.g., fan violence, BIRG or CORF, and perceptions of other fans) and selfesteem. He recognized fan identification may be impacted by their involvement level, game outcome, and previous game's location. Wann (1996) collected their data from undergraduate students once a week for 10 continuous weeks, and he discovered: (a) individuals with high sport team identification were more involved with the team, (b) individuals' reported significant changes in identification level, involvement, and team evaluations throughout the season, (c) previous game outcome impacted individuals team's performance evaluations and historically successful team fans' identification, and (d) location of previous game has minimum impact on fan identification. 
Wann (1996) implied research study examining sport spectator identification, involvement, and team evaluation relationship should be replicated to other fan groups (e.g., professional sports, youth teams, female sports, and individual sports). $\mathrm{He}$ suggested future researchers need to develop a comprehensive model to explain the relationship between sport spectators' identification, involvement, and behavioral outcomes. Sutton et al. (1997) responded to Wann's (1996) suggestion, and they developed a fan identification conceptual framework to predict and explain the relationship between fan identification levels, motivations, and benefits.

Sutton et al. (1997, p. 15) defined fan identification as "the personal commitment and emotional involvement customers have with a sport organization", and they suggested sports were unique from other entertainment sources because sports evoked high emotional attachment and identification levels. Sutton et al. (1997) also suggested highly identified fans were more likely to stay with the team when the team is not performing well. Sutton et al. (1997) argued positive fan identification can help sport organizations to minimize negative impact of poor team performance on the field, and categorized fans into three identification groups: (a) low identification fan (i.e., social fans), (b) medium identification fan (i.e., focused fans), and (c) high identification fan (i.e., vested fans). They outlined the customer organizational identification antecedents and outcomes. Customer organizational identification antecedents (i.e., managerial factors) include organization satisfaction, organization reputation, contact frequency, and affiliation visibility (Bhattacharya, Rao, \& Glynn, 1995).

Sutton et al. (1997) proposed positive customer organization identification created two beneficial outcomes (i.e., managerial and organizational benefits): (a) lower sport 
consumer's price sensitivity, and (b) lower sport consumer's performance-outcome sensitivity. They concluded sport consumer behavior was impacted by factors beyond team performance such as team identification and customer service, and there are several ways to increase sport fans' identification level. For example, sport team management or owners can increase customers' team identification level by (Sutton et al., 1997, p. 20): "(a) increasing their team or player accessibility to the public, (b) increasing their team community involvement, (c) reinforcing their team's history and tradition, and (d) creating opportunities for group affiliation and participation". Sutton et al. (1997) concluded it is important for sport managers to build long-term relationship (i.e., through positive team identification development) with their fans because it can lead to positive behavioral intentions such as positive word-of-mouth and re-patronage. Recently, Sutton et al.'s (1997) fan identification conceptual framework was adapted by other sport management researchers (e.g., Gwinder \& Swanson, 2003; Matsuoka et al., 2003; Van Leeuwen et al., 2002) to predict and explain sport spectator satisfaction and behavioral intentions, and sponsorship outcomes.

Relationship between Team Identification and Sport Consumption. In the past decade, team identification research has shifted from the theoretical conceptualization stage to the application stage. For instance, recent team identification researchers have been focusing on using team identification to predict and explain marketing outcomes such as corporate sponsorship, consumers' conative loyalty, and symbolic consumption patterns (Armstrong, 2007, Madrigal, 2001, Trail, Anderson, \& Fink, 2005). Madrigal (2001) is one of the earliest researchers to study the relationship between team identification and sport fans consumption behavior. Madrigal (2001) 
examined the beliefs-attitudes-intentions hierarchy in the university's sport team corporate sponsorship context, and analyzed the impact of team identification on sport consumers' behavioral intentions. He argued sport sponsorship can be used as a tool to communicate with consumers. Madrigal (2001) discovered sport consumers' team identification level moderated the relationship between their attitude and intentions to purchase the corporate sponsors' products or services. For example, individuals with low team identification level were more likely to rely on their attitudes to form purchase intentions in contrast to individuals with high team identification levels.

Madrigal (2001) concluded team identification is one of the dominant factors explaining highly identified sport fan tendency to purchase product from their team sponsor, and he suggested highly identified fans were more likely to purchase their team sponsor products because such behavior reinforced their identity as the affiliated team members. Madrigal (2001) implied future sport marketers need to find ways to strengthen fans' identification with the team, an implication similar to Sutton et al. (1997). Madrigal (2001) suggested future researchers need to expand the existing model (i.e., beliefs attitudes - behavior hierarchy) beyond fans' behavioral intentions (i.e., to actual purchase behavioral), and there were a group of researchers who developed the same conclusion as Madrigal (2001). For example, Fink, Trail, and Anderson (2002a, p. 195) concluded "highly identified fans were more likely to attend games, pay premium price for sporting event ticket and team merchandize, and remain loyal to the team through poor performance periods".

Trail et al. (2005) expanded Madrigal (2001) research study by analyzing consumer satisfaction and team identification impact on sport spectator conative loyalty. 
They argued conative loyalty (i.e., behavioral intentions) is an important construct in sport consumer behavior research because it impacts sport organization's profit. Trail et al. (2005) recognized there was a lack of research studies analyzing factors impacting sport spectator conative loyalty despites its' ability to impact sport organizations' profit, and they developed a sport spectator conative loyalty model using the consumer satisfaction and social identity theories.

Trail et al. (2005) developed three competing sport spectator conative loyalty models to explain sport consumer behavioral intentions, and they based their models on Oliver's (1997) consumer loyalty conceptual framework. Trail et al. (2005) discovered consumer loyalty contained four stages: (a) the cognitive stage based on service value premises, (b) the affective stage based on customer satisfaction premises, (c) the conative loyalty based on behavioral intentions premises, and (d) the action stage where consumer's consumption patterns become routine responses or habits. Trail et al. (2005) proposed a model integrating consumer satisfaction, team identification, and sport spectator consumer behavior theories, and the proposed model explained the highest variance (i.e., 49\%) in sport spectators' conative loyalty. Trail et al.'s (2005) best fit model demonstrated: (a) sport spectators' expectancies for event experience or outcome (dis)confirmation impacted their mood (i.e., affective stage), (b) sport spectators' team identification and mood impacted their self-esteem responses (i.e., BIRGing and CORFing), (c) sport spectators' self-esteem responses impacted their conative loyalty.

Trail et al. (2005) concluded future sport marketers need to create initiatives fostering sport spectators' team identification and focus on developing marketing strategy to maintain or enhance sport spectators' self-esteem. They recognized team performance 
was positively correlated with impulse buying behavior and recommended sport marketers to start collecting season ticket requests if their team ends the season on a positive note. On the contrary, sport marketers need to allow their consumers to settle down if there is a team's or player's controversy at the end of the season. Trail et al. (2005) implied sport marketers should focus on promoting sporting events using experiential or intangible values factors (e.g., sense of control, fun, aesthetic pleasure, and enhanced self-esteem).

Armstrong (2007) analyzed sport consumer behavior using team identification theory, and she examined self, situations, and sport consumption symbolic interactionism impact on sport spectators' behavior (i.e., attendance frequency). Armstrong (2007) recognized the task of explaining sport consumer behavior (i.e., using social cognition and social psychology constructs) is a huge challenge for sport marketing researchers, and she argued the challenge can be conquered using the symbolic interactionism theory. Armstrong (2007, p. 113) stated "symbolic interactionism helps to illuminate how human beings define their experiences and give meaning to their identities, behaviors, realities, and social interactions".

Armstrong (2007) suggested symbolic interactionism explained symbolic meaning of individuals' consumption experience using their self identity initiated by social interactions. Armstrong (2007) speculated individuals generally organize their behavior depending on their perceptions of others and situation awareness, and she construed symbolic interactionism existed in sport consumption behavior. Armstrong (2007) developed a sport consumer behavior (i.e., measuring attendance frequency) model using two symbolic interactionism constructs (i.e., self identity and situation 
awareness).

Armstrong (2007) surveyed spectators at a minor league ice hockey game and discovered both self identity and situation awareness explained $24 \%$ of the variance in spectators' game attendance frequency. She suggested sport spectators opportunity to practice self-expression while consuming sports was correlated with repeat attendance behavior, and sport spectators (i.e., both first time and repeat attendees) formed symbolic meanings to other sport consumers attending the game. Armstrong (2007) also discovered sport spectators' attendance frequency was negatively correlated with their tendencies to perceive other sport consumers' consumption choice (i.e., sport type), and she implied future researchers need to evaluate sport consumption motivations and team identification impact (i.e., moderating or mediating) on sport consumers' symbolic interactionism.

Kwon et al. (2007) added team identification alone did not impact sport consumers' purchase intentions, and they indicated service value explained more variance in sport consumers' purchase intentions than team identification. This study does not rely exclusively on team identification construct to explain sport consumer satisfaction and behavioral intentions. This study utilizes both sport consumers' service personal values and team identification level to explain their consumption satisfaction perceptions and behavioral intentions.

Team Identification Summary. Team identification theory originated from social identity theory (Wann \& Branscombe, 1990). Individuals' self-expression behavior and tendencies to identify with sport teams moderate the relationship between their personal values and behavioral outcomes (Allport et al., 1960; Kahle, 1983; Madrigal, 2001; Maslow, 1959). Individuals attempt to gain satisfactory public image, self-concept, 
pride, and sense of belongingness through social identification process (Cialdini et al., 1976, Synder et al., 1983, Tajfel, 1974, Wann, 1996). Several research studies suggested individuals attempt to associate themselves with the successful others or basking in reflected glory, BIRG (Wann, 1996; Wann \& Branscombe, 1990), and those individuals have no relationship with the successful others (Cialdini et al, 1976). SSIS has been identified as one the most effective team identification instrument (Matsuoka et al., 2003, Wann, 1996, Wann and Branscombe, 1993).

Individuals with high level of identification tend to be more involved, less price sensitive, less performance-outcome sensitive, basking in reflected glory, attend more games, and make positive evaluations of the team compared to individuals with moderate or low level of identification (Madrigal, 2001, Murrell \& Dietz, 1992, Sutton et al., 1997, Wann, 1996, Wann \& Branscombe, 1990). Sutton et al. (1997) suggested there are three levels of sport fan's team identification (i.e., social fans, focused fans, and vested fans). Sport fans identification level may change over the course of a sport season and previous game outcomes impacted sport fans' team identification level (Wann, 1996). It is critical for sport marketers to develop a comprehensive understanding of changes in sport fan team identification level because it impacts their consumption behaviors (Armstrong, 2007, Madrigal, 2001, Matsuoka et al, 2003, Sutton et al., 1997, Trail et al., 2005, Wann \& Branscombe, 1993).

Previous research studies (e.g., Lavarie \& Arnett, 2000, Matsuoka et al., 2003, Sirgy, 1982, Trail et al., 2005) typically utilized team identification as an independent variable rather than a moderator variable to explain sport consumer behaviors. Madrigal (2001) discovered team identification moderated the relationship between sport 
consumers' attitude and behavioral intentions (i.e., in the marketing through sport context). Madrigal (2001) argued team identification's moderating role in the relationship between sport consumers' attitude and behavioral intentions within the marketing of sport products or services context has not been widely research. This study examines the role of team identification (i.e., moderator or mediator) in the relationship between sport consumers' service personal values, and both consumption satisfaction perceptions and behavioral intentions.

\section{Sport Consumption}

Sport customer service and sport consumer behavior research studies suggested team identification predicted and explained sport consumers' decision making process and consumption behavior (Lavarie \& Arnett, 2000, Matsuoka et al., 2003, Sirgy, 1982). In addition, service personal values predicted and explained sport consumer decision making process and sport consumer behavior (Kahle et al., 2001, Quester et al., 2006, Shao, 2002). This study noted previous sport marketing research studies (e.g., Kwon et al., 2007, Lavarie \& Arnett, 2000, Matsuoka et al., 2003) predominantly utilize team identification as either one of the mediators or independent variable to explain and predict sport consumer behavior (i.e., consumption satisfaction perceptions and behavioral intentions). Madrigal (2001) suggested team identification moderated the relationship between consumers' attitudes and behavioral intentions but team identification has not been widely utilize by sport marketing researchers as a moderator of the relationship between sport consumers' attitudes and behavioral intentions. This study analyzes the impact of team identification on the relationship between sport consumers' service personal values and consumption behavior. 
The objectives of sport consumption literature review are: (a) examining the affective component of sport consumers' decision making process (i.e., focusing on sport consumers' consumption satisfaction perceptions), and (b) evaluating the sport consumers' behavioral outcomes (i.e., focusing on sport consumers' behavioral intentions). This study examines sport consumers' decision making process and behavioral intentions constructs research studies seeking to further understand the role of team identification (i.e., mediator or moderator) in the relationship between sport consumers' service personal values and consumption behavior. In addition, this study reviews research studies related to the college football to justify the selection of college football season ticket holders as the target population.

Sport Consumer Decision Making Process. One of the research purposes for this study is to develop an understanding of the relationship between college football season ticket holders' service personal values, customer satisfaction perceptions, and behavioral intentions. This study reviews research studies examining the impact of the sport consumers' decision making process (i.e., consumer cognitive and affective components) on their behavioral intentions (i.e., behavioral component). College football season ticket holders' purchase decision making process is considered an extensive decision making process because it involved significant financial and physical commitment (Young, 2001).

Customer satisfaction predicted and explained their behavioral intentions (Cronin et al., 2000; Lamb et al, 2004, Lavidge \& Steiner, 1961, Nicosa, 1966). Sport management literature indicated Lavarie and Arnett's (2000) research study is one of the most comprehensive studies examining the impact of sport consumer decision making 
process on their behavioral intentions. This study examines the Lavarie and Arnett (2000) research study to seek further understanding of the devoted sport consumers' (e.g., college football season ticket holders) decision making process impact on their behavioral intentions. Lavarie and Arnett (2000) developed a model to analyze women's college basketball fan attendance pattern using several psychology and business theories (i.e., social identity, involvement, attachment, and customer satisfaction theories).

Lavarie and Arnett (2000) recognized previous sport management and consumer behavior researchers attempted to explain the devoted sport consumer behavior using either single or two-factor social-psychological model. For example, Kerstetter and Kovich (1997) analyzed women's basketball fans' involvement and socio-demographics impact on their behavioral intentions. Cialdini et al. (1976) explained the university sport consumers' behavior using the social identity theory, and Madrigal (1995) created a model to explain sport consumer satisfaction using fan identification, and affect and enjoyment theories. Lavarie and Arnett (2000) expressed there is a need to examine sport consumer behaviors using multidimensional model and they developed a model to explain consumers attendance behavior using involvement (i.e., situational and enduring), attachment, identity salience, and consumption satisfaction perception.

Lavarie and Arnett (2000) collected their data from a large southwestern university and analyzed their data using structural equation modeling. They discovered women's college basketball fans' involvement, attachment, and identity salience together explained $65 \%$ of the variance in their attendance behavior and women's college basketball fans' situational involvement positively impacted their consumption satisfaction. Lavarie and Arnett (2000) also discovered women's college basketball fans' 
identity salience and satisfaction together positively impacted to their attendance frequency and women's college basketball fans' identity salience explained more variance in attendance behavior compared to their consumption satisfaction perceptions. They concluded customer satisfaction is a critical factor explaining sport fans' attendance behavior and it needs to be further explored by sport marketing researchers. Lavarie and Arnett (2000) implied identity salience can serve as a customer segmentation base for the sport marketers and suggested future sport management researchers need to investigate:

(a) the role of social influence on identity salience formation, (b) identity salience products (e.g., sport apparel and memorabilia) consumption, and (c) sport consumer behavior using multiple theoretical constructs. Matsuoka et al. (2003) research study is one of the many research studies supported Lavarie and Arnett's (2000) conclusion.

Matsuoka et al. (2003) evaluated sport spectators' team identification (i.e., direct and interaction effects) and game outcome satisfaction impacts on their future game attendance intentions. They argued not all sporting events have high attendance numbers, and it is important for sport marketers to develop strong sport consumers retention plans. Matsuoka et al. (2003) contended customer satisfaction and loyalty positively impacted customer retention and repurchase behavior, and they argued team identification positively impacted customer satisfaction.

Matsuoka et al. (2003) discovered sport consumers' team identification level and consumption satisfaction perceptions (i.e., with favorite team performance, with game score, and contest excellence) significantly correlated with their intention to attend future games. Matsuoka et al.'s (2003) findings also indicated team identification explained $17.1 \%$ of variance in intention to attend games (i.e., at least twice more than any facet of 
customer satisfaction, and the interaction of sport consumers' team identification and satisfaction was a significant predictor of their behavioral intentions. They concluded sport marketers need to actively promote activities enhancing sport consumers' team identification. Matsuoka et al. (2003) implied future researchers need to further investigate the link between consumer behavioral intentions and actual behavior using empirical research studies.

Both Lavarie and Arnett (2000), and Matsuoka et al. (2003) findings demonstrated sport consumers' consumption satisfaction perceptions and team identification level are strong predictor and explanatory variables of behavioral intentions. This study decides to use sport fans consumption satisfaction perceptions as one of the outcome variables for service personal values. A review of sport marketing literature indicated Madrigal (1995) sport fans satisfaction study is one of the earliest sport customer satisfaction studies examining sport fans' cognitive and affective reactions impact on their consumption satisfaction perceptions.

Madrigal (1995) investigated sport fans' cognitive (i.e., expectancy disconfirmation, team identification, and opponent quality) and affective (i.e., enjoyment and basking in reflective glory) reactions impact on sporting event attendance satisfaction. He noticed the hierarchical relationship between consumers' disconfirmation, affect, and satisfaction has been widely investigated by consumer behavior researchers, but it has not received extensive attention from the sport management or leisure study researchers. Madrigal (1995) proposed a structural satisfaction model to explain sport fans' cognitive and affective processes impact on their post consumption satisfaction. Madrigal (1995) collected the data from 242 sport fans attending women's 
basketball games at a large Midwestern state university and he analyzed the data collected using multivariate analysis of variance (MANOVA). The results indicated there is no significant difference existed between male and female spectators' cognitive and affective states, and Madrigal (1995) did not include gender in the succeeding data analysis (i.e., structural model development). Madrigal (1995) specified direct paths from cognitive states (i.e., expectancy disconfirmation, team identification, and quality of opponent) to affective states (i.e., BIRGing and enjoyment). He also specified affective state is one of the explanatory variables for sport fans' consumption satisfaction perceptions. Madrigal (1995) discovered all the hypothesized relationships were statistically significant, and he identified the most important variable in cognitive states is team identification, followed by expectancy disconfirmation and quality of opponent. He also discovered team identification (i.e., cognitive construct) has the strongest impact on the overall affect construct, and enjoyment (i.e., affective construct) has the strongest influence in fan satisfaction.

Madrigal (1995) concluded sport fan satisfaction is an important predictor for future economic activity (e.g., re-purchase behavioral intentions), and he suggested future sport management researchers need to further analyze the relationship between sport fan satisfaction construct and its antecedents (e.g., cognitive and affective factors). Madrigal (1995) findings paved way for other future sport management researchers to create more sophisticated sport consumer satisfaction models.

For example, Van Leeuwen et al. (2002) developed sport spectator satisfaction model (SSSM) based on sport product and service unique aspects, and sport service core and peripheral dimensions. They recognized there was a lack of sport-focused satisfaction 
research studies within sport marketing literature despite customer satisfaction significance to sport organizations continued existence (Madrigal, 1995). Van Leeuwen et al. (2002) also recognized not all sport consumers are sport fans and sport consumers are attach to sport organizations or teams on different levels.

Van Leeuwen et al. (2002) argued sport organizations cannot simply focus on external factors (e.g., team's performance, players' performance, opponent's quality, etc.) impacting sport fans behavior because there are too many external factors beyond sport marketers control. They suggested it is critical for sport marketing researchers to develop comprehensive sport consumer satisfaction model to gain thorough understanding of sport spectator satisfaction, and it is important for sport marketers to understand the internal factors (e.g., customer service and team identification) impacting customer satisfaction rather than just the customer satisfaction levels.

Van Leeuwen et al. (2002) developed SSSM based on Oliver's (1980) disconfirmation expectancy model, and SSSM included: (a) club or team identification level, (b) game outcome (i.e., win or lose), (c) core expectations, (d) core perceived performance, (e) core disconfirmation, (f) peripheral expectations, $(\mathrm{g})$ peripheral perceived performance, and (h) peripheral disconfirmation. They concluded SSSM is a theoretical model and future sport management researchers need to empirically test SSSM in different sport consumption contexts. At the same time, Greenwell et al. (2002) research study is another prominent sport marketing research studies empirically examining sport customer satisfaction.

Greenwell et al. (2002) examined the physical sports facility impact on sport consumers' satisfaction perceptions and evaluated sport service quality targets (i.e., core 
product and service personnel) impact on sport consumers' satisfaction perceptions. They developed a conceptual framework based on Cronin et al. (2000) theoretical framework. Greenwell et al. (2002) argued customer satisfaction perceptions mediated the relationship between customer service factors and consumer behavioral intentions, and they hypothesized sport consumers' cognitive evaluations of service quality impacted their emotional satisfaction assessment. Greenwell et al. (2002) also posited the customer emotional satisfaction assessment impacted consumer purchase behaviors (e.g., purchase intentions, repeat purchases, refer other customers, brand loyalty, and engage in word-ofmouth activities).

Greenwell et al. (2002) surveyed 218 ice hockey spectators attending two American Hockey League (AHL) games. They discovered spectators' physical facility perceptions explained $16.2 \%$ of the variance in customer satisfaction and physical facility as a whole impacted customer satisfaction, but individual physical facility attribute has minimum impact on customer satisfaction. Greenwell et al. (2002) also discovered service experience (i.e., core product, service personnel, and physical facility) explained $31 \%$ of the variance in customer satisfaction.

Greenwell et al. (2002) concluded future sport management researchers need to develop a comprehensive list of factors impacting sport customer satisfaction. They suggested future sport management researchers need to empirically test the relationship between physical facility, customer satisfaction, and profitability. Greenwell et al. (2002) findings indicated there is a relationship between customer service and sport consumer behavior. This study further examines literature examining the relationship between customers' service elements, satisfaction, and behavioral intentions. Cronin et al. (2000) 
is one of the earliest research studies to investigate customer service, sport customer satisfaction, and consumer behavioral intentions.

Cronin et al. (2000) examined service quality, service value, and customer satisfaction impact on consumer behavioral intentions. They recognized previous customer satisfaction research studies typically assessed single customer service construct or limited customer service subset impacts on consumer behavioral intentions, and the tendency to isolate customer service constructs impact on customer satisfaction may limit researchers understanding of consumer decision making process. Cronin et al. (2000) hypothesized: (a) behavioral intentions are influenced by satisfaction, service quality, and service value, (b) satisfaction is influenced by service value and service quality, and (c) service value is influenced consumer sacrifice. They collected the data from six service industries (i.e., spectator sports, participation sports, entertainment, health care, long distance carriers, and fast food) and analyzed their data using the structural equation modeling technique.

Cronin et al. (2000) discovered service value and service quality indirectly influenced behavioral intentions, and customer service components such as service quality and service value positively impacted their satisfaction evaluations. Consumers' cognitive evaluations preceded their emotional responses and service consumers considered service quality was more important than acquisition costs. Cronin et al. (2000) concluded the consumer decision making process for service industries is best explain using the behavioral intention model containing direct and indirect effects. They suggested customer service variables (i.e., service quality, service value, and satisfaction) directly and indirectly impacted consumers' behavioral intentions. 
Cronin et al. (2000) implied additional customer service variables (e.g., service attributes and service personal values) should be included in future consumer decision making models. This study uses service personal values to explain college football season ticket holders' consumption satisfaction perceptions. At the same time, a review of sport marketing literature indicated behavioral intentions is another important outcome of sport consumers' consumptions satisfaction perceptions (Cronin et al., 2000, Greenwell et al., 2002, Matsuoka et al., 2003) and this study examines research studies related to sport consumer behavioral intentions.

Sport Consumer Behavioral Intentions. College football season ticket holders' consumption satisfaction perceptions and behavioral intentions are the two dependent variables of this study. In the previous sub-section, this study reviewed literature related to sport consumer decision making process focusing on the sport consumers' consumption satisfaction perceptions. This study discovered sport consumers' satisfaction predicted and explained their behavioral intentions (Cronin et al., 2000; Lavarie \& Arnett, 2000). Cronin et al. (2000) argued the use of actual purchase behavior instead of behavioral intentions could potentially improve marketing research studies implications, but they recognized actual behavior data are extremely difficult to obtain. Cronin et al. (2000) suggested future researchers can utilize behavioral intentions to measure consumers' purchase behavior. This study uses behavioral intentions to measure consumer future behavior.

Fishbein and Azjen (1975) proposed theory of reasoned behavior suggesting behavioral intentions is a function of separable effects of attitude and the social or subjective norm. Zeithaml et al. (1996) suggested customer retention is positively 
correlated with service providers' overall profit and one of the main factors impacting customer retention is behavioral intentions. They discovered positive behavioral intentions are linked with service provider's tendency to have its customers to: (a) provide positive word-of-mouth, (b) recommend them to others, (c) re-purchase from them, (d) increase their spending with them, and (e) willing to pay premium price for the product or service. Zeithaml et al. (1996) findings are similar to Fink et al. (2002b) findings suggesting behavioral intentions of sport consumers include continued loyalty, attendance intentions, and merchandise-consumption intentions.

In the field of sport marketing, Trail et al. (2000) is one of the earliest researchers to develop a theoretical sport spectator consumption behavior model, incorporating sport consumers behavioral intentions. They suggested sport consumers affective states (i.e., consumption satisfaction perception) impact future consumption behaviors (e.g., media consumption, sport merchandise consumption, consumption of products marketed through sports, and attendance at events). Trail, Fink, and Anderson (2003) tested Trail et al. (2000) sport spectator consumption behavior model and discovered the interaction of six general factors (i.e., motives, level of identification, expectancies, confirmation or disconfirmation of expectancies, self esteem responses, and the affective state of the individual) explained $10.6 \%$ of the variance in sport spectator's behavioral intentions. Most of the sport consumer decision making process and behavioral intentions research studies did not focus on college football consumers with the exception for Cronin et al.'s (2000) research study, despite recent reports indicating college football as the most highest revenue generating college sports (Fulks, 2009, NCAA, 2010). This study focuses on research studies examining college football consumer behaviors, and the 
target population for this study is college football season ticket holders because they provide college sport organizations a consistent stream of revenue (Young, 2001).

College Football. A review of college football research studies demonstrated the study of college football is closely linked to several fields of study such as social identification and customer service studies. For example, individuals' university prestige perceptions and affiliations, and college football domain involvement predicted their fan identification level (Gwinner \& Swanson, 2003). Customer service variables such as service quality and service value also impacted college football consumers' satisfaction and behavioral intentions (Cronin et al., 2000). Early college football research studies focused on the game development (Rutgers University, n.d.) and issues related to professional organizations (e.g., National Collegiate Athletic Association, NCAA, and College Football Association, CFA) regulating college football competitions and television broadcasting rights analyses (Siegfried \& Burba, 2004).

In the 90 's, the college football literature focused on competitive balance among the college football teams. The college football Bowl Championship Series (BCS) was created after the 1997 post season bowl games and the BCS main goal is to create systematic post-season competition among college football teams and matchup top two ranked team in a national championship game using a mathematical formula (Bowl Championship Series, 2010). Overall, college football literature predominantly focused on macro college football issues such college football broadcasting rights, legal issues, and market structure issues in the $20^{\text {th }}$ century (Hales, 2003; Southall, Southall, \& Dwyer, 2009; Thieme, 2007). In the $21^{\text {th }}$ century, college football literature began focusing on 
micro college football issues such college football microeconomics variables and consumer behavior.

Several college football research studies in the early $21^{\text {th }}$ century focused on microeconomics variables impacting college football attendance. For example, Price and Sen (2003) discovered the home team's game day attendances were impacted by: (a) home and visiting teams' qualities, (b) traditional rivalry, (c) conference membership, (d) students living on-campus, and (e) professional football team presence nearby. Leonard (2005) discovered gravity model quotient, visitor's conference win, and previous season champion explained $42 \%$ of the variance in game ticket sales. Recently, college football researchers began to focus on the college football consumer behavior. For instance, Robinson et al. (2005) reported college football consumers can be classified either as fans or spectators based on their consumption motives and points of attachment, and sport consumption motives can be divided into two parts (i.e., fan motives and spectator motives). Sport consumption motives are correlated with different points of attachments (Woo, Trail, Kwon, \& Anderson, 2009).

A few college football researchers shifted their focus to the college football season ticket holders (Pan \& Baker, 2005; Young, 2001). Season ticket holders are critical to every sport organizations, and college football season ticket holders are considered the most important customer group in college sports because they provide the largest and most consistent stream of revenue for college football institutions (Fulks, 2009; Young, 2001). College football season ticket holders are inelastic to negative game outcomes (Young, 2001). Pan and Baker (2005) discovered team specific factors (e.g., tradition and performance), social interaction (e.g., attending games with family members 
and friends), and game specific factors (e.g., conference games and games against top 25 team) predicted and explained college football consumer behavior.

In conclusion, college football research studies shifted from examining competitive structure of college football competition and external factors impacting college football attendance (Price \& Sen, 2003, Siegfried \& Burba, 2004) to college football consumer behavior (Robinson et al., 2005). College football consumer behavior research studies suggested college football season ticket holders is the most important customer base because they provide college football organizations with the largest and most consistent stream of revenue (Fulks, 2009; Young, 2001). The college football season ticket holders' is the target population for this study.

Sport Consumption Summary. Sport consumers go through a series of cognitive processes (i.e., considering service attributes, service quality, service value, and service personal values) before reaching their consumption satisfaction perceptions (Cronin et al., 2000; Zeithaml, 1988). Sport consumers' team identification and personal values predicted and explained their consumption satisfaction perceptions and behavioral intentions (Kahle et al., 2001; Lavarie \& Arnett, 2000; Matsuoka et al., 2003; Quester et al., 2006; Shao, 2002; Sirgy, 1982), and in turn, customer satisfaction perceptions impacted their behavioral intentions (Lamb et al, 2004; Lavidge \& Steiner, 1961; Nicosa, 1966).

Several sport marketing researchers discovered sport consumers' consumption satisfaction perceptions and team identification (i.e., cognitive and affective variables) predicted and explained behavioral intentions (Cronin et al., 2000; Lavarie \& Arnett, 2000; Madrigal, 1995; Matsuoka et al., 2003). Several researchers suggested there is a 
need for future sport marketing studies to focus on using customer service initiatives (i.e., controllable variable) to impact sport consumers' consumption satisfaction perceptions and behavioral intentions (Cronin et al., 2000; Greenwell et al., 2002; Zeithaml, 1988). One of the research purposes is to understand service personal values ability to predict and explain college football season ticket holders' consumption satisfaction perceptions and behavioral intentions.

Previous sport marketing research studies (e.g., Kwon et al., 2007; Lavarie \& Arnett, 2000; Trail et al., 2000; Trail et al., 2003) typically utilized team identification either as a mediator or independent variable to explain and predict sport consumer behavior (i.e., consumption satisfaction perceptions and behavioral intentions). Madrigal (2001) discovered team identification moderated the relationship between sport consumers' attitude and behavior. Frazier et al. (2004) argued in order to advance a particular field of study's theory, research, and practice, it is critical for researchers to progress from the basic research questions (e.g., the relationship between team identification and customer satisfaction, and behavioral intentions) to sophisticated research questions involving moderator or mediator. Frazier et al. (2004, p. 116) emphasized "questions involving moderators address "when" or "for whom" a variable most strongly predicts or causes an outcome variable".

This study discovered sport consumers' team identification level fits the role of a moderator because sport consumers possessed different levels of identification to sport teams (Trail et al., 2003). Sport consumers' team identification levels may potentially moderate the relationship between their personal values and consumption satisfaction perceptions or behavioral intentions (Stewart, Smith, \& Nicholson, 2003). One of the 
research purposes of this study is to understand the moderating effect of college football season ticket holders' team identification level on the relationship between their service personal values constructs, and both consumption satisfaction perceptions and behavioral intentions.

Sport consumer segmentation (based on demographic profiles, consumption motives, and points of attachment) has been identified as one of the marketing tools to design effective sport marketing plan (Robinson et al., 2005; Woo et al., 2009). Young (2001) suggested the college football season ticket holders is the most important group of consumers for college football institutions, because they provide a consistent stream of revenue and less susceptible negative game outcomes. One of the purposes of this study is to gain an in-depth understanding of college football season ticket holders' service personal values. This study examines the relationship between the college football season ticket holders' demographic profiles and their service personal values dimensions such as service value to peaceful life (SVPL), service value to social recognition (SVSR), and service value to social integration (SVSI).

\section{Summary of Literature Review}

This study extensive literature review included: (a) personal values, (b) team identification, and (c) sport consumption. The main objective of the personal values section is to review literature related the theoretical and empirical development of personal values, and its impact on consumer behavior. Individuals' personal values orientation is the highest level of service consumer cognitive perception, and personal values consist of relatively small set of variables and consistent over time (Lages \& Fernandes, 2005; Rokeach, 1973; Zeithaml, 1988). The conceptualization of personal 
values can be explained using social adaptation theory (Kahle, 1983), which suggested "the concept of regarding personal values as mediators in the social adaptation process implies that value differences between cultures can be traced back to different ethnic background and the social, economic, political, and technological environments" (Wang et al., 1994, p. 185).

Individuals' life experiences, ethnic, cultural, and socioeconomic status backgrounds impact their personal values formation (Kahle et al., 2001; Lamb et al., 2004). The first research purpose of this study is to understand the relationship between college football season ticket holders' demographic profiles (i.e., independent variables) and their service personal values (i.e., dependent variables). Six research questions $(R Q)$ respond to the first research purpose of this study:

RQ1(a): Does college football season ticket holders' number of household member(s) correlate to their service personal values dimensions (i.e., service value to peaceful life or SVPL, service value to social recognition or SVSR, service value to social integration or SVSI)?

$R Q 1(b)$ : Does college football season ticket holders' gender correlate to their service personal values dimensions (i.e., SVPL, SVSR, and SVSI)?

RQ1(c): Does college football season ticket holders' ethnicity correlate to their service personal values dimensions (i.e., SVPL, SVSR, and SVSI)?

$R Q 1(d)$ : Does college football season ticket holders' annual household income, correlate to their service personal values dimensions (i.e., SVPL, SVSR, and SVSI)? RQ1(e): Does college football season ticket holders' alumni status correlate to their service personal values dimensions (i.e., SVPL, SVSR, and SVSI)? 
$R Q I(f)$ : Does college football season ticket holders' number of years holding season tickets correlate to their service personal values dimensions (i.e., SVPL, SVSR, and SVSI)?

Personal values research studies suggested personal values are important set of variables predicting and explaining consumer behavior (Homer \& Kahle, 1988; Madrigal \& Kahle, 1994; Quester et al., 2006; Shao, 2002; Vinson et al., 1977; Westerbeek \& Shilbury, 2003; Zeithaml, 1988). Previous sport marketing research studies have not extensively utilized personal values to explain consumer behavior despite its usefulness in predicting and explaining sport consumer behavior (Kahle et al., 2001, Lages \& Fernandes, 2005; Quester et al., 2006). The second research purpose of this study is to understand the relationship between college season ticket holders' service personal values (independent variables), and both consumption satisfaction perceptions and behavioral intentions (dependent variables). Two research questions $(R Q)$ respond to this study second research purpose:

$R Q 2:$ Which dimensions of the college football season ticket holders' service personal values (i.e., SVPL, SVSR, and SVSI) are significant in explaining and predicting their consumption satisfaction perceptions?

$R Q 3:$ Which dimensions of the college football season ticket holders' service personal values (i.e., SVPL, SVSR, and SVSI) are significant in explaining and predicting their behavioral intentions?

The main objective of the team identification section is to review the theoretical and empirical research studies related to the team identification construct. Previous research studies related to team identification indicated social identity theory motivated 
the development of the team identification theory (Cialdini et al., 1976, Wann \& Branscombe, 1990). Team identification is an important construct predicting and explaining sport consumer behavior (Madrigal, 2001, Murrell \&Dietz, 2001, Sutton et al., 1997, Wann, 1996). Sport consumers' level of team identification predicted and explained their consumption behaviors such as involvement level, price elasticity, performance outcome sensitivity, and game attendance frequency (Madrigal, 2001, Wann \& Branscombe, 1993).

Sport consumers' team identification level is correlated to their personal values, (Cialdini et al., 1976, Synder et al., 1983, Tajfel, 1974, Wann, 1996). Sutton et al. (1997) which suggested sport fans identified themselves to sport organizations at different levels (i.e., social fans, focused fans, and vested fans). Previous team identification research studies demonstrated sport fans' team identification level moderated their behavior (i.e., through BIRGing and CORFing) to boost their self-esteem (Cialdini et al., 1976, Synder et al., 1983, Wann \& Branscombe, 1993). Most of the previous team identification research studies (e.g., Lavarie \& Arnett, 2000, Madrigal, 2001, Matsuoka, 2003, Sirgy, 2001, Trail et al., 2005) generally utilized team identification as an independent variable or mediator rather than a moderator to explain sport consumer behavior.

The main objective of the sport consumption section is to examine the role of team identification in the relationship between college football season ticket holders' service personal values, consumption satisfaction perceptions, and behavioral intentions. This study reviewed research studies related sport consumers' decision making process (i.e., focusing on consumption satisfaction) and sport consumer behavioral intentions. Previous sport consumption research studies suggested: (a) service personal values 
explained and predicted both consumption satisfaction perceptions and behavioral intentions (Lages \& Fernandes, 2005), (b) service personal values are correlated to team identification level (Allport et al., 1960; Kahle, 1983; Maslow, 1959), (c) team identification level explained and predicted both consumption satisfaction prediction and behavioral intentions (Lavarie \& Arnett, 2000; Matsuoka et al., 2003; Wann \& Branscombe, 1993), and (d) consumption satisfaction perceptions predicted and explained their behavioral intentions (Cronin et al., 2000). This study proposes sport consumers' team identification moderates the relationship between their service personal values, and both consumption satisfaction perceptions and behavioral intentions.

College football is the highest revenue generating college sport (Fulks, 2005a), and college football season ticket holders provide college football programs with a consistent stream of revenue. This study selects college football season ticket holders at a conference with the declined average attendance as the research participants or target populations. College football season ticket holders possess different identification levels (Sutton et al., 1997) and those differences impacted their consumption satisfaction perceptions and behavioral intentions (Madrigal, 2001, Wann \& Branscombe, 1993). College football season ticket holders' team identification levels may potentially moderate the relationship between their personal values and consumption satisfaction perceptions or behavioral intentions (Stewart et al., 2003). Frazier et al. (2004) suggested future researchers need to address the questions involving moderators (e.g., whom or when) if they want to advance their field of study.

The third research purpose of this study is to understand the moderating effect of college football season ticket holders' team identification level on the relationship 
between their service personal values, and both consumption satisfaction perceptions and behavioral intentions. Six research questions $(R Q)$ respond to this study's third research purpose:

RQ4(a): How do college football season ticket holders' levels of team identification moderate the relationship between their service value to peaceful life and consumption satisfaction perceptions?

$R Q 4(b)$ : How do college football season ticket holders' levels of team identification moderate the relationship between their service value to social recognition and consumption satisfaction perceptions?

$R Q 4(c)$ : How do college football season ticket holders' levels of team identification moderate the relationship between their service value to social integration and consumption satisfaction perceptions?

RQ5(a): How do college football season ticket holders' levels of team identification moderate the relationship between their service value to peaceful life and behavioral intentions?

$R Q 5(b):$ How do college football season ticket holders' levels of team identification moderate the relationship between their service value to social recognition and behavioral intentions?

$R Q 5(c)$ : How do college football season ticket holders' levels of team identification moderate the relationship between their service value to social integration and behavioral intentions? 


\section{CHAPTER III}

\section{METHODOLOGY}

The previous chapter reviewed literature related to personal values, team identification, and sport consumption. The literature review process generated 14 research questions corresponding to three research purposes. This chapter explains the methodology for this study, and discusses research study purpose, research study target variables, research participants, data analysis, and methodology summary.

\section{Research Study Purpose}

Chapter I illustrated several research problems related to college football marketing such as inconsistency in college football attendance (NCAA, 2010), widening gap between universities possessing a positive revenue and universities possessing a negative revenue (Brown, 2009; NCAA, 2009), and stagnant revenue growth and increase competitions from other sport organizations (Fulks, 2009). The following are this study's three main research purposes:

(a) to understand the relationship between the college football season ticket holders' demographic profiles and their service personal values dimensions (i.e., service value to peaceful life, SVPL, service value to social recognition, SVSR, and service value to social integration, SVSI),

(b) to understand the relationship between college football season ticket holders' service personal values dimensions, and both consumption satisfaction perceptions and behavioral intentions, and 
(c) to understand the moderating effect of college football season ticket holders' team identification level on the relationship between their service personal values dimensions, and both consumption satisfaction perceptions and behavioral intentions.

Research Questions. This study developed 14 research questions $(R Q)$ related college football season ticket holders' service personal values corresponding to three research purposes:

RQ1(a): Does college football season ticket holders' number of household member(s) correlate to their service personal values dimensions (i.e., service value to peaceful life or SVPL, service value to social recognition or SVSR, service value to social integration or SVSI)?

$R Q 1(b)$ : Does college football season ticket holders' gender correlate to their service personal values dimensions (i.e., SVPL, SVSR, and SVSI)?

$R Q 1(c)$ : Does college football season ticket holders' ethnicity correlate to their service personal values dimensions (i.e., SVPL, SVSR, and SVSI)?

$R Q I(d)$ : Does college football season ticket holders' annual household income, correlate to their service personal values dimensions (i.e., SVPL, SVSR, and SVSI)?

RQ1(e): Does college football season ticket holders' alumni status correlate to their service personal values dimensions (i.e., SVPL, SVSR, and SVSI)?

$R Q 1(f)$ : Does college football season ticket holders' number of years holding season tickets correlate to their service personal values dimensions (i.e., SVPL, SVSR, and SVSI)?

$R Q 2$ : Which dimensions of the college football season ticket holders' service personal values (i.e., SVPL, SVSR, and SVSI) are significant in explaining and predicting their 
consumption satisfaction perceptions?

$R Q 3$ : Which dimensions of the college football season ticket holders' service personal values (i.e., SVPL, SVSR, and SVSI) are significant in explaining and predicting their behavioral intentions?

$R Q 4(a):$ How do college football season ticket holders' levels of team identification moderate the relationship between their service value to peaceful life and consumption satisfaction perceptions?

$R Q 4(b):$ How do college football season ticket holders' levels of team identification moderate the relationship between their service value to social recognition and consumption satisfaction perceptions?

$R Q 4(c):$ How do college football season ticket holders' levels of team identification moderate the relationship between their service value to social integration and consumption satisfaction perceptions?

$R Q 5(a):$ How do college football season ticket holders' levels of team identification moderate the relationship between their service value to peaceful life and behavioral intentions?

$R Q 5(b):$ How do college football season ticket holders' levels of team identification moderate the relationship between their service value to social recognition and behavioral intentions?

$R Q 5(c)$ : How do college football season ticket holders' levels of team identification moderate the relationship between their service value to social integration and behavioral intentions? 
Study Design. Johnson and Onwuegbuzie (2004) suggested research purposes and research questions should drive a researcher choice of study design. This study research's purposes are to understand service personal values antecedents and outcomes, and team identification's moderating effect on the relationship between service personal values, and both consumption satisfaction perceptions and behavioral outcomes. Fourteen research questions were developed to help accomplish research purposes of this study. These research questions involve theory testing and examining the relationship between college football season ticket holders' demographic profiles, service personal values, team identification levels, consumption satisfaction perceptions, and behavioral intentions to buy college football season tickets. This study utilized a correlational design, and it included a survey to collect data from the participants.

Survey is "a research technique in which information is gathered from a sample of people using a questionnaire" (Zikmund, 2003, p. 66). Thomas (2003, p. 41) explained "Survey methods involve gathering information about the status of some target variables within a particular collectivity, then reporting a summary of the findings. The summary (of the findings) includes data in quantitative form". Target variables referred to a specific characteristic of a population or collectivity, and population or collectivity is a cluster of specific individuals becoming the focal point of a survey (Thomas, 2003).

The typical procedure for survey design involves (Thomas, 2003): (a) specifying the target variable (i.e., exogenous and endogenous variables), (b) identifying the collectivity (i.e., survey population or participants), (c) deciding the data collection procedure (i.e., face to face, mail, or internet survey), (d) gathering the information, and (e) summarizing the results for statistical data analysis (i.e., using statistical methods such 
as analysis of variance, multiple regression, structural equation modeling, etc.). Several advantages and limitations are associated with the use of a survey design. The advantages of using the survey design include (Thomas, 2003): (a) exposing a snapshot (i.e., crosssectional) of a target variable within a particular large collectivity or population, (b) the data collected (i.e., if it is in a numerical form) can be used for statistical data analysis, and (c) the survey design can be easily modified. At the same time, limitations to survey design includes (Thomas, 2003): (a) the typical surveys generally describe only the target variables' averages and percentages, (b) the survey design fails to describe the qualitative features making each individual in the collectivity or population unique, and (c) survey questionnaires cannot probe the participants.

\section{Research Study Target Variables}

The collectivity or population for this study is the college football season ticket holders at a large Southeastern public university. This study examines four main target variables: (a) team identification, (b) customer satisfaction, (c) consumer behavioral intentions, and (d) service personal values. This study also examines college football season ticket holders' demographic profiles.

Demographic Questionnaire. The demographic questions included in this study are based on the United States Census Form (2010), Greenwell et al. (2002), and Gwinner and Swanson (2003), and those items are: (a) number of household member(s), (b) gender, (c) ethnicity, (d) annual household income, (e) university affiliation, and (f) number of years being season ticket holders. Keeping in mind individual personal values were shaped by demographic profiles, cultures, and life experiences (Kahle et al., 2001, Lamb et al, 2004). This study examines some of the college football season ticket 
holders' demographic variables (e.g., gender, ethnicity, and university affiliation) and their relationship to the respondents' service personal values (i.e., service value to peaceful life, SVPL, service value to social recognition, SVSR, and service value to social integration, SVSI).

Team Identification. Two major instruments measuring sport fans' team identification: (a) Wann and Branscombe's (1993) Sport Spectator Identification Scale (SSIS), and (b) Trail and James' (2001) Team Identification Index (TII). SSIS has seven items and those seven items measure "individuals' sense of belongingness perceptions to a sport team, where individuals defines himself or herself in terms of the team" (Matsuoka et al., 2003, p. 247). All seven items in the SSIS are scored using eight-point Likert-type scale ranging from 1 (low identification) to 8 (high identification). Wann and Grieve (2005) discovered the SSIS possessed high internal consistency (i.e., Cronbach's alpha coefficient $=.92)$, and Madrigal $(2000)$ posited the SSIS is a reliable and valid team identification scale.

SSIS contained multiple eight-point scale anchors (e.g., not very important vs. very important, not a fan at all vs. very much a fan, never vs. almost every day, and do not dislike vs. dislike very much). Dillman (2000) argued it is important for researchers to maintain consistency in scale anchors and he implied lack of consistency in the scale anchors development can lead to poor visual representation of the survey instrument. In turn, poor visual representations of the survey instrument discourage the research participants from completing the survey.

This study turns to Trail and James' (2001) TII and it has three items measuring sport fans' team identification level. TII is a more appropriate scale for this study because 
it utilized single seven-point scale anchors (i.e., ranged from strongly disagree to strongly agree) rather than multiple anchors in a single scale (i.e., SSIS) and focuses on the affective nature of team identification. Meanwhile, Wann and Branscombe's (1993) SSIS focuses on behavioral nature of team identification, which may be misleading or unnecessary. Trail and James (2001) indicated TII is a valid and reliable scale (i.e., Cronbach's alpha coefficient $=.85$ ) and several other researchers (e.g., Fink et al., 2002a, Trail et al., 2003) discovered TII possessed strong reliability (i.e., Cronbach's alpha coefficient ranging from .83 to .90 ). This study utilizes Trail and James' (2001) TII to measure the college football season ticket holders' team identification level.

Customer Satisfaction. Sport marketing researchers employed several scales to measure sport consumers' consumption satisfaction perceptions. For example, Trail et al. (2003) utilized a three items scale to measure customer satisfaction (i.e., a subscale of Affective State Index, ASI), and their customer satisfaction scale contained three items using seven-point Likert-type scale. Those items are: (a) I am satisfied, (b) I am satisfied with the outcome, and (c) I am satisfied with the performance of the team. Trail et al. (2003) discovered their customer satisfaction scale has a Cronbach's alpha coefficient of .60 .

Greenwell et al. (2002) and Madrigal (1995) utilized Oliver's (1980) three items scale to measure sport consumers' consumption satisfaction perceptions. This scale measures customer satisfaction using seven-point Likert-type scale spanning from 1 (i.e., strongly disagree) to 7 (i.e., strongly agree) and possessed strong reliability (i.e., Cronbach's alpha coefficient $=.90$ in Greenwell et al., 2002) and validity. Dillman (2000) suggested researchers maintain consistent measurement points throughout the entire 
survey instrument because inconsistent measurement points can lead to poor visibility for the survey respondents. In turn, poor visibility of the survey instrument can lead to poor results. This study's researchers utilized the Oliver's (1980) three items customer satisfaction scale because Oliver's (1980) scale possessed strong construct validity and it has the same measurement points (i.e., 7-point) as all the other subscales in this study.

Consumer Behavioral Intentions. Cronin et al. (2000) suggested the use of actual purchase behavior instead of behavioral intentions could potentially improve marketing research studies' implications, but they acknowledged actual behavior data are difficult to obtain. The purpose of this study is to understand college football season ticket holders' service personal values impact on future behaviors rather than past behaviors. Thus, this study's researchers utilized behavioral intentions to measure college football season ticket holders' purchase behavior. Sport marketing research studies indicated several scales are available to measure sport consumers' behavioral intentions (e.g., Cronin et al., 2000, Madrigal, 2001, Trail et al., 2005) and most of those sport consumers' behavioral intentions scale are based on Zeithaml et al.'s (1996) behavioral intentions scale.

Zeithaml et al.'s (1996) developed a 13 items, seven-point likelihood scale to capture multiple facets of behavioral intentions. They found those 13 items loaded on five dimensions using factor analysis and those dimensions were labeled as: (a) positive wordof-mouth, (b) recommending the product or service provider to others, (c) stay loyal to the product or service provider, (d) increase spending on the product or service providers, and (e) willing to pay premium a price for the product or service providers. Zeithaml et al.'s (1996) discovered the behavioral intentions scale possessed strong construct validity 
(i.e., five dimensions' Cronbach's alpha coefficient ranging from .61 to .94).

Cronin et al. (2000) developed a three items sport consumers' behavioral intentions scale based on Zeithaml et al.'s (1996) findings, and they measured the consumer behavioral intentions variable using nine-point Likert-type scale ranging from 1 (very low) to 9 (very high). Cronin et al.'s (2000) three items scale possessed strong construct validity (i.e., factor loading of .87) and extracted average variance of $68 \%$ using confirmatory factor analysis. This study will follow the procedure taken by Cronin et al. (2000) and adapted Ziethaml et al. (1996) consumers' behavioral intentions scale to meet its' research purpose. Four items from Ziethaml et al.'s (1996) behavioral intentions scale facilitated the measurement of re-purchase behavioral intentions for this study. Those four items are: (a) positive word-of-mouth, (b) recommending the product or service provider to others, (c) stay loyal to the product or service provider, and (d) increase spending on the product or service providers.

Service Personal Values. A review of the service marketing literature revealed Lages and Fernandes' (2005) service personal values (i.e., SERPVAL) scale is the only instrument available to measure consumers' service personal values. They utilized a 12 items scale to measure consumer service personal values and SERPVAL scale has three dimensions: (a) service values to peaceful life (SVPL) measured using four items on a seven-point Likert-type scale, (b) service values to social recognition (SVSR) measured using five items on a seven-point Likert-type scale, and (c) service values to social integration (SVSI) measured using three items on a seven-point Likert-type scale.

Service Personal Values Dimensions. Lages and Fernandez (2005) developed the SVPL scale based on Rokeach's (1973) Values Survey. SVPL variable is scored using a 
four items Likert-type scale ranging from 1 (i.e., strongly disagree) to 7 (i.e., strongly agree) and SVPL possessed strong construct reliability (i.e., coefficient alpha coefficient $=.77$ ) and validity (i.e., factor loading of 1.00 ). This study added two items from Kahle's (1983) List of Values (i.e., sense of accomplishment and self respect) to measure the SVPL. Sense of accomplishment is added to the SVPL because it corresponded with achievement and self-esteem motives in sport consumption (Trail \& James, 2001), and self respect is added to the SVPL scale because it corresponded with sport consumers' motivation to identify themselves with sport teams (Branscombe \& Wann, 1991).

Lages and Fernandez (2005) developed the SVSR scale based on Rokeach's (1973) Values Survey and Kahle's (1983) List of Values. SVSR dimension is scored using a five items seven-point Likert-type scale ranging from 1 (strongly disagree) to 7 (strongly agree). They suggested the scale possessed strong construct reliability (i.e., coefficient alpha coefficient $=.92$ ) and validity (i.e., factor loading of .70 ). Finally, Lages and Fernandez (2005) developed the SVSI scale based on Rokeach (1973) Values Survey (RVS) and Kahle (1983) List of Values (LOV). SVSI variable is scored using a three items seven-point scale ranging from 1 (strongly disagree) to 7 (strongly agree), and Lages and Fernandez (2005) suggested the scale possessed strong construct reliability (i.e., coefficient alpha coefficient $=.79$ ) and validity (i.e., factor loading of .85 ).

Thuy and Hau (2010) utilized Lages and Fernandes' (2005) SERPVAL scale to measure retail banking customers' service personal values, and in turn, they employed service personal values to predict and explain customers' satisfaction perceptions and loyalty towards banking services. Thuy and Hau (2010) conducted factor analysis for SERPVAL scale and eliminated: (a) more harmony and stability from the SVPL 
dimension, (b) a feeling that the world is more agreeable, more status, and more stimulating and adventurous life from the SVSR dimension, and (c) to strengthen my friendship relationships from the SVSI dimension. The remaining seven items from the SERPVAL scale possessed factor loading ranging from 0.69 to 0.79 .

\section{Field Study and Pilot Study}

This study's implemented a field study and a pilot study prior to the actual implementation of the survey because: (a) Lages and Fernandes' (2005) service personal values (SERPVAL) scale is a relatively new scale and it has been utilized only by Thuy and Hau (2010), (b) two items were added to the service value to peaceful life (SVPL) scale, and (c) modified team identification, customer satisfaction, and behavioral intention scales are utilize to fit the college football consumers context (Oliver, 1980, Trail \& James, 2001, Zeithaml et al., 1986). The objective of field study is to establish the survey instrument's content validity.

This study's researchers selected 20 individuals to participate in the field study. Ten students from on-campus university housing were chosen for the field study and ten university employees from the Division of Student Affairs were selected for the field study. All of the field study participants have attended the target population's college football games more than once within the past three years. The field study participants will be provided with the adapted SERPVAL scale and a brief description of all subscales in the study. The field study participants will be asked two main questions (Agosta, Daignault, Smith, \& Fortune, 2008, p. 1): "(a) does the adapted SERPVAL scale measures what it intends to assess?, and (b) do items represent what is being measured in each scale?" This study's researchers will then modify the SERPVAL scale based on the 
feedback provided by the field study participants.

Next, this study implements a pilot study using the modified SERPVAL scale and the objective of a pilot study is to examine the reliability (internal consistency) of items included the adapted SERPVAL scale (Lancaster, Dodd, \& Williamson, 2004, Zikmund, 2003). This study's researchers will analyze the internal consistency of the survey questionnaire items using Cronbach's alpha coefficient and items with Cronbach's alpha coefficient less than 0.60 (i.e., based on lenient criteria set by social scientists because this study is an exploratory research) will be removed from the modified SERPVAL scale (Cronbach, 1951). This study's researchers also examines if any items in the survey questionnaire generate high non-response rate. Thomas (2003) recommended researchers to conduct a pilot study on approximately $20 \%$ of the actual sample population and the required minimum sample size for this study is 287 . Fifty eight attendees of a men's college basketball game at the target population's institution selected to participate in the pilot study.

\section{Research Participants}

The research participants or collectivity (i.e., population) for this study was college football season ticket holders from a large public university located in Southeastern U.S. This institution competes in a conference with a declining average college football attendance. This study decided to focus only on the season ticket holders because they provide a consistent stream of revenue (i.e., through pre-sale of the game tickets) for sport organizations and college football season ticket holders' consumption behaviors are inelastic to the team performance (Young, 2001).

This study's researchers obtained the list of college season ticket holders from the 
Alumni Association and more than 1000 individuals purchased college football season tickets in 2010. Krejcie (1970) developed a table to assist researchers in selecting the appropriate sample size using total population size, margin of error, and confidence levels. He recommended future researchers should use a $95 \%$ confidence level and $5 \%$ margin of error as the minimum sample size selection criteria. This study employed Krejcie's (1970) recommendations (i.e., based on a total population of approximately 1000 respondents) and the sample size required for this study is 287.

This study's researchers perform a regression analysis to determine if survey responses possess external validity (Radhakrishna \& Doamekpor, 2008). External validity refers to the degree to which the study's conclusions would generalizable to other individuals in other places and at other times (Zikmund, 2003). This study's researchers examine differences between respondents and non-respondents, to determine if response bias exists (i.e., there are differences between respondents and non-respondents). Nonrespondents tend to be similar to late respondents (Miller \& Smith, 1983).

\section{Data Collection Procedure}

There are several ways (e.g., mail, fax, or web based surveys) researchers can collect their data (Dillman, 2000). Recently, the web based survey has emerged as the dominant data collection procedure (Couper, 2000) and web based survey has several advantages over mail or fax surveys (Cobanoglu, Warde, \& Moreo, 2001; Kaplowitz, Hadlock, \& Levine, 2004): (a) cost savings linked with the elimination of printing and mailing of survey instruments, (b) time savings associated with data entry process (i.e., internet survey data returned already in electronic format), (c) faster response speed compared to mail, and (d) higher response rate compared to mail and fax surveys. 
Initially, this study's researchers contacted the potential respondents (i.e., through email) to introduce the research purposes of this study, and three days after the initial contact, this study's researchers provided (i.e., through email) a link to the online or webbased survey. Finally, a reminder notification was sent (i.e. through email) to the potential respondents who had not responded, seven days after a survey link was sent to them.

This study incorporates web based survey design to collect data and utilizes Qualtircs web-based survey program to collect data. Qualtrics web-based survey program was founded in 1997 and Qualtrics, Inc.'s client list includes all business schools listed on Business Weeks' Top 30 Business Schools, over a quarter of the Fortune 100 companies, and several leading government and non-profit entities (Qualtrics, Inc., 2010). This study utilizes web based survey to collect the data because it is a cost and time efficient data collection procedure.

\section{Data Analysis}

This study computes descriptive statistics (i.e., means and standard deviations) for all the demographic questions. Next, this study utilizes multivariate analysis of variance (MANOVA) to analyze $R Q 1(a), R Q 1(b), R Q 1(c), R Q 1(d), R Q 1(e)$, and $R Q 1(f)$. This study utilizes multiple regression analysis to analyze $R Q 2$ and $R Q 3$, and hierarchical regression analysis to analyze $R Q 4(a), R Q 4(b), R Q 4(c), R Q 5(a), R Q 5(b)$, and $R Q 5(c)$. This study employs IBM SPSS Statistics 19 statistical software to analyze the data.

Factorial Multivariate Analysis of Variance. Factorial multivariate analysis of variance (MANOVA) is utilized to detect the interaction effects of categorical independent variables (i.e., factors) on multiple interval dependent variables, and to 
discover the data from several groups may have a common mean (Stevens, 2002). The main difference between factorial analysis of variance (ANOVA) and factorial MANOVA is factorial ANOVA can analyze one dependent variable at a time, whereas factorial MANOVA can analyze more than one dependent variables simultaneously (Stevens, 2002). Factorial MANOVA examined the differences in vector means of several interval dependent variables for several categories of categorical interval variables, and to determine if the researcher warranted to go ahead with a MANOVA rather than a series of ANOVA (Stevens, 2002). It is appropriate to proceed with MANOVA if the Bartlett's test of sphericity is significant. Post hoc comparisons (e.g., Scheffe or Tukey's test) help to determine if the independent variable's categorical means (i.e., three or more means) are significantly different from one another (Stevens, 2002).

Factorial MANOVA is a preferred statistical technique to analyze the relationship between multiple categorical independent and interval dependent variables because analyzing group differences using multiple ANOVA involves a loss of power and increased the change of Type I error (Huberty \& Morris, 1989). In addition, factorial MANOVA is a more appropriate statistical technique compared to multiple univariate ANOVA for this study because the dependent variables (i.e., SVPL, SVSR, and SVSI) are conceptually related or they are measuring service personal values. Bartlett's test of sphericity can be used to determine if MANOVA or multiple ANOVA is the appropriate choice of statistical analysis technique for a research study (Stevens, 2002).

Multivariate Analysis of Variance Assumptions. Multivariate Analysis of Variance (MANOVA) has three main assumptions (Stevens, 2002): (a) normal distribution, (b) independence data of collection, and (c) homoscedasticity. According to 
Stevens (2002), researchers can test the normal distribution assumption using skewness and kurtosis statistic for each variable, and meet the independence assumption through random distribution of survey. Researchers can ensure the homoscedasticity assumption is met by examining the Box's M or Levene's statistics (Stevens, 2002).

Multiple Regression Analysis. The advantages of using multiple regression analysis include (Thomas, 2003): (a) researchers can formally assess the uncertainty in their evidence or data appraisal (i.e., using significance testing), (b) researchers can simultaneously analyze the relationship between several variables at the same time, and (c) researchers can filter variables that might be covered by other variables. On the contrary, the limitations of multiple regression analysis include (Thomas, 2003): (a) multiple regression analysis is highly dependent on the variable (i.e., construct or content) validity and reliability, and (b) researchers might include too many variables to find significance relationship in the phenomena of interest.

This study used multiple regression analysis because it involves theories testing and quantitative statistical analysis. This study attempts to explain and predict the college football season ticket holders' service personal values (i.e., service value to peaceful life, SVPL, service value to social recognition, SVSR, and service value to social integration, SVSI) impact on their consumption satisfaction perceptions (i.e., $R Q 2$ ) and behavioral intentions (i.e., $R Q 3$ ). Stevens (2003) suggested researchers can utilize simple regression analysis if the theory does not suggest a clear order of entry, and utilize the hierarchical regression analysis if the theory suggests a clear order of entry. Hierarchical regression analysis enters one predictor variable at a time to see how each predictor variable contributes to explaining the regression model variance (Stevens, 2002). 
Hierarchical Regression Analysis. The final regression coefficients of hierarchical regression analysis and multiple regression analysis are the same if the predictor variables are the same (Stevens, 2002). The hierarchical order in which the predictor variables are entered may affect the amount of variation explained by the independent variables, and the hierarchical order to enter the predictor variables is based on a theory (Stevens, 2002). Researchers' choice of a moderator and the hypothesized nature of the interaction should be based on a theory (Jaccard, Turrisi, \& Wan, 1990).

This study developed the $R Q 4(a), R Q 4(b), R Q 4(c), R Q 5(a), R Q 5(b)$, and $R Q 5(c)$ based on the team identification, service personal values (i.e., service value to peaceful life, SVPL, service value to social recognition, SVSR, and service value to social integration, SVSI), and consumer behavior theories. Team identification theory suggested team identification moderated the relationship between customer service constructs and consumer behavior variables (Madrigal, 2001; Stewart et al., 2003). The purpose of $R Q 4(a), R Q 4(b), R Q 4(c), R Q 5(a), R Q 5(b)$, and $R Q 5(c)$ is to examine the moderating effect of college football season ticket holders' team identification on the relationship between their service personal values, and both consumption satisfaction perceptions and behavioral intentions.

There are three types of moderations or interactions (Cohen, Cohen, West, \& Aiken, 2003, p. 285): "(a) enhancing interactions in which both the predictor and moderator affect the outcome variable in the same direction and together have a stronger than addictive effect, (b) buffering interactions in which the moderator variable weakens the effect of the predictor variable on the outcome, and (c) antagonistic interactions in which the predictor and moderator have the same effect on the outcome but the 
interaction is in the opposite direction".

There are two problems associated with using hierarchical regression analysis to detect the moderator effects (Frazier et al., 2004): (a) low power to detect true interactions, and (b) choosing the right types of variables (i.e., continuous or categorical). Jaccard et al. (1990) recommended the moderator effects are best detected when the relationship between predictor and outcome variables is substantial (i.e., Pearson's correlation of .5 and statistically significant at .05 level), and Aguinis (1995) suggested researchers need to have equal samples sizes across the categorical data to get sufficient power to detect the interactions. Aguinis (1995) reported the reliability of interaction term and outcome variable is critical to the power of test and he recommended several steps in analyzing the data: (a) representing categorical data with code variables, (b) centering or standardizing continuous variables, (c) creating product terms by multiplying the predictor and moderator variables, and (d) structuring the equation.

Frazier et al (2004) suggested researchers utilizing the hierarchical regression analysis to analyze moderator effects need to (i.e., structuring the equation): (a) first includes the code variables or centered/standardized variables representing the predictor and the moderator variables, and (b) enter the product term into the regression equation after the predictor and moderator variables. There are several steps involved in examining the moderator effect (Frazier et al., 2004, p. 121): "(a) interpreting the effects of the predictor and moderator variables, (b) testing the significance of the moderator effect, and (c) plotting or interpreting significant moderator effects". Researchers need to meet several statistical assumptions in order to obtain valid multiple regression results.

Regression Analysis Assumptions. There are five major assumptions for the 
multiple regression analysis. According to Pedhazur (1997) and Stevens (2002), the multiple regression assumptions are: (a) normal distribution of the variables (i.e., no variables with substantial outliers), (b) existence of a linear relationship between the independent and dependent variables, (c) variables measured are error free or possess internal consistency (i.e., the variables measured possess construct reliability), (d) variance of errors are the same across all levels of the independent variables (i.e., Homoscedasticity), and (e) absence of multicollinearity among the target variables.

This study checks the normal distribution of the variables using the residuals analysis and leverage statistics, and checks for the linearity using the residual plot. In addition, this study checks for the variables' construct reliability using Cronbach's alpha coefficient and evaluates homoscedasticity through visual inspection of the standardized residuals by the regression standardized predicted value plot. Finally, this study will examine multicollinearity using the variance inflation factor (VIF) and multicollinearity problem exists if the VIF is more than 10 (Stevens, 2002).

Data Analysis Summary. This study analyzes $R Q 1(a), R Q 1(b), R Q 1(c), R Q 1(d)$, $R Q I(e)$, and $R Q I(f)$ using MANOVA because the independent variables questions are categorical data, and there are more than one dependent variables, college football season ticket holders' service personal values (i.e., service value to peaceful life, SVPL, service value to social recognition, SVSR, and service value to social integration, SVSI). In addition, the dependent variables are also interval data. This study enters service personal values (i.e., SVPL, SVSR, and SVSI) as dependent variables, and demographic question as fixed factor in the initial SPSS multivariate General Linear Model (GLM) dialog.

This study analyzes $R Q 2$ and $R Q 3$ data using multiple regression analysis because 
college football season ticket holders' service personal values (i.e., independent variables), consumption satisfaction perceptions, and behavioral intentions (i.e., dependent variable) are interval data. Independent variables for $R Q 2$ includes college football season ticket holders' service personal values (i.e., SVPL, SVSR, and SVSI) and the dependent variable is college football season ticket holders' consumption satisfaction perceptions (i.e., SAT). This study uses simultaneous data entry method, which enters all variables at the same time (Pedhazur, 1997). Simultaneous data entry method suggests each independent variable is analyzed as if it were entered after all independent variables were entered and analyzed by what it offers to the dependent variable prediction that is different from the predictions offered by other independent variables entered into the model. This study computes a regression model to analyze $R Q 2$ :

$$
\mathrm{SAT}=\mathbf{b}_{1} \mathrm{SVPL}+\mathrm{b}_{2} \mathrm{SVSR}+\mathrm{b}_{3} \mathrm{SVSI}+\mathrm{C} .
$$

The independent variables for $R Q 3$ include college football season ticket holders' service personal values (i.e., SVPL, SVSR, and SVSI) and the dependent variables are college football season ticket holders' behavioral intentions (i.e., BIT). This study employs simultaneous data entry approach which enters all variables at the same time (Pedhazur, 1997). This study computes a regression model to analyze RQ3:

$$
\text { BIT }=b_{1} \text { SVPL }+b_{2} \text { SVSR }+b_{3} \text { SVSI }+C .
$$

This study employs hierarchical regression analysis to examine $R Q 4$ and $R Q 5$. This study uses hierarchical regression analysis to test the moderating effect of college football season ticket holders' team identification level on the relationship between their service personal values, and both consumption satisfaction perceptions and behavioral intentions. Hierarchical regression analysis was recommended by several researchers 
(e.g., Frazier et al., 2004, Jaccard et al., 1990) for moderator testing analysis.

The independent variables for $R Q 4(a), R Q 4(b)$, and $R Q 4(c)$ are college football season ticket holders' service personal values (i.e., SVPL, SVSR, and SVSI), the moderating variable is team identification level (i.e., TID), and the dependent variable is consumption satisfaction perceptions (i.e., SAT). This study utilizes hierarchical data entry method which enters independent variables according to specified hierarchy dictated in advance based on purpose and logic of the study or a theory (Pedhazur, 1997). Marketing research studies suggested service personal values are temporally or logically present prior to team identification level (Allport et al., 1960; Kahle, 1983; Maslow, 1959). First, this study enters college football season ticket holders' service personal values, followed by their team identification level. Lastly, this study enters the interaction term (i.e., service personal values multiplied by team identification level). Next, this study examines the independent and moderating variables effects, and analyzes the interaction effect for statistical significance. This study computes three regressions to analyze $R Q 4(a), R Q 4(b)$, and $R Q 4(c)$ :

$$
\begin{aligned}
& R Q 4(a) \mathrm{SAT}=\mathrm{b}_{1} \mathrm{SVPL}+\mathrm{b}_{2} \mathrm{TID}+\mathrm{b}_{3} \mathrm{SVPL} * \mathrm{TID}+\mathrm{C}, \\
& R Q 4(b) \mathrm{SAT}=\mathrm{b}_{1} \mathrm{SVSR}+\mathrm{b}_{2} \mathrm{TID}+\mathrm{b}_{3} \mathrm{SVSR} * \mathrm{TID}+\mathrm{C}, \text { and } \\
& R Q 4(c) \mathrm{SAT}=\mathrm{b}_{1} \mathrm{SVSI}+\mathrm{b}_{2} \mathrm{TID}+\mathrm{b}_{3} \mathrm{SVSI}^{*} \mathrm{TID}+\mathrm{C} .
\end{aligned}
$$

The independent variables for $R Q 5$ are college football season ticket holders' service personal values (i.e., SVPL, SVSR, and SVSI), the moderator is team identification level (i.e., TID), and the dependent variable is behavioral intentions (i.e., BIT). This study enters the data for $R Q 5$ using the hierarchical data entry method. Marketing research studies suggested service personal values are temporally or logically 
present prior to team identification level (Allport et al., 1960; Kahle, 1983; Maslow, 1959). This study enters college football season ticket holders' service personal values first, and then team identification level. Next, this study enters the interaction term (i.e., service personal values multiply by team identification level). This study analyzes the team identification level's moderating effect by (Frazier et al., 2004): (a) interpreting predictor and moderator variables' effects, (b) testing moderator or interaction effect significance, and (c) plotting or interpreting significant moderator effects. This study computes three regressions to analyze $R Q 5(a), R Q 5(b)$, and $R Q 5(c)$ :

$$
\begin{aligned}
& R Q 5(a) \mathrm{BIT}=\mathrm{b}_{1} \mathrm{SVPL}+\mathrm{b}_{2} \mathrm{TID}+\mathrm{b}_{3} \mathrm{SVPL} * \mathrm{TID}+\mathrm{C}, \\
& R Q 5(b) \mathrm{BIT}=\mathrm{b}_{1} \mathrm{SVSR}+\mathrm{b}_{2} \mathrm{TID}+\mathrm{b}_{3} \mathrm{SVSR} * \mathrm{TID}+\mathrm{C}, \text { and } \\
& R Q 5(c) \mathrm{BIT}=\mathrm{b}_{1} \mathrm{SVSI}+\mathrm{b}_{2} \mathrm{TID}+\mathrm{b}_{3} \mathrm{SVSI} * \mathrm{TID}+\mathrm{C} .
\end{aligned}
$$

The data analyses for $R Q 4$ and $R Q 5$ involve multiple statistical comparisons (i.e., three regression analyses for each research question) and multiple data analyses can create a problem where a certain, but unknown, probability exists that one or more significant differences will be found by chance alone (Brown, 2008). The problem is also referred as Type I error, where one rejects the null hypothesis when it is true (Stevens, 2002). The Bonferroni adjustment can be used to reduce probability of Type I error (Keppel \& Wickens, 2004, Stevens, 2003). Bonferroni adjustment or procedure reduces the Type I error rate by adjusting the $p$-value downwards for declaring statistical significance (Keppel \& Wickens, 2004). For example, this study conducts three regression analyses for $R Q 4$ or $R Q 5$, and the $p$-value for $R Q 4$ and $R Q 5$ will be reduce to .05 divided by 3 or approximately .0167 . 


\section{Methodology Summary}

This study selected the survey design because (Thomas, 2003): (a) it is able to demonstrate a cross-sectional view of several target variables within the target population, (b) it collects quantitative data that can be used in statistical analysis, and (c) it can be easily altered. There are five target variables in this study (i.e., demographics, consumer behavioral intentions, customer satisfaction, service personal values, and team identification) and there are three dimensions in the service personal values construct (i.e., service value to peaceful life, SVPL, service value to social recognition, SVSR, and service value to social integration, SVSI). The target population for this study is college football season ticket holders at a large Southeastern U.S. This study utilized the required sample size table developed by Krejcie (1970) to determine the appropriate sample size for meaningful statistical analysis, and this study's researchers determined sample size required is 287 .

This study used the Qualtrics web based survey program because it is time and cost efficient. This study used MANOVA to analyze the relationship between demographic profiles and service personal values (i.e., $R Q I(a), R Q I(b), R Q I(c), R Q I(d)$, $R Q I(e)$, and $R Q I(f))$ because demographic profiles (i.e., independent variables) are measured using categorical data and service personal values (i.e., dependent variables) are measure using interval data. This study utilized multiple regression analysis for $R Q 2$ and $R Q 3$ because multiple regression analysis allows researchers (Thomas, 2003): (a) to conduct the significance testing of research questions or hypotheses posited, (b) to analyze the relationship between multiple variables, (c) to avoid multicollinearity issue among the variables. Hierarchical regression analysis was recommended by Frazier et al. 
(2004) to analyze the moderator effects, and this study utilizes hierarchical regression analysis to analyze research questions (i.e., $R Q 4$ and $R Q 5$ ) involving moderator effects. This study's data analyses needed to meet several statistical assumptions in order obtain justifiable multiple and hierarchical regression results. These regression analysis assumptions include (Pedhazur, 1997, Stevens, 2002): (a) normality, (b) linearity, (c) target variables' construct validity, (d) homoskedasticity, and (e) target variables are free from multicollinearity issue. This study employs several statistical techniques (e.g., the residual and leverage statistics, residual plot, Cronbach's alpha coefficient, standardized residual plot, and variance inflator factor) to check for the multiple regression assumptions. 


\section{CHAPTER IV}

\section{RESULTS}

The previous chapter explained how this study were conducted and described three research purposes for this study: (a) to understand the relationship between college football season ticket holders' demographic profiles and service personal values dimensions (i.e., service value to peaceful life, SVPL, service value to social recognition, SVSR, and service value to social integration, SVSI), (b) to understand the relationship between college football season ticket holders' service personal values dimensions (i.e., SVPL, SVSR, and SVSI), and both consumption satisfaction perceptions and behavioral intentions, and (c) to understand the moderating effect of college football season ticket holders' team identification level on the relationship between service personal values dimensions (i.e., SVPL, SVSR, and SVSI), and both consumption satisfaction perceptions and behavioral intentions. This chapter summarizes the findings from statistical procedures described in the previous chapter, discusses respondents' profiles, response rate, field test and pilot study results, scale reliability, key results, and data analysis summary.

\section{Field Test and Pilot Study Results}

A field test was conducted prior to the implementation of actual online survey for this study with the purpose of assessing survey questions' or items' validity (i.e., clear up any poorly worded survey questions). The field test was administered to ten students 
from on-campus university housing and ten university employees from the Division of Student Affairs at a large Southeastern public university. The field test participants were asked to complete an evaluation form (see Appendix C). The field test findings suggested three items needed to be deleted from service value to peaceful life (SVPL) dimension, and those three items were: (a) more harmony in life, (b) more self-respect in life, and (c) more family security. The field test findings also suggested two items needed to be removed from service value to social recognition (SVSR) dimension, and those two items were: (a) the feeling that the world is more pleasant, and (b) a higher social status. The original survey instrument (see Appendix B) was modified based on the findings from field test, and the modified survey instrument is included in this study as Appendix D. A pilot test was conducted after the field test in order to assess survey questions' or items' reliability (i.e., delete survey questions or items possessing poor replicability). The modified survey instrument (see Appendix D) is distributed to 80 attendees before a men's college basketball game at a large Southeastern public university, and 75 surveys were deemed usable. The reliability of the survey questions or items was assessed for construct reliability using the Cronbach's alpha coefficient. This study's researchers analyzed the internal consistency of the survey questions or items using Cronbach's alpha coefficient, and items with Cronbach's alpha coefficient less than 0.60 (i.e., based on lenient criteria set by social scientists because this study is an exploratory research) were removed from the modified survey questionnaire (Cronbach, 1951). This study's pilot study findings (see Table 3) suggested all of the items in the modified survey instrument possessed strong internal consistency reliability (i.e., with Cronbach's alpha coefficient ranging from 0.812 to 0.854 ), and all of the items in the modified survey instrument were 
included in the final online survey, distributed to this study's college football season ticket holders (i.e., research participants). No participants from the field test and pilot study were included in the final sample, to avoid final result contamination (Van Teijlingen \& Hundley, 2001) . 
Table 3

Pilot Test Results

Source

Cronbach's alpha

Service Value to Peaceful Life (SVPL)

More balance in life

More enjoyable life

More sense of accomplishment in life

Service Value to Social Recognition (SVSR)

.854

More respect from others

More social recognition

A more stimulating and adventurous life

Service Value to Social Integration (SVSI)

A higher acceptance in my social group

Better relationship with friends, co-workers, and family members

Better friendship with others

Team Identification (TID)

I think of myself as a "real" fan of the college football team

I would experience a loss if I had to stop being a fan of the college football team

Being a fan of the college football team is very important to me

Consumption Satisfaction (SAT)

I am satisfied with my decision to purchase college football season tickets

I think that I did the right thing by purchasing college football season tickets

I am not happy that I purchased college football season tickets

Behavioral Intentions (BIT)

I plan to renew my college football season tickets next year

I will recommend my family members and friends to purchase college football season tickets

I would like to share my college football game spectating experience with others

I plan to purchase more college football season tickets next year

$N=75$ 


\section{Respondents}

This study surveyed sport consumers purchasing 2010/2011 college football season tickets at a large Southeastern university, and a total of 1027 college football season tickets holders (i.e., entire study population) were invited to participate in this study. Initially, this study's researchers contacted the potential respondents (i.e., through email) to introduce the research purposes of this study, and three days after the initial contact, this study's researchers provided (i.e., through email) a link to the online or webbased survey. Finally, a reminder notification was sent (i.e. through email) to the potential respondents who had not responded, seven days after a survey link was sent to them. Data were collected after the 2010/2011 college football season, because collecting data before and during the college football season would not provide accurate data related to college football season ticket holders' overall consumption satisfaction perceptions and behavioral intentions.

Response Rate. The response rate for this study was $35.54 \%$, with 365 out of the 1027 potential respondents completing the online survey. Out of 365 college football season ticket holders responding to the online survey, a total of 348 were deemed usable surveys for the data analysis. A total of 17 survey responses were excluded from the final data analysis because they were incomplete. The total responses $(N=348)$ or final sample size exceeded the sample requirement suggested by Krejcie (1970), discussed in the previous chapter (i.e., minimum responses required for a research study with a total population of approximately 1000 respondents is 287 responses).

A regression analysis was performed to determine if this study's survey responses possessed external validity. This study's researchers examined if there were differences 
between this study's respondents and non-respondents, to determine if any response bias existed. Late respondents, individuals who responded after the reminder notification was sent, were considered to be similar to non-respondents. A total of 282 respondents were classified as early respondents and a total of 66 responders were classified as late respondents.

Regression analysis was performed to determine if differences existed between respondents (early respondents) and non-respondents (i.e., late respondents) on all six target variables (i.e., service values to peaceful life, SVPL; service values to social recognition, SVSR; service values to social integration, SVSI; team identification, TID; customer satisfaction perceptions, SAT; and behavioral intentions, BIT). The regression analysis results demonstrated no significant differences in any of the target variables: (a) SVPL $(p=.679),(\mathrm{b}) \operatorname{SVSR}(p=.514),(\mathrm{c}) \operatorname{SVSI}(p=.548),(\mathrm{d}) \mathrm{TID}(p=.947),(\mathrm{e}) \mathrm{SAT}$ $(p=.328)$, and (f) BIT $(p=.093)$. These results indicated no significant differences between early and late respondents, and indicating there was no response bias among the respondents. This study's researchers concluded the final sample size for this study was deemed to possess sufficient statistical power and external validity, and the data analysis findings could be generalized to the entire population.

Respondents' Demographic Profiles. This study yielded the following demographic information: (a) $60.3 \%$ of the college football season ticket holders have three or fewer household members living in their household and $39.7 \%$ have four or more household members living in their household, (b) $58.0 \%$ of the college football season tickets holders are male and $42.0 \%$ are female, (c) $61.2 \%$ of the college football season tickets holders are students, alumnae, and university booster club members, and 
$38.8 \%$ are employee of the university and others, (d) $47.1 \%$ of the college football season ticket holders have been college football season ticket holders for three years or less, $46.3 \%$ hold season tickets for $4-6$ years, and $6.6 \%$ hold season tickets for 7 years or more, (e) $57.2 \%$ of the college football season ticket holders are Hispanic/Latino/Spanish Origin, $31.3 \%$ are White, $7.2 \%$ are Black/African American, $1.1 \%$ are Asian or Pacific Islander, and $3.2 \%$ are others, and (f) $27.6 \%$ of the college football season ticket holders earned $\$ 39,999$ or less annually, $63.5 \%$ earned $\$ 40,000$ to $\$ 79,999$ annually, and $8.9 \%$ earned more than $\$ 80,000$ annually. 
Table 4

Demographic Profiles of Respondents

\begin{tabular}{|c|c|c|c|}
\hline Characteristics & Category & Frequency & $\%$ \\
\hline \multirow[t]{3}{*}{ Household Members } & 3 or less & 210 & 60.3 \\
\hline & 4 or more & 138 & 39.7 \\
\hline & Total & 348 & 100.0 \\
\hline \multirow[t]{3}{*}{ Gender } & Male & 202 & 58.0 \\
\hline & Female & 146 & 42.0 \\
\hline & Total & 348 & 100.0 \\
\hline \multirow[t]{3}{*}{ University Affiliation } & $\begin{array}{l}\text { Student, Alumni, and } \\
\text { Booster Club Members }\end{array}$ & 213 & 61.2 \\
\hline & $\begin{array}{l}\text { University Employees } \\
\text { and Others }\end{array}$ & 135 & 38.8 \\
\hline & Total & 348 & 100.0 \\
\hline \multirow{4}{*}{$\begin{array}{l}\text { Number of Years as } \\
\text { Season Ticket Holders }\end{array}$} & 3 years or less & 164 & 47.1 \\
\hline & $4-6$ & 161 & 46.3 \\
\hline & 7 or more & 23 & 6.6 \\
\hline & Total & 348 & 100.0 \\
\hline \multirow[t]{6}{*}{ Ethnicity } & $\begin{array}{l}\text { Hispanic/Latino/Spanish } \\
\text { Origin }\end{array}$ & 199 & 57.2 \\
\hline & White & 109 & 31.3 \\
\hline & Black/African American & 25 & 7.2 \\
\hline & Asian or Pacific Islander & 4 & 1.1 \\
\hline & Others & 11 & 3.2 \\
\hline & Total & 348 & 100.0 \\
\hline
\end{tabular}


Demographic Profiles of Respondents (continued)

\begin{tabular}{llll} 
Characteristics & Category & Frequency & $\%$ \\
\hline Annual Household Income & $\$ 39,999$ or less & 96 & 27.6 \\
& $\$ 40,000-\$ 79,999$ & 221 & 63.5 \\
& $\$ 80,000$ or more & 31 & 8.9 \\
& Total & 348 & 100.0 \\
\hline
\end{tabular}




\section{Scale Reliability}

This study's researchers tested items in service personal values (SERPVAL), team identification, consumer satisfaction perceptions, and behavioral intentions scales for internal consistency reliability using Cronbach's alpha coefficient. Cronbach (1951) recommended a survey question or item has to possess a minimum Cronbach's alpha coefficient value of .60 (i.e., "adequate" scale) to be included in the final data analysis. The SERPVAL scale has three dimensions: (a) service value to peaceful life (SVPL) subscale consisted of three items $(\alpha=.809)$, service value to social recognition (SVSR) subscale consisted of three items $(\alpha=.862)$, and service value to social integration (SVSI) subscale consisted of three items $(\alpha=.814)$

The Cronbach's alpha coefficient for the three-item team identification scale, three-item consumer consumption satisfaction scale, and four-item behavioral intentions scale were $.745, .691$, and .829 respectively. All scales in this study possessed strong internal consistency reliability, and were deemed reliable for further data analysis (See Table 5). Composite index scores were computed for all the scales for subsequent inferential statistical analysis (i.e., MANOVA, multiple regression analysis, and hierarchical regression analysis). 
Table 5

Scale Reliability Results

Source

Cronbach's alpha

Service Value to Peaceful Life (SVPL) .809

Service Value to Social Recognition (SVSR) .862

Service Value to Social Integration (SVSI) .814

Team Identification (TID) .745

Consumption Satisfaction (SAT) .691

Behavioral Intentions (BIT) .829

$N=348$ 


\section{Results for Research Question (1)}

To accomplish the research purpose of understanding the relationship between demographic profiles and service personal values dimensions (service value to peaceful life, SVPL; service value to social recognition, SVSR; and service value to social integration, SVSI), a factorial multivariate analysis of variance (MANOVA) was performed with each of the demographic variables as an independent variable and service personal values (SVPL, SVSR, and SVSI) as dependent variables. Prior to the factorial MANOVA, this study's researchers conducted Bartlett's test of sphericity to determine if factorial MANOVA is warranted. The Bartlett's test of sphericity is significant $(p<.001)$ and this study's researchers concluded it is appropriate to proceed with MANOVA. Three assumptions of MANOVA (i.e., normal distribution, independence of data collection, and homoscedasticity) were tested to ensure sample population represents the research population and to ensure this study's results possess external validity.

The MANOVA assumption of normal distribution was met for this study because skewness and kurtosis statistics' values are close to zero. The MANOVA assumption of independence of data collection was not met for this study, because the samples were not randomly selected from the entire population. This study's researchers collected the data using census data collection procedure (i.e., inviting the entire population to participate in the research study), rather than sampling data collection procedure. This study's researchers performed a regression analysis to determine if differences existed between respondents and non-respondents (i.e., late respondents) to overcome the violation of independence of data collection assumption. The regression results demonstrated this

study's data possessed external validity (see regression results on p. 112), and this study's 
researchers concluded the MANOVA results obtained are justifiable.

The homoscedasticity assumption was not met because Levene's Tests are significant $(p<.05)$ for most of the main effects (see Table 6 for results).

Homoscedasticity or homogeneity of variance means that the variance of errors is the same across all levels of the independent variables (Pedhazur, 1997). A serious lack of homoscedasticity (i.e., heteroscedasticity) can increase Type I error and distort significance test result (Erceg-Hurn \& Mirosevich, 2008). Keppel and Wickens (2004) recommended researchers can overcome homoscedasticity problem by reducing significance testing $\alpha$ to .01 and increase the required sample size by $20 \%$. This study's researchers reduce the $\alpha$ from .05 to .01 , and the actual sample size of this study is 348 or $21.25 \%$ more than required sample size suggested by Krejcie (1970). 
Table 6

Levene's Test Results for $R Q(1)$

RQ IV

1(a) Number of household members

1(a) Number of household members

1(a) Number of household members

1(b) Gender

1(b) Gender

1(b) Gender

1(c) University Affiliation

1(c) University Affiliation

1(c) University Affiliation

1(d) Years as Season Ticket Holder

1(d) Years as Season Ticket Holder

1(d) Years as Season Ticket Holder

1(e) Ethnicity

1(e) Ethnicity

1(e) Ethnicity

1(f) Annual Household Income

1(f) Annual Household Income

1(f) Annual Household Income

$N=348$
DV

SVPL

SVSR

SVSI

SVPL

SVSR

SVSI

SVPL

SVSR

SVSI

SVPL

SVSR

SVSI

SVPL

SVSR

SVSI

SVPL

SVSR

SVSI
Levene's Test

$F(1,346)=.010 \quad>.05$

$F(1,346)=.518 \quad>.05$

$F(1,346)=.004 \quad>.05$

$F(1,346)=6.674 \quad<.01$

$F(1,346)=44.603<.01$

$F(1,346)=29.475<.01$

$F(1,346)=4.224 \quad>.01$

$F(1,346)=27.757<.01$

$F(1,346)=36.364<.01$

$F(2,345)=2.381 \quad>.05$

$F(2,345)=26.302<.01$

$F(2,345)=22.530<.01$

$F(4,343)=2.813 \quad>.01$

$F(4,343)=11.645<.01$

$F(4,343)=20.459<.01$

$F(2,345)=1.218 \quad>.05$

$F(2,345)=2.086 \quad>.05$

$F(2,345)=.558>.05$ 
College football season ticket holders' number of household members were categorized into two groups based on U.S. Census Report 2005 - 2009, average U.S. household members is 2.60 (U.S. Census Bureau, 2011): (a) three or fewer household members, and (b) four or more household members. MANOVA result for college football season ticket holders' number of household members was statistically significant, Wilks' Lambda $=.964, F(3,344)=40.534, p<.01$. Analysis of variance (ANOVA) was performed to test if there is a significant difference in service personal values dimensions' means with respect to college football season ticket holders' number of household members.

A main effect of college football season ticket holders' number of household members was found for SVPL, $F(1,346)=120.989, p<.01$. College football season ticket holders with three or fewer household members $(M=4.08, S D=.89)$ reported significantly higher SVPL scores than did college football season ticket holders with four or more household members $(M=3.07, S D=.77)$.

The main effect of number of household members was not significant for SVSR, $F(1,346)=.948, p>.05$, or SVSI, $F(1,346)=.693, p>.05$. Partial eta squared is a measure of effect size for use in ANOVA, and a partial eta squared score of: (a) .010 to .059 is considered small, (b) .060 to .139 is considered medium, and (c) .140 or higher is considered large. Partial eta squared statistics was .259 for SVPL, indicating college football season ticket holders' number of household members had large effect size on SVPL.

The MANOVA result for college football season ticket holders' gender was statistically significant, Wilks' lambda $=.632, F(3,344)=66.884, p<.01$. Analysis of 
variance (ANOVA) was performed to test if there was a significant difference in service personal values dimensions' means (i.e., SVPL, SVSR, and SVSI) with respect to college football season ticket holders' gender.

A main effect of college football season ticket holders' gender was found for SVSR, $F(1,346)=133.732, p<.01$. Male college football season ticket holders members $(M=6.46, S D=.67)$ reported significantly higher SVSR scores than did female college football season ticket holders $(M=5.32, S D=1.16)$. A main effect of college football season ticket holders' gender was also found for SVSI, $F(1,346)=24.442, p<.01$. Female college football season ticket holders members $(M=6.48, S D=.67)$ reported significantly higher SVSI scores than did male college football season ticket holders $(M=$ $6.00, S D=1.01)$

The main effect of gender was not significant for SVPL, $F(1,346)=1.247, p$ $>$.05. Partial eta squared statistics was .279 for SVSR, indicating college football season ticket holders' gender had large effect size on SVSR, and partial eta squared statistics was .066 for SVSI, indicating college football season ticket holders' gender had medium effect size on SVSI.

College football season ticket holders' university affiliation were categorized into two groups based on their monetary contribution to the university: (a) college season ticket holders who contributed financially to the university (i.e., students, alumnae, and university booster club members), and (b) college football season ticket holders' who received financial benefits from the university (i.e., university employees and others). The MANOVA result for college football season ticket holders' university affiliation was statistically significant, Wilks' lambda $=.669, F(3,344)=56.837, p<.01$. Analysis of 
variance (ANOVA) was performed to test if there is a significant difference in service personal values dimensions' means (i.e., SVPL, SVSR, and SVSI) with respect to college football season ticket holders' university affiliation.

A main effect of college football season ticket holders' university affiliation was found for SVSR, $F(1,346)=112.527, p<.01$. College football season tickets who contributed financially to the university $(M=6.40, S D=.75)$ reported significantly higher SVSR scores than college football season ticket holders who received financial benefits from the university $(M=5.32, S D=1.16)$. A main effect of college football season ticket holders' university affiliation was also found for SVSI, $F(1,346)=23.671$, $p<.01$. College football season ticket holders who received financial benefits from the university $(M=6.49, S D=.61)$ reported significantly higher SVSI scores than College football season tickets who contributed financially to the university $(M=6.02, S D=$ $1.03)$.

The main effect of university affiliation was not significant for SVPL, $F(1,346)=$ $1.318, p>.05$. Partial eta squared statistics was .245 for SVSR, indicating college football season ticket holders' university affiliation had large effect size on SVSR, and partial eta squared statistics was .064 for SVSI, indicating college football season ticket holders' university affiliation had medium effect size on SVSI.

The data for this study were collected from a university with a relatively new college football program, and the college football program existed for nine years. College football season ticket holders' number of years holding season tickets were categorized into three groups based on the stages of the college football programs existence (i.e., early stage, mid stage, and late stage): (a) early stage college season ticket holders (i.e., 
individuals who had been college football season ticket holders for three years of less), (b) mid stage college football season ticket holders (i.e., individuals who had been college football season ticket holders for four to six years), and (c) late stage college football season ticket holders (i.e., individuals who had been college football season ticket holders for seven years or more). The MANOVA result for college football season ticket holders' number of years holding season tickets was statistically significant, Wilks' lambda $=586, F(3,344)=34.989, p<.01$. Analysis of variance $($ ANOVA $)$ was performed to test if there is a significant difference in service personal values dimensions' means (i.e., SVPL, SVSR, and SVSI) with respect to college football season ticket holders' number of years holding season tickets.

A main effect of college football season ticket holders' number of years holding season tickets was found for SVSR, $F(2,345)=57.340, p<.01$. Post-hoc Tukey's Honestly Significant Difference (HSD) test demonstrated early stage college football season ticket holders $(M=6.48, S D=.61)$ and late stage college football season ticket holders $(M=6.45, S D=.99)$ reported significantly higher SVSR scores than mid stage college football season ticket holders $(M=5.41, S D=1.16)$. A main effect of college football season ticket holders' number of years holding season tickets was also found for SVSI, $F(2,345)=27.347, p<.01$. Late stage college football season ticket holders $(M=$ $6.61, S D=.91)$ and mid stage college football season ticket holders $(M=6.51, S D=.62)$ reported significantly higher SVSI scores than early stage college football season ticket holders $(M=5.85, S D=1.03)$.

The main effect of college football season ticket holders' number of years holding season tickets was not significant for SVPL, $F(2,345)=1.554, p>.05$. Partial eta squared 
statistics was .249 for SVSR, indicating college football season ticket holders' university affiliation had large effect size on SVSR, and partial eta squared statistics was .137 for SVSI, indicating college football season ticket holders' university affiliation had medium effect size on SVSI.

The MANOVA result for college football season ticket holders' ethnicity was statistically significant, Wilks' lambda $=.676, F(12,902)=12.019, p<.01$. Analysis of variance (ANOVA) was performed to test if there is a significant difference in service personal values dimensions' means (i.e., SVPL, SVSR, and SVSI) with respect to college football season ticket holders' ethnicity.

A main effect of college football season ticket holders' ethnicity was found for SVPL, $F(4,343)=4.260, p<.01$. Post-hoc Tukey's Honestly Significant Difference (HSD) test demonstrated college football season ticket holders who identified themselves as bi-racial or others $(M=4.73, S D=1.36)$ reported significantly higher SVPL scores than Asian or Pacific Islander $(M=3.33, S D=.54)$, Hispanic/Latino/Spanish origin $(M=$ 3.58, $S D=.84)$, Black/African American $(M=3.75, S D=1.11)$, and White $(M=3.77$, $S D=1.11$ ). A main effect of college football season ticket holders' ethnicity was also found for SVSR, $F(4,343)=8.774, p<.01$. Post-hoc Tukey's HSD showed college football season ticket holders who identified themselves as White $(M=6.43, S D=.60)$ reported significantly higher SVSR scores than did Hispanic/Latino/Spanish origin ( $M=$ $5.72, S D=1.19)$ and Black/African American $(M=5.93, S D=1.21)$.

A main effect of college football season ticket holders' ethnicity was found for SVSI, $F(4,343)=19.436, p<.01$. Post-hoc Tukey's HSD showed college football season ticket holders who identified themselves as Hispanic/Latino/Spanish origin $(M=6.53, S D$ 
$=.50)$ reported significantly higher SVSI scores than did White $(M=5.69, S D=1.03)$, and Black/African American $(M=5.87, S D=1.49)$. Partial eta squared statistics was .047 for SVPL, indicating college football season ticket holders' ethnicity had small effect size on SVPL, partial eta squared statistics was .093 for SVSR, indicating college football season ticket holders' university affiliation had medium effect size on SVSR, and partial eta squared statistics was .185 for SVSI, indicating college football season ticket holders' university affiliation had large effect size on SVSI.

The MANOVA result for college football season ticket holders' ethnicity was statistically insignificant, Wilks' lambda $=.974, F(6,686)=1.522, p>.05$, and no analysis of variance (ANOVA) was performed to test if there is a significant difference in service personal values dimensions' means (i.e., SVPL, SVSR, and SVSI) with respect to college football season ticket holders' ethnicity.

Target Variables' Descriptive Statistics and Zero-Order Correlations. This study's researchers computed the means, standard deviations, and zero-order correlations or intercorrelations of all target variables (service value to peaceful life, SVPL, service value to social recognition, SVSR, service value to social integration, SVSI, team identification level, TID, consumption satisfaction perceptions, SAT, and behavioral intentions, BIT), and the findings are presented in Table 7. This study's researchers computed the means, standard deviations, and zero-order correlations of all target variables to understand the degree of linear relationship between the target variables and examine if there is any sign of multicollinearity between the target variables. If there is a lack of relationship between target variables, this study's researchers may not obtain significant inferential statistical results, and if there is a sign of excessive correlations 
(i.e., multicollinearity) among target variables, subsequent inferential data analyses may not possess practical implications. Overall, descriptive statistics and zero-order correlations provide researchers with an overview of possible outcome for this study.

According to Cohen (1988), a correlation coefficient of .10 to .30 is considered small (i.e., weak) effect, .30 to .50 is considered moderate effect, .50 and above is considered large (i.e., strong) effect, and anything less than .10 is considered insubstantial, trivial, or otherwise not worth worrying about. The findings indicated college football season ticket holders':

(a) SVPL and SVSI were weakly correlated, $r(346)=. .13, p<.05$,

(b) SVSR and TID were weakly correlated, $r(346)=.12, p<.05$,

(c) SVSR and SAT were weakly correlated, $r(346)=.24, p<.01$,

(d) SVSR and BIT were weakly correlated, $r(346)=.27, p<.01$,

(e) SVSI and BIT were weakly correlated, $r(346)=.15, p<.01$,

(f) TID and SAT were strongly correlated, $r(346)=.65, p<.01$,

(g) TID and BIT were moderately correlated, $r(346)=.50, p<.01$,

(h) SAT and BIT were strongly correlated, $r(346)=.63, p<.01$. 
Table 7

Means, Standard Deviations, and Intercorrelations of All Variables

\begin{tabular}{|c|c|c|c|c|c|c|c|c|}
\hline Source & Mean & $\begin{array}{l}\text { Standard } \\
\text { Deviation }\end{array}$ & SVPL & SVSR & SVSI & TID & SAT & BIT \\
\hline SVPL & 3.683 & .978 & --.- & .001 & $-.130^{*}$ & .040 & -.011 & -.050 \\
\hline SVSR & 5.981 & 1.070 & .001 & ---- & .077 & $.124^{*}$ & $.235^{* *}$ & $.265^{* *}$ \\
\hline SVSI & 6.203 & .916 & $-.130^{*}$ & .077 & ---- & .045 & .086 & $.146^{* *}$ \\
\hline TID & 6.101 & .859 & .040 & $.124^{*}$ & .045 & ---- & $.648^{* *}$ & $.498 * *$ \\
\hline SAT & 6.116 & .801 & -.011 & $.235^{* *}$ & .086 & $.648 * *$ & ---- & $.631 * *$ \\
\hline BIT & 6.447 & .728 & -.050 & $.265^{* *}$ & $.146^{* *}$ & $.498 * *$ & $.631^{* *}$ & $-\cdots$ \\
\hline
\end{tabular}

Note: $N=348, *$ Correlation is significant at the .05 level, and ${ }^{* *}$ Correlation is significant at .01 level. 


\section{Results for Research Question 2}

There are five major statistical assumptions for the multiple regression analysis and those assumptions are described in Chapter III. The leverage statistics showed there are no extreme outliers (i.e., there is no hat values greater than 3 times the average, Stevens, 2002), and residual plot showed existence of a liner relationship between the independent and dependent variables. All the target variables measured in this study possessed adequate internal consistency (see Table 5). The standardized residuals by the regression standardized predicted value plot was examined and there is no sign of homoscedasticity. The variance inflation factor is less than 10 and multicollinearity problem does not exist in this study. In conclusion, the data in this study met all multiple regression analysis' statistical assumptions and this study's researchers proceed with the data analysis for $R Q(2), R Q(3), R Q(4)$, and $R Q(5)$.

Multiple regression analysis was used to test if service personal values dimensions (i.e., service value to peaceful life, SVPL, service value to social recognition, SVSR, and service value to social integration, SVSI) significantly explained and predicted college football season ticket holders' consumption satisfaction perceptions (SAT). The independent variables for $R Q 2$ are SVPL, SVSR, and SVSI, and the dependent variable for $R Q 2$ is SAT. This study's researchers selected the simultaneous data entry approach for $R Q 2$, which means all independent variables are entered into the equation at the same time. Simultaneous data entry method is an appropriate approach when dealing with a small set of predictors and when the researcher does not know which independent variables will create the best prediction equation (Pedhazur, 1997). Each independent variable is examined as if it was entered after all the independent variables 
were entered, and examined by what it offers to the prediction of dependent variable (i.e., different from predictions provided by other independent variables entered into the equation).

The results of multiple regression analysis indicated the college football season ticket holders' service personal values dimensions explained a significant proportion of variance in consumption satisfaction perceptions, $R^{2}=.060, F(3,344)=7.275, p<.01$. This study's results indicated SVSR significantly predicted college football season ticket holders' consumption satisfaction perceptions, $\beta=.172, F(344)=4.372, \mathrm{p}<.01$. SVPL did not significantly predict college football season ticket holders' consumption satisfaction, $\beta=-.002, F(344)=-.038, p>.05$, and SVSI did not significantly predict college football season ticket holders' consumption satisfaction, $\beta=.060, F(344)=1.286$, $p>.05$. College football season ticket holders' SVSR standard coefficient beta .23 . Table 8 presents a summary of $R Q(2)$ findings. 
Table 8

Correlations of Consumption Satisfaction with Service Personal Values Dimensions

\begin{tabular}{llll} 
& $\beta$ & SE $\beta$ & B \\
\hline SVPL & -.002 & .043 & -.002 \\
SVSR & $.172 * *$ & .039 & .229 \\
SVSI & .060 & .046 & .068 \\
\hline Note: & $.060(p<.01), * *$ Correlation is significant at the .01 level and* Correlation
\end{tabular}

Note: $R^{2}=.060(p<.01),{ }^{*}$ Correlation is significant at the .01 level, and ${ }^{*}$ Correlation is significant at .05 level. 


\section{Results for Research Question 3}

Multiple regression analysis was used to test if service personal values dimensions (i.e., service value to peaceful life, SVPL, service value to social recognition, SVSR, and service value to social integration, SVSI) significantly predicted and explained college football season ticket holders' behavioral intentions (BIT). The independent variables for $R Q 3$ are SVPL, SVSR, and SVSI, and the dependent variable for $R Q 3$ is BIT. This study's researchers selected the simultaneous data entry approach for $R Q 3$, which means all independent variables are entered into the equation at the same time. The results of multiple regression analysis indicated the service personal values dimensions explained a significant proportion of the variance in college football season ticket holders' behavioral intentions, $R^{2}=.087, F(3,344)=7.275, p<.01$.

This study's results indicated SVSR significantly predicted college football season ticket holders' behavioral intentions, $\beta=.174, F(344)=4.956, \mathrm{p}<.01$, and SVSI significantly predicted college football season ticket holders' behavioral intentions, $\beta=$ $.096, F(344)=2.325, \mathrm{p}<.05$. SVPL did not significantly predict college football season ticket holders' consumption satisfaction, $\beta=.-.026, F(344)=-.673, \mathrm{p}>.05$. Based on the standardized coefficients beta (i.e., .256 for SVSR, and .121 for SVSI), SVSR is considered a more important factor in explaining the variance in college football season ticket holders' behavioral intentions compared to SVSI. Table 9 presents a summary of $R Q(3)$ findings. 
Table 9

Correlations of Behavioral Intentions with Service Personal Values Dimensions

\begin{tabular}{|c|c|c|c|}
\hline & $\beta$ & $\mathrm{SE} \beta$ & $B$ \\
\hline SVPL & -.026 & .039 & -.673 \\
\hline SVSR & $.172 * *$ & .035 & 4.956 \\
\hline SVSI & $.096 *$ & .041 & 2.325 \\
\hline
\end{tabular}

Note: $R^{2}=.087(p<.01),{ }^{*}$ Correlation is significant at the .01 level, and ${ }^{*}$ Correlation is significant at .05 level. 


\section{Results for Research Question 4}

Several authors (Aguinis, 1995; Baron \& Kenny, 1986; Jaccard et al., 1990) recommended researchers to use structural equation modeling (SEM) to analyze moderating effect, however using SEM techniques to test for moderating effect between continuous variables are complex (Frazier et al., 2004). This study's researchers selected hierarchical regression analysis to test if college football season ticket holders' team identification level (TID) significantly moderated the relationship between service personal values (SERPVAL) dimensions (i.e., service value to peaceful life, SVPL, service value to social recognition, SVSR, and service value to social integration, SVSI) and consumption satisfaction perceptions (SAT). The interaction term is also known as the SERPVAL dimensions (i.e., SVPL, SVSR, or SVSI) x TID cross product term. This study's researchers centralized the main effect or independent variable (i.e., SERPVAL dimensions) by creating two values, one standard deviation above the mean of SERPVAL value and one standard deviation below the mean of SERPVAL value (Baron \& Kenny, 1986).

Results for Research Question 4(a). The results of hierarchical regression analysis indicated SVPL, TID, and SVPL $\mathrm{x}$ TID interaction term explained a significant proportion of variance in college football season ticket holders' consumption satisfaction perceptions, $R^{2}=.422, F(3,344)=83.565, p<.01$. It was found SVPL x TID interaction term did not significantly predict college football season ticket holders' consumption satisfaction perceptions, $\beta=-.010, F(344)=-.234, p>.05$. This study's researchers concluded college football season ticket holders' team identification level did not moderate the relationship between SVPL and SAT. Table 15 shows the results of 
moderated regression analyses of SVPL and TID on college football season ticket holders' consumption satisfaction perceptions.

Results for Research Question 4(b). The results of hierarchical regression analysis indicated SVSR, TID, and SVSR x TID interaction term explained a significant proportion of the variance in college football season ticket holders' consumption satisfaction perceptions, $R^{2}=.473, F(3,344)=102.979, p<.01$. It was found SVSR x TID interaction term significantly predicted college football season ticket holders' consumption satisfaction perceptions, $\beta=-.130, F(344)=-.234, p<.05$, and the addition of SVSR x TID interaction term added $2.90 \%$ of explained variance to college football season ticket holders' consumption satisfaction perceptions (See Table 15). SVSR x TID interaction is considered antagonistic interaction, in which both SVSR and TID affect college football season ticket holders' consumption satisfaction perceptions in the same direction (i.e., positive correlation), but the interaction is in the opposite direction (i.e., negative correlation). This study researchers' concluded higher SVSR is associated with higher consumption satisfaction perceptions, under the condition of lower team identification level (See Figure 2).

Results for Research Question 4(c). The results of hierarchical regression analysis indicated SVSI, TID, and SVSI x TID interaction term explained a significant proportion of the variance in college football season ticket holders' consumption satisfaction perceptions, $R^{2}=.423, F(3,344)=84.197, p<.01$. It was found SVSI x TID interaction term did not significantly predict college football season ticket holders' consumption satisfaction perceptions, $\beta=-.005, F(344)=-.142, p>.05$. This study's researchers concluded college football season ticket holders' team identification level did 
not moderate the relationship between SVSI and SAT. Table 10 shows the results of moderated regression analyses of SVSI and TID on college football season ticket holders' consumption satisfaction perceptions. 
Table 10

Results of Moderated Regression Analyses SERPVAL Dimensions and TID on

Consumption Satisfaction Perceptions

Source $\Delta R^{2}$ $p$ of $\Delta$ Overall $R^{2}$ $\beta$

SVPL

SVPL

.000

.844

.000

.034

TID

.421

.000

.421

.644

SVPL $x$ TID

.000

.815

.422

$-.010$

SVSR

SVSR

.055

.000

.055

.885

TID

.389

.000

.444

1.339

SVSR $x$ TID

$.029^{*}$

.000

.473

$-.130$

SVSI

SVSI

.007

.109

.007

.079

TID

.416

.000

.423

.632

SVSI $x$ TID

.000

.887

.423 $-.005$

Note: Dependent variable is consumption satisfaction. ${ }^{*} p<.05$ 
Figure 2

SVSR $x$ TID Interaction Effect on Consumption Satisfaction Perceptions

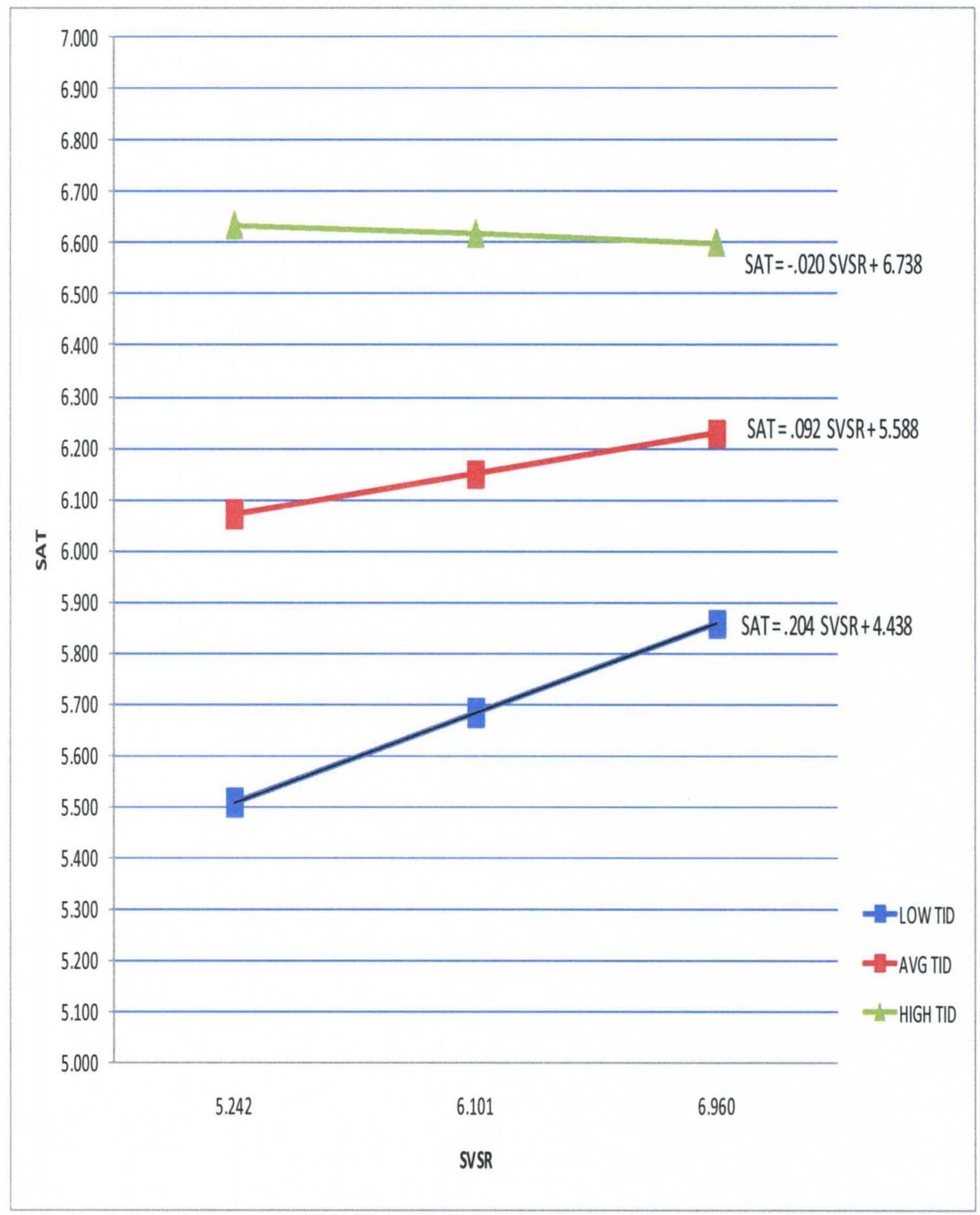




\section{Results for Research Question 5}

Hierarchical regression analysis was used to test if college football season ticket holders' team identification level (TID) significantly moderated the relationship between service personal values (SERPVAL) dimensions (i.e., service value to peaceful life, SVPL, service value to social recognition, SVSR, and service value to social integration, SVSI) and behavioral intentions (BIT). The interaction term is also known as the SERPVAL dimensions (i.e., SVPL, SVSR, or SVSI) x TID cross product term. This study's researchers centralized the main effect or independent variable (i.e., SERPVAL dimensions) by creating two values, one standard deviation above the mean of SERPVAL value and one standard deviation below the mean of SERPVAL value (Baron \& Kenny, 1986).

Results for Research Question 5(a). The results of hierarchical regression analysis indicated SVPL, TID, and SPVL x TID interaction term explained a significant proportion of the variance in college football season ticket holders' consumption satisfaction perceptions, $R^{2}=.254, F(3,344)=38.943, p<.01$. It was found SVPL x TID interaction term did not significantly predict college football season ticket holders' behavioral intentions, $\beta=-.020, F(344)=-.446, p>.05$. This study's researchers concluded college football season ticket holders' team identification level did not moderate the relationship between SVPL and BIT. Table 16 shows the results of moderated regression analyses of SVPL and TID on college football season ticket holders' behavioral intentions.

Results for Research Question 5(b). The results of hierarchical regression analysis indicated SVSR, TID, and SVSR x TID interaction term explained a significant 
proportion of the variance in college football season ticket holders' behavioral intentions, $R^{2}=.302, F(3,344)=49.515, p<.01$. It was found SVSR $\times$ TID interaction term significantly predicted college football season ticket holders' behavioral intentions, $\beta=-$ $.074, F(344)=-2.364, p<.05$, and the addition of SVSR $\times$ TID interaction term added $1.10 \%$ to explained variance in college football season ticket holders' behavioral intentions (See Table 16). SVSR x TID interaction is considered antagonistic interaction, in which both SVSR and TID affect college football season ticket holders' behavioral intentions in the same direction (i.e., positive correlation), but the interaction is in the opposite direction (negative correlation). This study's researchers concluded higher SVSR is associated with higher behavioral intentions, under conditions of lower team identification (See Figure 3).

Results for Research Question 5(c). The results of hierarchical regression analysis indicated SVSI, TID, and SVSI x TID interaction term explained a significant proportion of the variance in college football season ticket holders' behavioral intentions, $R^{2}=.271, F(3,344)=42.658, p<.01$. It was found SVSI $\mathrm{x}$ TID interaction term did not significantly predict college football season ticket holders' behavioral intentions, $\beta=$ $.068, F(344)=-1.925, p>.05$. This study's researchers concluded college football season ticket holders' team identification level did not moderate the relationship between SVSI and BIT. Table 11 shows the results of moderated regression analyses of SVSI and TID on college football season ticket holders' behavioral intentions. 
Table 11

Results of Moderated Regression Analyses SERPVAL Dimensions and TID on Behavioral Intentions

Source

$\Delta R^{2}$ $p$ of $\Delta$

Overall $R^{2}$ $\beta$

SVPL

SVPL

.003

.348

.003

.072

TID

.251

.000

.254

.499

SVPL $x$ TID

.000

.656

.254

$-.020$

SVSR

SVSR

.070

.002

.070

.578

TID

.220

.000

.290

.829

SVSR x TID

$.011^{*}$

.019

.301

$-.074$

SVSI

\begin{tabular}{lcccc} 
SVSI & .021 & .007 & .021 & .505 \\
TID & .242 & .000 & .263 & .831 \\
SVSI x TID & .008 & .055 & .271 & -.068 \\
\hline Note: & & & &
\end{tabular}

Note: Dependent variable is behavioral intention. ${ }^{*} p<.05$ 
Figure 3

\section{SVSR $x$ TID Interaction Effect on Behavioral Intentions}

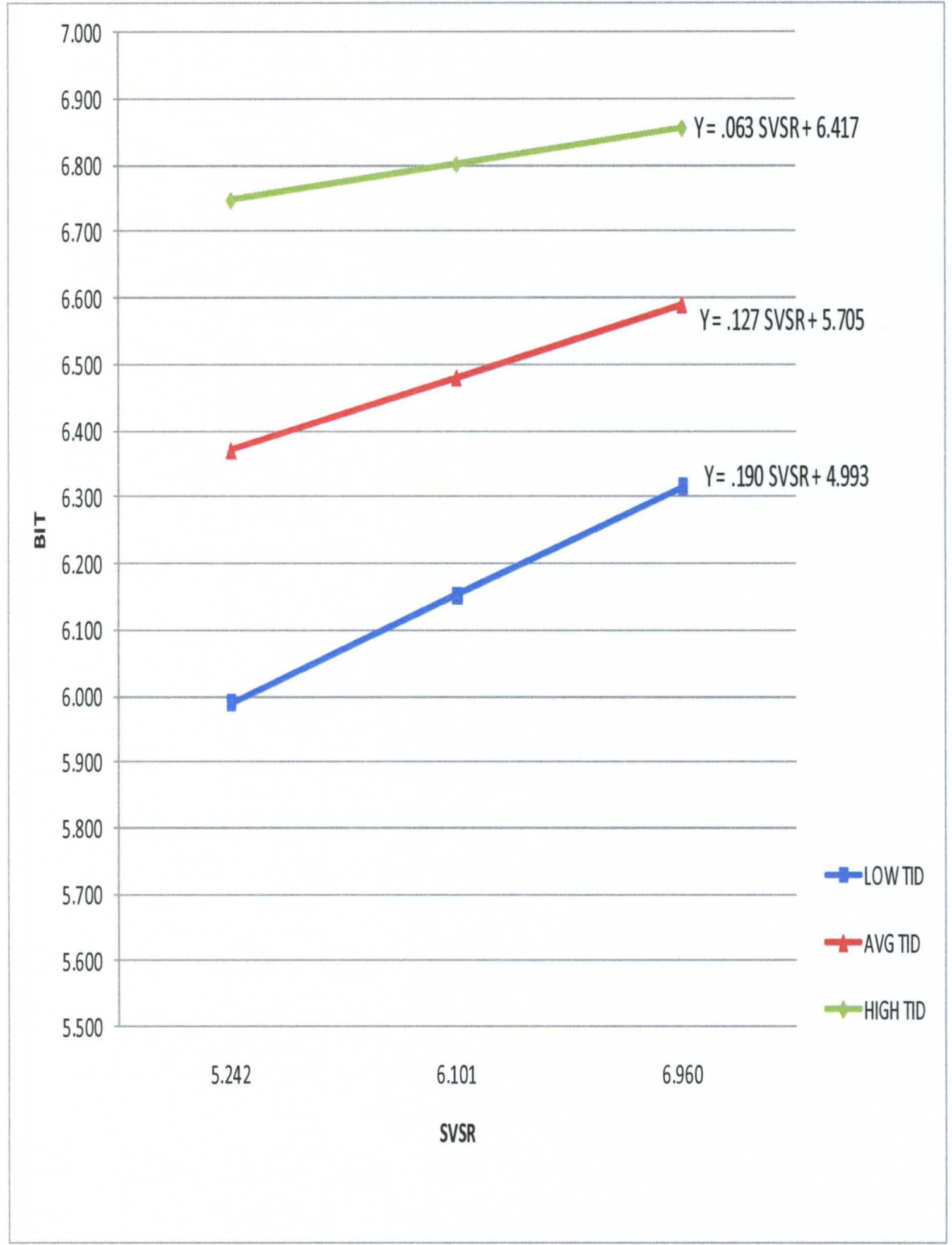




\section{Data Analysis Summary}

This study's results showed college football season ticket holders' service value to peaceful life (SVPL) means are significantly different based on their number of household members and ethnicity. This study's results demonstrated college football season ticket holders with three or fewer household members $(M=4.08, S D=.89)$ rated SVPL higher compared to college football season ticket holders with four or more household members $(M=3.07, S D=.77)$, and college football season ticket holders who identified themselves as bi-racial or others $(M=4.73, S D=.1 .36)$ rated SVPL higher compared to college football season ticket holders who identified themselves as White $(M$ $=3.77, S D=1.11)$, Black $/$ African American $(M=3.75, S D=.93)$, Hispanic/Latino/Spanish origin $(M=3.58, S D=.84)$, and Asian or Pacific Islander $(M=$ $3.33, S D=.54)$

This study's findings also demonstrated college football season ticket holders' service value to social recognition (SVSR) means are significantly different based on their gender, university affiliation, number of years holding season tickets, and ethnicity. Male college football season ticket holders reported higher SVSR $(M=6.46, S D=.67)$ compared to female college football season ticket holders $(M=5.32, S D=1.16)$, and college football season ticket holders who contributed financially to the university $(M=$ $6.40, S D=.75)$ rated SVSR higher compared to college football season ticket holders who received financial benefits from the university $(M=5.32, S D=1.16)$. At the same

time, mid stage college football season ticket holders rated SVSR $(M=5.41, S D=1.16)$ lower compared to late stage $(M=6.45, S D=.99)$ and early stage $(M=6.48, S D=.61)$ college football season ticket holders, and college football season ticket holders who 
identified themselves as White $(M=6.42, S D=.60)$ rated SVSR higher compared to college football season ticket holders who identified themselves as Black/African American $(M=5.93, S D=1.21)$ and Hispanic/Latino/Spanish origin $(M=5.72, S D=$ 1.19).

This study's findings also demonstrated college football season ticket holders' service value to social integration (SVSI) means are significantly different based on their gender, university affiliation, number of years holding season tickets, and ethnicity. Female college football season ticket holders $(M=6.48, S D=.67)$ reported higher SVSI compared to male college football season ticket holders $(M=6.00, S D=1.01)$, and college football season ticket holders who received financial benefits from the university $(M=6.49, S D=.61)$ rated SVSI higher compared to college football season ticket holders who contributed financially to the university $(M=6.02, S D=1.03)$. In addition, late stage college football season ticket holders $(M=6.61, S D=.91)$ rated SVSI higher compared to mid stage $(M=6.51, S D=.62)$ and early stage $(M=5.85, S D=1.03)$ college football season ticket holders, and college football season ticket holders who identified themselves as Hispanic/Latino/Spanish origin $(M=6.53, S D=.50)$ rated SVSI higher compared to college football season ticket holders who identified themselves as Black/African American $(M=5.87, S D=1.49)$ and White $(M=5.69, S D=1.03)$. Table 12 presents a summary of $R Q(1)$ findings. 
Table 12

Summary of $R Q(1)$ Findings

IV

SVPL

SVSR

SVSI

Household with three or fewer members

4.09

Household with four or more members

3.07

Male

6.46

6.00

Female

5.32

6.48

Contributed financially to the university

6.40

6.02

Received financial benefits from the university

5.32

6.49

Mid stage college football season ticket holders

5.41

6.51

Late stage

6.45

6.61

Early stage

6.48

5.85

Hispanic/Latino/Spanish origin

3.58

5.72

6.53

Black/African American

3.75

5.93

5.87

White

3.77

6.42

5.69

Asian or Pacific Islander

3.33

Bi-racial or others

4.73 
This study's results demonstrated SVSR significantly predicted college football season ticket holders' consumption satisfaction perceptions, $\beta=.172, F(344)=4.372, \mathrm{p}<$ .01 , explaining $5.5 \%$ of the variance in their consumption satisfaction perceptions, and significantly predicted college football season ticket holders' behavioral intentions, $\beta=$ $.174, F(344)=4.956, \mathrm{p}<.01$, explaining $7.0 \%$ of the variance in their behavioral intentions. This study's findings also showed SVSI significantly predicted college football season ticket holders' behavioral intentions, $\beta=.096, F(344)=2.325, \mathrm{p}<.05$, explaining $1.4 \%$ of the variance in their behavioral intentions. SVSR standardized coefficients beta is .256 , and SVSI standardized coefficients beta is .121 for college football season ticket holders' behavioral intentions. Thus, SVSR is considered a more important factor compared to SVSI, in explaining the variance in college football season ticket holders' behavioral intentions.

Several researchers (e.g., Cronin et al., 2000; Greenwell et al., 2002; Kahle et al., 2001; Zeithaml, 1988) reported customer service initiatives can have an impact on consumers' consumption satisfaction perceptions and behavioral intentions, however there is another group of researchers (Kahle, 1983; Madrigal, 2001; Matsuoka et al., 2003; Murrell \& Dietz, 1992) who argued the relationship between customer service, customer satisfaction, and behavioral intentions is more sophisticated than previous sport customer service research studies have suggested. This study identified sport consumers' team identification level can potentially moderate the relationship between sport consumers' customer service assessment (i.e., cognitive structure), consumption satisfaction perceptions (i.e., affective structure), and behavioral intentions (i.e., behavioral structure), and developed a study to examine the moderating effect of team 
identification in the relationship between college football cognitive, affective, and behavioral structure.

This study's findings showed team identification (TID) significantly moderated the relationship between college football season ticket holders' SVSR and consumption satisfaction perceptions, $\beta=-.130, F(344)=-.234, p<.01$. The moderation discovered in the relationship between college football season ticket holders' SVSR and consumption satisfaction perceptions is considered an antagonistic interaction, in which both SVSR and TID affect college football season ticket holders' consumption satisfaction perceptions in the same direction, but the interaction is in the opposite direction. This study's researchers concluded higher SVSR is associated with higher consumption satisfaction perceptions, under conditions of lower team identification.

This study's findings also showed team identification (TID) significantly moderated the relationship between college football season ticket holders' SVSR and behavioral intentions, $\beta=-.074, F(344)=-2.364, p<.05$. The moderation discovered in the relationship between college football season ticket holders' SVSR and behavioral intentions is considered an antagonistic interaction, in which both SVSR and TID affect college football season ticket holders' behavioral intentions in the same direction, but the interaction is in the opposite direction. This study's researchers concluded higher SVSI is associated with higher behavioral intentions, under conditions of lower team identification. 


\section{CHAPTER V \\ DISCUSSION}

The previous chapter presents findings of this research study and answers to the study's research questions. The findings of this study demonstrated service personal values predicted and explained college football season ticket holders' consumption satisfaction perceptions and behavioral intentions. The findings of this study also showed team identification levels moderated the relationship between service personal values, and both consumption satisfaction perceptions and behavioral intentions. This chapter summarizes the main findings of this study, compares and contrasts the meanings of this study's findings in light of previous service personal values studies, and discusses the implications of this study's findings for practitioners. This chapter concludes with limitations of this study and suggestions for future researchers.

One of the research purposes of this study was to understand the relationship between the college football season ticket holders' demographic profiles and their service personal values dimensions (i.e., service value to peaceful life, SVPL; service value to social recognition, SVSR; and service value to social integration, SVSI). College football season ticket holders' service value to peaceful life was significantly different based on their number of household members and ethnicity. College football season ticket holders' service value to social recognition and service value to social integration ratings were significantly different based on their gender, university affiliation, number of years holding season tickets, and ethnicity. College football season ticket holders' personal 
values were not significantly different based on their household income.

Another research purpose of this study was to understand the relationship between college football season ticket holders' service personal values dimensions (i.e., service value to peaceful life, SVPL; service value to social recognition, SVSR; and service value to social integration, SVSI), and both consumption satisfaction perceptions (SAT) and behavioral intentions (BIT). College football season ticket holders' service value to social recognition significantly predicted and explained their consumption satisfaction perceptions, and both college football season ticket holders' service value to social recognition and service value to social integration significantly predicted and explained their behavioral intentions.

The final research purpose was to understand the moderating effect of college football season ticket holders' team identification level on the relationship between their service personal values dimensions (i.e., service value to peaceful life, SVPL; service value to social recognition, SVSR; and service value to social integration, SVSI). College football season ticket holders' team identification level moderated the relationship between service value to social recognition, and both consumption satisfaction perceptions and behavioral intentions. Table 13 presents a summary of statistical significance findings for this study. 
Table 13

Summary of Main Findings

IV/Moderator

Number of household members

Gender

University affiliation

Years of holding season tickets

Ethnicity

SVSR (IV), Team Identification (moderator)
Findings

College football season ticket holders with three or fewer household members rated SVPL higher than college football season ticket holders with four or more household members

Males rated SVSR higher than females, while females rated SVSI higher than males.

University financial contributors rated SVSR higher compared to university financial recipients, while university financial contributors rated SVSI higher compared to university financial contributors.

Mid stage college football season ticket holders rated SVSR lower compared late and early stage college football season ticket holders.

Late stage college football season ticket holders rated SVSI higher compared to mid and early stage college football season ticket holders.

College football season ticket holders who identified themselves as White rated SVSR higher compared to college football season ticket holders who identified themselves as Black/African American and Hispanic/Latino/Spanish origin.

College football season ticket holders who identified themselves as Hispanic/Latino/Spanish origin rated SVSI higher compared to college football season ticket holders who identified themselves as Black/African American and White.

Team identification moderated the relationship between college football season ticket holders' SVSR and consumption satisfaction perceptions. 
Summary of Main Findings (continued)

IV/Moderator

Findings

SVSR (IV), Team Identification

Team identification moderated the relationship (moderator) between college football season ticket holders' SVSR and behavioral intentions. 


\section{Main Findings and Implications}

Kahle et al. (2001) argued one of the keys to successful sport organizations rested on the sport marketers capability to understand and satisfy their sport consumers' personal values, and individuals' values is a function of socio-cultural, economic, and family environment (Vinson et al., 1977). In this section, this study's main findings (see Table 13) are tied to previous research studies' findings, and practical implications are provided.

Demographic Profiles and Service Value to Peaceful Life. The factorial multivariate analysis of variance (MANOVA) results indicated college football season ticket holders service personal values (i.e., service value to peaceful life, SVPL; service value to social recognition, SVSR; and service value to social integration, SVSI) varied based on their demographic profiles. This study's findings demonstrated college football season ticket holders' service value to peaceful life, service value to social recognition, and service value to social integration ratings were significantly different based on their gender, university affiliation, number of years holding season tickets, and ethnicity (see Table 17).

This study's findings indicated college football season ticket holders who identified themselves as bi-racial or others $(M=4.73, S D=1.36)$ reported significantly higher service value to peaceful life scores compared to college football season ticket holders' who identified themselves as Asian or Pacific Islander $(M=3.33, S D=.54)$, Hispanic/Latino/Spanish origin $(M=3.58, S D=.84)$, Black/African American $(M=3.75$, $S D=1.11)$, and White $(M=3.77, S D=1.11)$. This study's findings showed college football season ticket holders with three or fewer household members $(M=4.08, S D=$ 
.89) rated service value to peaceful life higher compared to college football season ticket holders with four or more household members $(M=3.07, S D=.77)$. College football season ticket holders with three or fewer household members are more likely to value tranquility, family security, and pleasurable life more compared to college football season ticket holders with four or more household members. This study's findings are consistent with Kahle et al. (2002), Schwarz (1992), and Shao (2002), reporting single individuals or small families tend focus on themselves or spending more time with each other, activities promoting work-leisure balance, and living in an environmentally healthy world. Sport marketers can promote game attendance as an opportunity for single individuals or small families to stay closer and spend quality time with each other. For example, sport marketers can add after game concert and build environmentally friendly stadiums to attract sport consumers who valued service value to peaceful life. Sport marketers can also promote activities that relieve stress such as yoga in your seat during game intermissions, for sport consumers who valued service value to peaceful life.

\section{Demographic Profiles, Service Value to Social Recognition, and Service}

Value to Social Integration. This study's findings showed male college football season ticket holders $(M=6.46, S D=.67)$ rated service value to social recognition higher than female college football season ticket holders $(M=5.32, S D=1.16)$, and female college season ticket holders $(M=6.48, S D=.67)$ rated service value to social integration more higher than male college football season ticket holders $(M=6.00, S D=1.01)$. Male college football season ticket holders valued respect from others, greater sense of personal accomplishment in life, and more social recognition (i.e., focus on personal development), more higher than female college football season ticket holders. Female 
college football season ticket holders tend to value opportunity to develop better relationship with others (i.e., focus on social development), compared to male college football season ticket holders. This study's findings are consistent with Kahle et al. (2001) and Shao (2002), reporting female sport consumers rated service value to social integration components such as sense of belongingness, higher in group acceptance, and better relationship with friends, co-workers, and family members higher, compared to male sport consumers.

Sport marketers marketing toward women can highlight opportunities to create better relationship with friends, co-workers, and family members (e.g., family section with no alcohol consumption and profanity, family oriented pre-game or post-game activities such as children run the field and kiss cam featuring couples attending games) while promoting college football season tickets to female sport consumers. Sport marketers can also highlight the prestige of owning college football season tickets and ways college football season tickets can enhance an individuals' social status and self image to male sport consumers. For instance, sport marketers can designate exclusive box seating for season ticket holders and refreshment areas exclusive to college football season ticket holders.

This study's findings also indicated college football season ticket holders' service value to social recognition and service value to social integration are significantly different based on their university affiliation. College football season ticket holders who contributed financially to the university such as students, alumni, or university booster club members $(M=6.40, S D=.75)$ rated service value to social recognition higher than college football season ticket holders who received financial benefits from the university 
such as university employees and others $(M=5.32, S D=1.16)$. Alumni and students are more likely to identify themselves with college football teams and utilize their college football team affiliation to gain social recognition, compared to university employees and general public (Harrison, Mitchell, \& Peterson, 1995).

The findings of this study are consistent with Lavarie and Arnett's (2000) findings, reporting individuals' team attachment explained their tendency to maintain their self-concept and gaining social recognition through identification with college football team. Sport marketers can promote college football season tickets to university employees as an opportunity to socialize outside of work with co-workers and a way to orient themselves to the university community. Sport marketers can also utilize college football games to recognize alumnae and students contributions to the society or personal accomplishment.

This study's results indicated college football season ticket holders who received financial benefits from the university $(M=6.49, S D=.61)$ rated service value to social integration higher compared to college football season ticket holders who contributed financially to the university $(M=6.02, S D=1.03)$. This study's researchers posited college football season ticket holders who received financial benefits from the university appreciate the opportunity to strengthen relationships with others and sport marketers can promote college football games as a way for university employees to build and strengthen relationship with others.

College football season ticket holders' number of years holding season tickets were categorized into three groups based on the stages of the college football programs existence (i.e., early stage, mid stage, and late stage): (a) early stage college season ticket 
holders (i.e., individuals who had been college football season ticket holders for three years of less), (b) mid stage college football season ticket holders (i.e., individuals who had been college football season ticket holders for four to six years), and (c) late stage college football season ticket holders (i.e., individuals who had been college football season ticket holders for seven years or more).

This study's results revealed mid stage college football season ticket holders $(M=$ $5.41, S D=1.16)$ rated service value to social recognition lower compared to late stage $(M$ $=6.45, S D=.99)$ and early stage $(M=6.48, S D=.61)$. In the beginning of the college football program (i.e., first three years of the college football program existence) and in the recent history of the college program (i.e., the past three years of the college football program existence), the college football program attracted season ticket holders who appreciate more respect from others and more social recognition. At the same time, this study's results also exhibited late stage college football season ticket holders $(M=6.61$, $S D=.91)$ rated service value to social integration higher compared to mid stage $(M=$ $6.51, S D=.62)$ and early stage $(M=5.85, S D=1.03)$ college football season ticket holders. Late stage college football season ticket holders are attracted to attending the football games because it is an opportunity for them to develop better relationships with friends, co-workers, and family members.

This study's findings showed college football season ticket holders' service value to social recognition and service value to social integration are significantly different based on their ethnicity. College football season ticket holders' identifying themselves as White $(M=6.42, S D=.60)$ reported significantly higher service value to social recognition compared to the minorities such as Black/African American $(M=5.93, S D=$ 
1.21) and Hispanic/Latino/Spanish origin $(M=5.72, S D=1.19)$, and minorities such as Hispanic/Latino/Spanish origin $(M=6.53, S D=.50)$ and Black/African American $(M=$ $5.87, S D=1.49)$ reported higher service value to social integration compared to college football season ticket holders' identifying themselves as White $(M=5.69, S D=1.03)$. This study's researchers posited the minority college football season ticket holders value opportunities to develop better relationship with others because social integration allows the minorities to form something bigger than themselves, and White college football season ticket holders value more respect from others and more social recognition, because they want to maintain their social status.

The findings of this study are consistent with Quester et al. (2006), Shao (2002), Vinson et al. (1977), and Wang et al. (1994), reporting value differences among individuals can be traced back to their different ethnic background and environments (i.e., social, economic, political, and technological). Sport marketers can utilize service personal value as a segmentation base of sport consumers. For instance, sport marketers with predominantly Hispanic sport consumers (who valued service value to social integration) can create opportunity for their consumers to host family gatherings (e.g., tailgating area) before and during college football games.

In conclusion, service value to social recognition (i.e., self-enhancement values) and service value to social integration (self-transcendence values) are considered conflicting values in Schwartz's (1992) circular values system. This study's findings supported Schwartz (1992) conclusion.

\section{Service Value to Social Recognition and Consumption Satisfaction}

Perceptions. This study's findings showed service value to social recognition was the 
only service personal values dimension which predicted $(\beta=.172, F(344)=4.372, \mathrm{p}<$ $.01)$ college football season ticket holders' consumption satisfaction perceptions, and explaining $5.5 \%$ of the variance. The findings of this study are consistent with Armstrong (2007), Lages and Fernandes (2005), Madrigal (2001), and Thuy and Hau (2010), reporting sport consumers' consumption satisfaction perceptions were driven by opportunities for them to practice self-expression (e.g., gaining more social recognition and more respect from others). Neither service value to peaceful life, $\beta=-.002, F(344)=$ $-.038, p=.970$, nor service value to social integration, $\beta=.060, F(344)=1.286, p=.199$, significantly predicted college football season ticket holders' consumption satisfaction. This may be attributable to the fact that individuals' external esteem needs (e.g., social status and recognition) are more important in explaining and predicting service consumption satisfaction, compared to their sense of belongingness (Maslow, 1943; Vinson et al, 1977; Zeithaml, 1988). American psychologist and philosopher, William James, suggested the need to be appreciated by others is more important human need compared to gaining personal accomplishment (Schultz, 2004).

Sport consumers' consumption satisfaction perceptions are important in predicting and explaining sport consumers' behavioral intentions (Cronin et al., 2000, Lavarie \& Arnett, 2000, Matsuoka et al., 2003, Trail et al., 2003), and sport organizations success and profitability depend on their ability to satisfy sport consumers' service personal values (Kahle et al., 2001; Quester et al., 2006; Shao, 2002). The findings of this study demonstrated sport organizations can utilize service value to social recognition as a promotional theme or marketing strategy to enhance sport consumers' consumption satisfaction perceptions. For example, sport organizations can create events to recognize 
their season ticket holders who have been with the organization for an extended period of time during game timeout promotions, and have the best seats in the stadium or tailgating areas reserved (e.g., "Area Reserved for Season Ticket Holders") for individuals who have been season ticket holders for an extended period of time.

\section{Service Value to Social Recognition, Service Value to Social Integration, and}

Behavioral Intentions. This study's findings illustrated both college football season ticket holders' service value to social recognition, $\beta=.174, F(344)=4.956, \mathrm{p}<.01$, and service value to social integration, $\beta=.096, F(344)=2.325, \mathrm{p}<.05$, predicted their behavioral intentions. Service value to social recognition and service value to social integration explained $7.0 \%$ and $1.4 \%$ of the variance in college football season ticket holders' behavioral intentions respectively. Personal values such as sense of belonging, developing warm relationships with others, gaining social recognition, and sense of accomplishment may impact college football season ticket holders' future behaviors such as renewing season tickets or sharing their game attendance with others. Based on their relative standardized beta coefficients, service value to social recognition (.256) was a more important factor than service value to social integration (.121), in explaining the variance in college football season ticket holders' behavioral intentions. Service value to peaceful life did not significantly predict college football season ticket holders' consumption satisfaction, $\beta=-.026, F(344)=-.673, \mathrm{p}=.502$. Service value to peaceful life may not have predicted college football season ticket holders' behavioral intentions because peaceful and pleasurable life were considered the lowest level of physiological and safety needs (Maslow, 1943). Sport consumption is considered a higher form consumption known as hedonic consumption, and hedonic consumption was based on 
experience of subjectively desirable emotion (Horiuchi, 2003).

Behavioral intentions measured college football season ticket holders' plan to renew their season tickets, recommend their family members or friends to purchase season tickets, share their college football game spectating experience with others, and purchase additional college football season tickets next year. Customer retention is positively correlated with service providers' overall profit and one of the most important factors impacting customer retention is behavioral intentions (Zeithaml et al., 1996). The findings of this study are similar with Quester et al. (2006), reporting sense of belongingness or service value to social recognition as a critical predictor and explanatory variable for sport consumers' behavioral intentions. The findings of this study also consistent with Lages and Fernandes (2005), Shao (2002), and Thuy and Hau (2010), reporting better social relationship with others or SVSI predicted and explained consumers' behavioral intentions.

Sport marketers can enhance college football season ticket holders' sense of service value to social recognition on a team's website or using a team's social networks such as Facebook or Twitter, creating special messages to spotlight and recognize the contribution of season ticket holders to the team success. Sport marketers can also recognize the demographic make-up or something special about their season ticket holders. For instance, if a team's season ticket holders are predominantly Hispanic, sport marketers can recognize their season ticket holders during Hispanic Heritage month by providing Hispanic singers concerts before or after the game or playing more Hispanic music during game intermissions.

Sport marketers can satisfy college football season ticket holders' sense of service 
value to social integration by allowing college season tickets holders and their companies to host gathering at very important people (VIP) areas (before, during or after the game). Sport marketers can also create family promotional programs for college football season ticket holders who appreciate service values to social integration. For instance, sport organizations can giveaway tickets for season ticket holders encouraging them to bring their family members and friends to the games.

Team Identification and Consumption Satisfaction Perceptions. This study's findings illustrated college football season ticket holders' team identification moderated the relationship between their service value to social recognition (SVSR) and consumption satisfaction perceptions. The moderation effect is considered an antagonistic interaction, because service value to social recognition and team identification have the same effect (i.e., positive correlation) on college football season ticket holders' consumption satisfaction perceptions but the interaction term (SVSR $x$ TID) is in the opposite direction (i.e., negative correlation). College football season ticket holders with low team identification level are more likely to depend on social recognition values to formulate their consumption satisfaction perceptions, compared to college football season ticket holders with high team identification level. The findings of this study are consistent with Armstrong (2007), reporting sport consumers' opportunity to practice selfexpression (e.g., social recognition) impacted their attendance behavior.

College football season ticket holders' team identification level did not moderate the relationship between either service value to peaceful life or service value to social integration and their consumption satisfaction perceptions, and service value to peaceful life and service value to social integration did not have an impact on college football 
season ticket holders' consumption satisfaction perceptions. College football season ticket holders' with lower team identification level were more likely to be satisfied with their consumption because the consumption of college football season tickets allowed them to enhance their social recognition values, while college football season ticket holders' with high team identification level were more likely to be satisfied because the consumption of college football season tickets make them feel that they are attached to the team.

Sport marketers need to develop additional promotional activities enhancing social recognition for college football season ticket holders with low team identification level. For instance, sport marketers can recognize college football season ticket holders with low team identification by providing free team paraphernalia (e.g., team t-shirt mentioning "team supporters make the our dreams come true" or car decals or flags stating "you are our \#1 supporter") with new season tickets purchase or season ticket renewals. Individuals' personal values are more difficult to alter compared to their social or team identification level (Kahle et al., 2001; Sutton et al., 1997) and team identification is one of the strongest sport consumers' consumption satisfaction predictors (Lavarie \& Arnett, 2000; Madrigal, 1995; Matsuoka et al., 2003; Wann and Branscombe, 1993).

Sport marketers can increase college football season ticket holders' team identification level, so college football season ticket holders' can decrease their reliance on SVSR to formulate consumption satisfaction perceptions. Sport marketers can reinforce their team's history and tradition in conjunction with season ticket holders' contributions. For example, sport marketers can create team memorabilia (e.g., football, t-shirt, or plaque) commemorating team success with season ticket holders' contribution 
to the team (e.g., "my first championship as a season ticket holders" or "ten years with the team and celebrating our first championship").

Team Identification and Behavioral Intentions. Similarly, team identification did not moderate the relationships between pleasurable life and behavioral intentions or social integration and behavioral intentions. However, college football season ticket holders' team identification moderated the relationship between their service value to social recognition (SVSR) and behavioral intentions. The moderation effect is considered antagonistic interaction, because service value to social recognition and team identification have the same effect (i.e., positive correlation) on college football season ticket holders' behavioral intentions but the interaction term (SVSR $\mathrm{x}$ TID) is in the opposite direction (i.e., negative correlation). College football season ticket holders with low team identification level are more likely to depend on service value to social recognition to formulate their behavioral intentions, compared to college football season ticket holders with high team identification level. The findings of this study are consistent with Gwinner and Swanson (2003), Madrigal (2001), Murrell and Dietz (1992), and Wann and Branscombe (1993), reporting sport consumers' attitudes and team identification level impacted their consumption behavior.

College football season ticket holders' with low team identification level were satisfied with their consumption because the purchase of college football season tickets allowed them to enhance their social recognition values, while college football season ticket holders' with high team identification level were satisfied because the purchase of college football season tickets make them feel that they are attached to the team. The implications for sport marketers are similar to those presented in previous sub-section 
(i.e., Team Identification and Consumption Satisfaction Perceptions).

\section{Suggestions for Future Research}

Future research on sport consumers' service personal values should further examine sport consumers' personal values in different sport contexts, professional sports, and U.S. regions, because personal values are strong and consistent predictors of consumer satisfaction perceptions and behavioral intentions (Kahle et al., 2001; Lages \& Fernandes, 2005; Shao, 2002; Quester et al., 2006; Zeithaml, 1988). Future researchers can use sport consumers' personal values to develop promotional and marketing activities to satisfy their personal values needs, and develop long term relationship with sport consumers. Future research on sport consumers' service personal values should also further investigate the difference between season ticket holders and regular individual game ticket purchasers, and the findings can help sport marketers to better allocate their marketing resources and target their promotional activities.

Future researchers should expand on Quester et al.'s (2006) research study, and develop a more in-depth sport consumers' service personal values scale. Quester et al. (2006) discovered personal values dimensions such as freedom, belongingness, excellence, and connection are key predictors driving sport consumer brand choice. Future research studies should focus on using developing survey questionnaires to assess sport consumers' perceptions of freedom, belongingness, excellence, and connection dimensions. Future researchers can also further investigate the difference between service personal values driving sport consumers' sport product and service consumption decision, and the findings can help sport service marketers select the right sport product partners. For example, if the National Basketball Association (NBA) consumers predominantly 
rated service value to social integration as their primary service personal values, NBA can partner with sport product manufacturer whose mission is to promote social integration.

Funk et al. (2003, p. 204) suggested future sport marketing researchers "need to avoid doing a single-shot studies, and instead, build programmatic lines of research that allow us to build a better understanding of sport consumers." Future researchers can include all customer service dimensions proposed by Zeithaml (1988) and the team identification construct to increase the overall variance explained in both sport consumers' consumption satisfaction perceptions and behavioral intentions (i.e., developing a sport customer service model). Future researchers can develop a sport customer service model using structural equation modeling technique.

An examination of the change in sport consumers' service personal values over time is another recommendation for future research. Future sport marketing researchers can track sport consumers' service personal values over time using time series analysis or repeated measures experiment, similar to Wann (1996) approach (i.e., tracking the changes in sport consumers' team identification level over the course of a season). The findings can help sport marketers to develop short term and long term plan fostering steady revenue growth.

\section{Conclusion}

The main purpose of this study was to examine the moderating effect of college football season ticket holders' team identification on the relationship between their service personal values and consumption behavior. This was accomplished by examining the moderating effect of college football team identification level in the relationship 
between service value to peaceful life, service value to social recognition, and service value to social integration, and both consumption satisfaction perceptions and behavioral intentions. Two other purposes of this study were analyzing antecedents (i.e., demographic profiles), and outcomes (i.e., consumption satisfaction perceptions and behavioral intentions) of college football season ticket holders.

The findings of this study indicated college football season ticket holders' team identification level moderated the relationship between service value to social recognition, and both consumption satisfaction and behavioral intentions. College football season ticket holders with low team identification level were more likely to depend on service value to social recognition to formulate their consumption satisfaction perceptions and behavioral intentions, compared to college season ticket holders' with high team identification levels. These study's findings are consistent with Armstrong (2007), Gwinner and Swanson (2003), Madrigal (2001), Murrell and Dietz (1992), and Wann and Branscombe (1993). Individuals' service personal values are more consistent over time compared to team identification level (Kahle et al., 2001; Sutton et al., 1997), and team identification is one of the strongest sport consumers' consumption satisfaction predictors (Lavarie \& Arnett, 2000; Madrigal, 1995; Matsuoka et al., 2003; Wann and Branscombe, 1993). These findings imply sport marketers need to develop more promotional activities, pricing strategies, and facility planning based on service personal values targeting consumers with low team identification level.

This study's results indicated service value to social recognition is an important predictor of college football season ticket holders' consumption satisfaction perceptions and behavioral intentions. The desire for social recognition originated from an 
individual's tendency to possess the ability to imagine and feel the extent of his or her world, rather than just the material sense of his or her world (Reik, 1957). During early childhood, individuals generally seek love and admiration from their family members (i.e., internal circle), however, individuals' need for recognition extend to larger groups of people (i.e., external circle) as they continue to grow (Reik, 1957). People continue to search for social recognition from their families and friends alone and beyond (e.g., the community, the nation, the continent, the whole world), based on the extent and character of their ambition (Reik, 1957).

While new facilities and friendly services may help to increase sport consumers' consumption satisfaction perceptions (Ko \& Pastore, 2004; Theodorakis, Kambitsis, Laios, \& Koustelios, 2001; Wakefield \& Blodgett, 1996), ultimately sport marketers need to focus on creating a service environment eliciting emotional connections with sport consumers (Pullman \& Gross, 2004). Sport marketers need to help sport consumers feel like they matter, by providing sport consumers the feeling their service personal values are noticed, understood, cared about, and critical to sport organization's success (Rosenberg \& McCullough, 1981; Schlossberg, 1989). Sport consumers who feel like they matter are more likely to have positive re-purchase intentions (Kahle et al., 2004).

One of the ways sport marketers can make their customers feel appreciated is adopting the relationship marketing approach. Berry (2002) suggested relationship marketing focuses on simultaneously attracting new customers, and maintaining and enhancing existing customer base. Relationship marketing approach has been proven to be extremely beneficial for firms that are new to a market (Ravald \& Gronroos, 1996), and the college football team in this study is new to the Division - I Football Bowl Series. 
College football season ticket holders' cultural and social economic background impacted their service personal values. In addition, college football season ticket holders' service value to social integration impacted their behavioral intentions. The findings indicated sport marketers can develop promotional and marketing activities based on their consumers' service personal values and team identification level.

Previous research studies (Lavarie \& Arnett, 2000; Matsuoka et al., 2003; Trail et al, 2005; Wann \& Branscombe, 1993) investigated the impact of team identification on sport consumer behavior, and the impact of sport consumers' personal values on their consumption behavior (Kahle et al., 2001; Shao, 2002; Quester et al., 2006). This study is the first study to combine both service personal values and team identification to explain and predict college football season ticket holders' consumption satisfaction perceptions and behavioral intentions. This study also expanded Madrigal's (2001) study to further investigate the moderating role of sport consumers' team identification level. Team identification level is an important variable linking college football season ticket holders' service personal values, and both consumption satisfaction perceptions and behavioral intentions. The findings of this study indicated team identification level can change the magnitude of service personal values' impact on college football season ticket holders' consumption satisfaction perceptions and behavioral intentions.

Funk et al. (2003) suggested a good research study should generate more questions rather than just results for publication. A critical question for future sport marketing researchers is should sport marketers develop their promotional and marketing activities based on their consumers' service personal values, team identification level, or a combination of both? Future sport marketing researchers should conduct research studies 
examining the relative importance of service personal values and team identification explaining the variance in sport consumers' consumption satisfaction perceptions and behavioral intentions.

This study combined social adaptation (i.e., sociology), social identity (i.e., social psychology), and consumer behavior (i.e., marketing) theories to explain college football season ticket holders' consumption satisfaction perceptions and behavioral intentions. Future sport marketing researchers should develop a comprehensive sport customer service model (i.e., based on theories from other fields of social studies such as psychology, economics, and sociology), using structural equation modeling. Future researchers also need to further investigate the role of sport consumers' team identification level (i.e., moderator or mediator) to gain a comprehensive understanding of sport consumer behavior. The success of future sport marketing researchers may depend on their ability to develop a comprehensive understanding of team identification role in sport marketing through the lenses of sociologists, psychologists, and marketing researchers. Sophisticated and integrated interdisciplinary sport marketing theories can help sport marketers to develop the best practice to allocate their resources meeting sport consumers' needs. 


\section{REFERENCES}

Agle, B. R., \& Caldwell, C. B. (1999). Understanding research on values in business. Business and Society, 38(3), 326-387.

Agosta, J., Daignault, J., Smith, D., \& Fortune, J. (2008). Assessing the face, content, and construct validity of the Florida Questionnaire for Situational Information.

Retrieved from http://apd.myflorida.com/qsi-wsc-training/docs/assessing-the-fccvalidity-of-the-fl-qsi.pdf

Aguinis, H. (1995). Statistical power problems with moderated multiple regression in management research. Journal of Management Research, 21, 1141-1158.

Aguinis, H, Boik, R. J., \& Pierce, C. A. (2001). A generalized solution for approximating the power to detect effects of categorical moderator variables using multiple regression. Organizational Research Methods, 4, 291-323.

Akaah, I. P., \& Lund, D. (1994). The influence of personal and organizational values on marketing professionals' ethical behavior. Journal of Business Ethics, 13(6), 417430 .

Allport, G., Vernon, P., \& Lindzey, G. (1960). Study of values. Boston: Houghton Mifflin.

Armstrong, K. L. (2007). Self, situations, and sport consumption: An exploratory study of symbolic interactionism. Journal of Sport Behavior, 30(2), 111-129.

Baron, R. M., \& Kenny, D. A. (1986). The moderator-mediator variable distinction in social psychological research: Conceptual, strategic, and statistical consideration. Journal of Personality and Social Psychology, 51, 1173-1182.

Berry, L. L. (2002). Relationship marketing of services - perspectives from 1983 and 2000. Journal of Relationship Marketing, I(1), 59-78.

Bhattacharya, C. B., Rao, H., \& Glynn, M. A. (1995). Understanding the bond of identification: An investigation of its correlates among art museum. Journal of Marketing, 59(4), 46-57. 
Bitner, M. J., \& Hubbert, A. R. (1994). Encounter satisfaction versus overall satisfaction versus quality. In R. T. Rust, \& R. L. Oliver (Eds.), Service quality: New directions in theory and practice (pp. 72-84). New York, NY: Sage Publications, Inc.

Bowl Championship Series. (2010). BCS chronology. Retrieved from http://www.bcsfootball.org/news/story?id=4819366

Brangule-Vlagsma, K., Pieters, R., \& Wedel, M. (2002). The dynamics of value segments: Modeling framework and empirical illustration. International Journal of Research Marketing, 19(3), 267-285.

Branscombe, N. R., \& Wann, D. L. (1991). The positive social and self concept consequences of sports team identification. Journal of Sport and Social Issues, 15(2), 115-127.

Bronowski, J. (1956). The real responsibilities of the scientist. Bulletin of the Atomic Scientists, 12(1), 10-13, \& 20.

Brown, G. (2009). Latest athletics fiscal data hint at moderation. The NCAA News. Retrieved from http://www.ncaa.org/wps/wcm/connect/ncaa/ncaa/ncaa+news/ncaa+news+online/ 2009/division +i/latest+athletics +fiscal +data +hint +at +moderation_10_20_09_ncaa news

Brown, J. D. (2008). The Bonferroni adjustment. Shiken: JALT testing \& evaluation SIG newsletter, 12(1), 23-28.

Burgess, S. M., \& Steenkamp, J. E. M. (1999). Value priorities and consumer behavior in a transitional economy. In R. Batra (Ed.), Marketing issues in transitional economies (pp. 85-105). Boston, MA: Kluwer Academic Publishers.

Chalip, L. (2006). Toward a distinctive sport management discipline. Journal of Sport Management, 20(1), 1-21.

Cialdini, R. B., Borden, R. J., Thorne, A., Walker, M. R., Freeman, S., \& Sloan, L. R. (1976). Basking in reflected glory: Three (football) field studies. Journal of Personality and Social Psychology, 34(3), 366-375.

Clawson, C. J., \& Vinson, D. E. (1978). Human values: A historical and interdisciplinary analysis. In H. K. Hunt (Ed.), Advances in consumer research (pp. 396-402). Ann Arbor, MI: Association for Consumer Research.

Cobanoglu, C. Warde, B., \& Moreo, P. J. (2001). A comparison of mail, fax, and web survey methods. International Journal of Market Research, 43(4), 441-452. 
Cohen, J. (1988). Statistical power analysis for the behavioral sciences (2nd ed.). Hillsdale, NJ: Lawrence Erlbaum.

Cohen, J., Cohen, P., West, S. G., \& Aiken, L. S. (2003). Applied multiple regression/correlation analysis for the behavioral sciences (3rd ed.). Mahwah, NJ: Erlbaum.

Cornwell, T. B., \& Coote, L.V. (2005). Corporate sponsorship of a cause: The role of identification in purchase intent. Journal of Business Research, 58, 268-276.

Couper, M. P. (2000). Web surveys: A review of issues and approaches. Public Opinion Quarterly, 64, 230-253.

Cronbach, L. J. (1951). Coefficient alpha and the internal structure of tests. Psychometrika, 16(3), 297-334.

Cronin, J. J., Jr. (2003). Looking back to see forward in services marketing: some ideas to consider. Managing Service Quality, 13(5), 332-337.

Cronin, J. J., Jr., Brady, M. K., \& Hult, G. T. M. (2000). Assessing the effects of quality, value, and customer satisfaction on consumer behavioral intentions in service environments. Journal of Retailing, 76(2), 193-218.

Curtin, R. T. (1982). Indicators of consumer behavior: The University of Michigan surveys of consumers. Public Opinion Quarterly, 46(3), 340-352.

Dillman, D. A. (2000). Mail and internet surveys: The tailored design method (2nd ed.). New York, NY: John Wiley \& Sons, Inc.

Erceg-Hurn, D. M., \& Mirosevich, V. M. (2008). Modern robust statistical methods: An easy way to maximize the accuracy and power of your research. American Psychologist, 63(7), 591-601.

England, G. W. (1967). Personal values systems of American managers. Academy of Management Journal, 10, 107-117.

England, G., \& Lee, R. (1971). Organizational goals and expected behavior among American, Japanese, and Korean managers - A comparative study. Academy of Management Journal, 14(4), 425-438.

ESPN. (2010). NCAA FBS (Division I-A) football standings - 2009. Retrieved from http://espn.go.com/college-football/standings.

Feather, N. T. (1975). Values in education and society. New York, NY: Free Press. 
Fink, J. S., Trail, G. T., \& Anderson, D. F. (2002a). An examination of team identification: Which motives are most salient to its existence. International Sports Journal, 6(2), 195-207.

Fink, J. S., Trail, G. T., \& Anderson, D. F. (2002b). Environmental factors associated with spectator attendance and sport consumption behavior: Gender and team differences. Sport Marketing Quarterly, 11(1), 8-19.

Fishbein, M., \& Azjen, I. (1975). Belief, attitude, intention, and behavior: An introduction to theory and research. Reading, MA: Addison-Wesley Pub.

Frazier, P. A., Tix, A. P., \& Barron, K. E. (2004). Testing moderator and mediator effects in counseling psychology research. Journal of Counseling Psychology, 51(1), 115-134.

Fulks, D. L. (2005a). 2002-03 NCAA revenues and expenses of Divisions I and II intercollegiate athletics programs report (National Collegiate Athletic Association). Retrieved from http://www.ncaa.org/library/research/i_ii_rev_exp/2003/200203 dl_d2_rev_exp.pdf

Fulks, D. L. (2005b). Revenue and expenses, profits and losses of Division I-A intercollegiate athletics programs aggregated by conference 2002- 2003 Fiscal Year (National Collegiate Athletic Association). Retrieved from http://www.ncaa.org/library/research/i_ii_rev_exp/2003/2003D1aConfReport.pdf

Fulks, D. L. (2009). 2004-2008 revenue and expenses, profits and losses of Division I-A intercollegiate athletics programs report (National Collegiate Athletic Association). Retrieved from http://www.smudailycampus.com/polopoly_fs/1.1289588!/RE09.pdf

Fulks, D. L. (2010). 2004-2008 revenue and expenses, profits and losses of Division I-A intercollegiate athletics programs report (National Collegiate Athletic Association). Retrieved from http://www.ncaapublications.com/productdownloads/REV_EXP_2010.pdf

Fullerton, S., \& Morgan, M. J. (2009, October). Sports marketing in an economic quagmire. Paper presented at the annual meeting of the Sport Marketing Association, Cleveland, $\mathrm{OH}$.

Funk, D. C., Mahony, D. F., \& Havitz, M. E. (2003). Sport consumer behavior: Assessment and direction. Sport Marketing Quarterly, 12(4), 200-205.

Greenwell, T. C., Fink, J. S., \& Pastore, D. L. (2002). Assessing the influence of the physical sports facility on customer satisfaction within the context of the service experience. Sport Management Review, 5, 129-148. 
Grunert, S. C., \& Juhl, H. J. (1995). Values, environmental attitudes, and buying of organic foods. Journal of Economic Psychology, 16(1), 39-62.

Gwinner, K., \& Swanson, S. R. (2003). A model of fan identification: Antecedents and sponsorship outcomes. The Journal of Services Marketing, 17(2/3), 275-294.

Hales, M. (2003). The antitrust issues of NCAA college football within the Bowl Championship Series. Sports Lawyers Journal, 10, 97-134.

Harrison, W. B., Mitchell, S. K., \& Peterson, S. P. (1995). Alumni donations and colleges' development expenditures: Does spending matter. American Journal of Economics and Sociology, 54(4), 397-412.

Homer, P. M., \& Kahle, L. R. (1988). A structural equation test of the value-attitudebehavior hierarchy. Journal of Personality \& Social Psychology, 54(4), 638-646.

Horiuchi, K. (2003). A new perspective of hedonic consumption. European Advances in Consumer Research, 6, 265-269.

Huberty, C. J., \& Morris, J. D. (1989). Multivariate analysis of variance versus multiple univariate analyses. Psychological Bulletin, 105(2), 302-308.

Jaccard, J., Turrisi, R., \& Wan, C. K. (1990). Interaction effects in multiple regression. Newbury Park, CA: Sage.

Jackson, D. Z. (2005). The squeeze on college funding. Retrieved from http://www.boston.com/news/globe/editorial_opinion/oped/articles/2005/10/18/th e_squeeze_on_college_funding/

Jalilvand, M. (2000). Married women, work, and values. Monthly Labor Review, 123(8), 26-31.

Johnson, G. K. (2009, February 11). Football attendance continues to rise amid economic uncertainty: Records set for Division I and total attendance. NCAA News. Retrieved from http://www.ncaa.org/wps/portal/ncaahome

Johnson, R. B., \& Onwuegbuzie, A. J. (2004). Mixed methods research: A research paradigm whose time has come. Educational Researcher, 33(7), 14-26.

Kahle, L. R. (1983). (Ed.). Social values and social change: Adaptation to life in America. New York: Praeger. 
Kahle, L., Duncan, M., Dalakas, V., \& Aiken, D. (2001). The social values of fans for men's versus women's university basketball. Sport Marketing Quarterly, 10(2), 156-162.

Kahle, L. R., \& Homer, P. M. (1985). Physical attractiveness of the celebrity endorser: A social adaptation perspective. Journal of Consumer Research, 11(4), 954-961.

Kahle, L. R., Liu, R., \& Watkins, H. (1992). Psychographic variation across United States geographic regions. Advances in Consumer Research, 19, 346-352.

Kahle, L. R., Rose, G. M., \& Shoham, A. (1999). Findings of LOV throughout the world, and other evidence of cross-national consumer psychographics: Introduction. Journal of Euromarketing, 8(1/2), 1-13.

Kaplowitz, M. D., Hadlock, T. D., \& Levine, R. (2004). A comparison of web and mail survey response rates. Public Opinion Quarterly, 68(1), 94-101.

Katona, G. (1974). Psychology and consumer economics. Journal of Consumer Research, I(1), 1-8.

Kelley, S. W., \& Turley, L. W. (2001). Consumer perceptions of service quality attributes at sporting events. Journal of Business Research, 54(2), 161-166.

Keppel, G., \& Wickens, T. D. (2004). Design and analysis: A researchers' handbook (4th Ed.). Upper Saddle River, NJ: Pearson Education, Inc.

Kerstetter, D. L., \& Kovich, G. M. (1997). An involvement profile of Division I women's basketball spectators. Journal of Sport Management, 11(3), 234-249.

Kluckhorn, F. R., \& Strodtbeck, F. L. (1961). Variations in value orientations. Evanston, IL: Row, Peterson.

Ko, Y. J., \& Pastore, D. L. (2004). Current issues and conceptualizations of service quality in the recreation sport industry. Sport Marketing Quarterly, 13(2), 158166.

Kohls, L. R. (1981). Developing intercultural awareness. Washington, DC: Sietar Press.

Krejcie, R. V. (1970). Determining sample size for research activities. Educational and Psychological Measurement, 30(3), 607-610.

Kwon, H. H., Trail, G., \& James, J. D. (2007). The mediating role of perceived value: Team identification and purchase intention of team-licensed apparel. Journal of Sport Management, 21(4), 540-554. 
Lamb, C. W., Jr., Hair, J. F., Jr., \& McDaniel, C. (2004). In C. W. Lamb, Jr., J. F. Hair, Jr., \& C. McDaniel (Eds.). Marketing (7th ed.), (pp. 9-16). Mason, OH: SouthWestern.

Lancaster, G. A., Dodd, S., \& Williamson, P. R. (2004). Design and analysis of pilot studies: Recommendations for good practice. Journal of Evaluation in Clinical Practice, 10(2), 307-312.

Lages, L. F., \& Fernandes, J. C. (2005). The SERPVAL scale: A multi-items for measuring service personal values. Journal of Business Research, 58(11), 15621572 .

Lavarie, D. A., \& Arnett, D. B. (2000). Factors affecting fan attendance: The influence of identity salience and satisfaction. Journal of Leisure Research, 32(2), 225-246.

Lavidge, F. J., \& Steiner, G. A. (1961). A model for the predictive measurement of advertising effectiveness. Journal of Marketing, 25(6), 59-62.

Leidtka, J. (1989). Value congruence: The interplay of individual and organizational value systems. Journal of Business Ethics, 8(10), 805-815.

Leonard, J. M. (2005). The geography of visitor attendance at college football games. Journal of Sport Behavior, 28(3), 231-252.

Liberty University. (2008). Dissertation manual. Retrieved from http://www.liberty.edu/media/1118/CCFS\%20Dissertation\%20Manual\%20\%20F ebruary\%202008.pdf

Lovelock, C. (1991). Services marketing. Englewood Cliffs, NJ: Prentice Hall.

Lusk, E. J., \& Oliver, B. L. (1974). Research notes: American managers' personal value systems - Revisited. Academy of Management Journal, 17(3), 549-554.

Lutz, R. J. (1977). An experimental investigation of causal relations among cognitions, affect, and behavioral intention. Journal of Consumer Research, 3(4), 197-208.

Madrigal, R. (1995). Cognitive and affective determinants of fan satisfaction with sporting event attendance. Journal of Leisure Research, 27(3), 205-227.

Madrigal, R. (2000). The influence of social alliances with sports teams on intentions to purchase corporate sponsors' products. Journal of Advertising, 29(4), 13-24.

Madrigal, R. (2001). Social identity effects in a belief-attitude-intentions hierarchy: Implications for corporate sponsorship. Psychology \& Marketing, 18(2), 145-165. 
Madrigal, R., \& Kahle, L. R. (1994). Predicting vacation activity preferences on the basis of value-system segmentation. Journal of Travel Research, 32(3), 22-28.

Maslow, A. H. (1943). A theory of human motivation. Psychological Review, 50(4), 370 396.

Maslow, A. H. (1954). Motivation and personality. New York: Harper \& Row.

Maslow, A. H. (1959). (Ed.). New knowledge in human values. New York: Harper \& Row.

Maslow, A. H. (1968). (Ed.). Toward a psychology of being (2nd ed.). New York: Van Nostrand.

Matsuoka, H., Chelladurai, P., \& Harada, M. (2003). Direct and interaction effects of team identification and satisfaction on intention to attend games. Sport Marketing Quarterly, 12(4), 244-253.

McDonald, M. A., Sutton, W. A., \& Milne, G. R. (1995). TEAMQUAL ${ }^{\text {TM}}$ : Measuring service quality in professional team sports. Sport Marketing Quarterly, 4(2), 9-15.

Miller, L. E., \& Smith, K. (1983). Handling non-response issues. Journal of Extension, 21(5). Retrieved from http://www.joe.org/joe/1983september/83-5-a7.pdf

Mittal, V., Anderson, E. W., Sayrak, A., \& Tadikamalla, P. (2005). Dual emphasis and the long-term financial impact of customer satisfaction. Marketing Science, 24(4), 544-558.

Mullin, B., Hardy, S., \& Sutton, W. (2000). Sport marketing (2nd Ed.). Champaign, IL: Human Kinetics.

Murrell, A. J., \& Dietz, B. (1992) Fan support of sport teams: The effect of a common group identity. Journal of Sport \& Exercise Psychology, 14(1), 28-39.

NCAA. (2008). About the NCAA. Retrieved from http://www.ncaa.org/wps/portal/ncaahome?WCM_GLOBAL_CONTEXT=/ncaa/ ncaa/about+the+ncaa

NCAA. (2009). 2009 NCAA Division I FBS conference attendance. Retrieved from http://www.ncaa.org/wps/wcm/connect/94f3dd004181e04f987bd8734e8667f6/A wide_FB+ATT+lists.pdf?MOD=AJPERES\&CACHEID=94f3dd004181 e04f987b $\mathrm{d} 873 \overline{4} \mathrm{e} 8667 \mathrm{f} 6$ 
NCAA. (2010, February 22). 2009 NCAA college football attendance. The NCAA News. Retrieved from http://www.ncaa.org/wps/portal/ncaahome?WCM_GLOBAL_CONTEXT=/ncaa/ ncaa/ncaa+news/ncaa+news +online/2010/association-

wide $/ 2009+$ ncaa + division $+\mathrm{i}+\mathrm{fbs}+$ attendance + team + leaders_02_22_10_ncaa_new $S$

Nicosa, F. M. (1966). Consumer decision processes. Englewood Cliffs, NJ: Prentice Hall, Inc.

Nunnelly, J. C. (1970). Psychometric theory (2nd Ed.). New York, NY: McGraw Hill.

Oliver, R. L. (1980). A cognitive model of the antecedents and consequences of satisfaction decisions. Journal of Marketing Research, 17, 460-469.

Oliver, R. L. (1997). Satisfaction: A behavioral perspective on the consumer. New York, NY: McGraw-Hill Companies, Inc.

Pan, D. W., \& Baker, J. A. W. (2005). Factors, differential market effects, and marketing strategies in the renewal of season tickets for intercollegiate football games. Journal of Sport Behavior, 28(4), 351-377.

Parasuraman, A., Zeithaml, V. A., \& Berry, L. L. (1985). A conceptual model of service quality and its implications for future research. Journal of Marketing, 49(4), 4150.

Parsons, T., \& Shils, E. A. (Eds). (1951). Toward a general theory of action. Cambridge: Harvard University Press.

Pedhazur, E. J. (1997). Multiple regression in behavioral research: Explanation and prediction (3rd ed.). Belmont, CA: Wadsworth-Thompson Learning.

Price, D. I., \& Sen, K. C. (2003). The demand for game day attendance in college football: An analysis of the 1997 Division 1-A season. Managerial and Decision Economics, 24(1), 35-46.

Pullman, M. E., \& Gross, M. A. (2004). Ability of experience design elements to elicit emotions and loyalty behaviors. Decision Sciences, 35(3), 551-578.

Qualtrics, Inc. (2010). About Qualtrics. Retrieved from http://www.qualtrics.com/aboutqualtrics/

Quester, P., Beverland, M., \& Farrelly, F. (2006). Brand-personal values fit and brand meanings: Exploring the role individual values play in ongoing brand loyalty in extreme sports subcultures. Advances in Consumer Research, 33, 21-27. 
Radhakrishna, R., \& Doamekpor, P. (2008). Strategies for generalizing findings in survey research. Journal of Extension, 46(2). Retrieved from http://joe.org/joe/2008april/tt1.php

Ravald, A., \& Gronroos, C. (1996). The value concept and relationship marketing. European Journal of Marketing, 30(2), 19-30.

Reik, T. (1957). Of love and lust: On the psychoanalysis of romantic \& sexual emotions. New York, NY: Ferrar, Straus \& Cudahy.

Robinson, M. J., Trail, G. T., Dick, R. J., \& Gillentine, A. J. (2005). Fans vs. spectators: An analysis of those who attend intercollegiate football games. Sport Marketing Quarterly, 14(1), 43-53.

Rokeach, M. J. (1973). The nature of human values. New York, NY: The Free Press.

Rosenberg, M., \& McCullough, B. C. (1981). Mattering: Inferred significance and mental health among adolescents. Research in Community Mental Health, 2, 163-182.

Rudy, M. (2008, May 26). How healthy is our game? Business Week, p. 20.

Rutgers University, New Brunswick, The Rutgers Touchdown Club History/Tradition. (n.d.). Rutgers University - The birthplace of college football. Retrieved from http://www.touchdownclub.rutgers.edu/history.htm

Schlossberg, N. K. (1989). Marginality and mattering: Key issues in building community. New Directions for Student Services, 48, 5-15.

Schultz, D. P. (2004). A history of modern psychology. Belmont, CA: Wadsworth Thompson Press.

Schwartz, S. H. (1992). Universal in the content and structure of values: Theoretical advances and empirical tests in 20 countries. Advances in Experimental Social Psychology, 25, 1-65.

Schwartz, S. H. (1994). Are there universal aspects in the structure and contents of human values? Journal of Social Issues, 50(4), 19-45.

Schwartz, S. H., \& Bilsky, W. (1987). Toward a psychological structure of human values. Journal of Personality and Social Psychology, 53(3), 550-562.

Shao, Y. (2002). An exploratory examination of the impact of personal values on sport consumption preferences and behaviors: A cross-cultural study. Unpublished doctoral dissertation, The Ohio State University, Columbus. 
Siegfried, J. J., \& Burba, M. G. (2004). The College Football Association television broadcast cartel. Antitrust Bulletin, 49(3), 799-819.

Sirgy, M. J. (1982). Self-concept in consumer behavior: A critical review. Journal of Consumer Research, 9(3), 287-300.

Sloan, L. R. (1989). The motives of sports fans. In J.H. Goldstein (Ed.), Sports, games, and play: Social and psychological viewpoints (2nd ed.), (pp. 175-240). Hillsdale, NJ: Lawrence Erlbaum Associates.

Snyder, C. R., Higgins, R. L., \& Stucky, R. J. (1983). Excuses: Masquerades in search of grace. New York, NY: Wiley-Interscience.

Snyder, C. R., Lassegad, M. A., \& Ford C. E. (1986). Distancing after group success and failure: Basking in reflected glory and cutting off reflected failure. Journal of Personality and Social Psychology, 51(2), 382-388.

Solomon, M. R., Surprenant, C., Czepiel, J. A., \& Gutman, E. G. (1985). A role theory perspective on dynamic interactions: The service encounter. Journal of Marketing, 4I(1), 99-111.

Southall, R. M., Southall, C., \& Dwyer, B. (2009). 2009 Bowl Championship Series telecasts: Expressions of big-time college-sports' commercial institutional logics. Journal of Issues in Intercollegiate Athletics, 2, 150-176.

Stevens, J. P. (2002). Applied multivariate statistics for the social sciences (4th ed.). Mahwah, NJ: Lawrence Erlbaum Associates, Publishers.

Stewart, B., Smith, A. C. T., \& Nicholson, M. (2003). Sport consumer typologies: A critical review. Sport Marketing Quarterly, 12(4), 206-216.

Stigler, G. J. (1950). The development of utility theory. II. The Journal of Political Economy, 58(5), 373-396.

Sutton, W. A., McDonald, M. A., Milne, G. R., \& Cimperman, J. (1997). Creating and fostering fan identification in professional sports. Sport Marketing Quarterly, $6(1), 15-22$.

Tajfel, H. (1974). Social identity and intergroup behaviour. Social Science Information, 13(2), 65-93.

Tajfel, H. \& Turner, J. C. (1979). An integrative theory of intergroup conflict. In W. G. Austin \& S. Worchel (Eds.), The Social Psychology of Intergroup Relations (pp.33-48). Monterey, CA: Brooks-Cole. 
Theodorakis, N., Kambitsis, C., Laios, A., \& Koustelios, A. (2004). Relationship between measures of service quality and satisfaction of spectators in professional sports. Managing Service Quality, 11(6), 431-438.

Thieme, E. (2007). You can't win 'em all: How the NCAA's dominance of the college basketball postseason reveals there will never be an NCAA football playoff. Indiana Law Review, 40, 453-478.

Thomas, R. M. (2003). Blending qualitative \& quantitative research methods in theses and dissertations. Thousand Oaks, CA: Corwin Press, Inc.

Thuy, P. N., \& Hau, L. N. (2010). Service personal values and customer values: A study of banking services in a transitional economy. International Journal of Bank Marketing, 28(6), 465-478.

Trail, G. T., \& James, J. D. (2001). The motivation scale for sport consumption: Assessment of the scale's psychometric properties. Journal of Sport Behavior, 24(1), 108-127.

Trail, G., Anderson, D. F., \& Fink, J. (2000). A theoretical model of sport spectator consumption behavior. International Journal of Sport Management, 1, 154-180.

Trail, G., Anderson, D. F., \& Fink, J. (2005). Consumer satisfaction and identity theory: A model of sport spectator conative loyalty. Sport Marketing Quarterly, 14(2), 98-111.

Trail, G. T., Fink, J. S., \& Anderson, D. F. (2003). Sport spectator consumption behavior. Sport Marketing Quarterly, 12(1), 8-17.

Trail, G. T., Robinson, M. J., Dick, R. J., \& Gillentine, A. J. (2003). Motives and points of attachment: Fans versus spectators in intercollegiate athletics. Sport Marketing Quarterly, 12(4), 217-227.

University of Georgia. (2010). 2010 football ticket information. Retrieved from http://www.georgiadogs.com/tickets/geo-m-footbl-tix.html

University of Florida. (2010). 2010 football season ticket information. Retrieved from http://www.gatorzone.com/tickets/pdf/footb2010_season.pdf

University of Miami. (2010). 2010 football season and club ticket pricing. Retrieved from http://grfx.cstv.com/photos/schools/mifl/sports/footbltickets/auto_pdf/Football_Season_Pricing.pdf 
U.S. Census Bureau. (2011). 2005-2009 American Community Survey 5-Year Estimates. Retrieved from

http://factfinder.census.gov/servlet/ACSSAFFFacts? event $=\&$ geo_id $=01000$ US \& geoContext $=01000 \mathrm{US} \&$ \&street $=\&$ \&count $y=\&$ \&ityTown $=\&$ \&state $=\&$ \&ip $=\&$ \&lan $\overline{\mathrm{g}}=$ en\&_sse $=$ on \&ActiveGeoDiv $=\& \_$useEV $=\& \mathrm{pctxt}=$ fph\&pgsi $=010 \&$ submenu $\overline{\text { sud }}$ $=$ factsheet_1\&ds_name $=$ DEC_2000_SAFF\&_ci_nbr=null\&qr_name $=$ null \&reg $=$ \&_keyword $=$ \&_industry $=$

U.S. Census Form. (2010). The questions on the form - 2010 Census. Retrieved from http://2010.census.gov/2010census/how/interactive-form.php

Van Leeuwen, L., Quick, S., \& Daniel, K. (2002). The sport spectator satisfaction model: A conceptual framework for understanding the satisfaction of spectators. Sport Management Review, 5, 99-128.

Van Teijlingen, E. R., \& Hundley, V. (2001). The importance of pilot studies. Social Research Update, 35. Retrieved from http://sru.soc.surrey.ac.uk/SRU35.pdf

Vinson, D. E., Scott, J. E., \& Lamont, L. M. (1977). The role of personal values on marketing and consumer behavior. Journal of Marketing, 4l(2), 44-50.

Wagenheim, G. D., \& Reurink, J. H. (1991). Customer service in public administration. Public Administration Review, 51(3), 263-270.

Wakefield, K. L., \& Blodgett, J. G. (1996). The effect of the servicescape on customers' behavioral intentions in leisure service settings. The Journal of Services Marketing, 10(6), 45-61.

Wang, Z., Rao, C. P., \& D'Auria, A. (1994). A comparison of the Rokeach Value Survey (RVS) in China and the United States. Asia Pacific Advances in Consumer Research, 1, 185-190.

Wann, D. L. (1996). Seasonal changes in spectators' identification and involvement with and evaluations of college basketball and football teams. The Psychological Record, 46(1), 201-215.

Wann, D. L., \& Branscombe, N. R. (1990). Die-hard and fair-weather fans: Effects of identification on BIRGing and CORFing tendencies. Journal of Sport and Social Issues, 14(2), 103-117.

Wann, D. L., \& Branscombe, N. R. (1993). Sports fans: Measuring degree of identification with their team. International Journal of Sport Psychology, 24(1), $1-17$. 
Wann, D., \& Grieve, F. G. (2005). Biased evaluations of ingroup and outgroup spectator behavior at sporting events: The importance of team identification and threats to social identity. Journal of Social Psychology, 140, 531-545.

Westerbeek, H. M., \& Shilbury, D. (2003). A conceptual model for sport services marketing research: Integrating quality, value and satisfaction. International Journal of Sports Marketing \& Sponsorship, 5(1), 11-31.

Whitely, W., \& England, G. (1980). Variability in common dimensions of managerial values due to value orientation and country differences. Personnel Psychology, $33(1), 77-89$.

Wilson, M. S. (2005). A social-value analysis to postmaterialism. The Journal of Social Psychology, 145(2), 209-224.

Woo, B., Trail, G. T., Kwon, H. H., \& Anderson, D. (2009). Testing models of motives and points of attachment among spectators in college football. Sport Marketing Quarterly, 18(1), 38-53.

Young, P. L. (2001). Items related to the intercollegiate athletic ticket purchasing behavior or and former football season ticket holders: Implication for institutional market planning. Unpublished Ph.D. dissertation, The University of Miami.

Young, S., \& Feigin, B. (1975). Using the benefit chain for improved strategy formulation. Journal of Marketing, 39(3), 72-74.

Zaretsky, E. (Ed.). (1996). The Polish peasant in Europe and America: A classic work in immigration history. Urbana, IL: University of Illinois Press.

Zeithaml, V. A. (1988). Consumer perceptions of price, quality, and value: A means-end model and synthesis of evidence. Journal of Marketing, 52(3), 2-22.

Zeithaml, V. A., Berry, L. L., \& Parasuraman, A. (1996). The behavioral consequences of service quality. Journal of Marketing, 60(2), 31-46.

Zikmund, W. G. (2003). Business research methods (7th ed.). Mason, OH: Thompson Southwestern.

Znidar, M. (2007). Running on empty. Retrieved from http://www.dispatch.com/live/content/sports/stories/2007/05/03/ou_track.ART_A RT 05-03-07_C1_JV6IUI9.html 
Appendix A

IRB Informed Consent Preamble

For IRB Approval Stamp

\section{EXAMINING THE MODERATING EFFECT OF TEAM IDENTIFICATION ON THE RELATIONSHIP BETWEEN COLLEGE FOOTBALL SEASON TICKET HOLDERS' SERVICE PERSONAL VALUES AND THEIR BEHAVIORAL INTENTIONS}

December 25, 2010

Dear Participants:

You are being invited to participate in a research study by answering the attached survey about you demographic profile, service personal values, team identification, consumption satisfaction perceptions, and behavioral intentions. There are no known risks for your participation in this research study. The information collected may or may not benefit you directly. However, the information learned this study may be helpful to others. The information you provide will help sport organizations wishing for serving college football consumers better. Your completed survey will be stored at the University of Louisville, KY. The survey will take approximately 10-15 minutes to complete.

Individuals from the University of Louisville's Department of Sport Administration, the Institutional Review Board (IRB), the Human Subjects Protection Program Office (HSPPO), and other regulatory agencies may inspect these records. In all other respects, however, the data will be held in confidence to the extent permitted by law. Should the data be published, your identity will not be disclosed.

Taking part in this study is voluntary. By completing this survey you agree to take part in this study. You do not have to answer any questions that make you uncomfortable. You may choose not to take part at all. If you decide to be in this study, you may stop taking part at any time. If you decide not to be in this study or if you stop taking part at any time, you will not lose any benefits for which you may qualify. 
If you have any questions, concerns, or complaints about the research study, please contact the researchers Gary Tan at (305) 348-3983 or Dr. Chris Greenwell at (502) 852-0555.

If you have any questions about your rights as a research subject, you may call the Human Subjects Protection Office at (502) 852-5188. You can discuss any questions about your rights as a research subject, in private, with a member of the Institutional Review Board (IRB). You may also call this number if you have other questions about the research, and you cannot reach the research staff, or want to talk to someone else. The IRB is an independent committee made up of people from the University community, staff of the institutions, as well as people from the community not connected with these institutions. The IRB has reviewed this research study.

If you have concerns or complaints about the research or research staff and you do not wish to give your name, you may call 1-877-852-1167. This is a 24 hour hot line answered by people who do not work at the University of Louisville.

Sincerely,

Chris Greenwell, PhD

Principal Investigator

Associate Professor

University of Louisville
Gary Tan

Co-Investigator

Doctoral Candidate

University of Louisville 


\section{Appendix B}

\section{Original Survey Instrument}

Please answer EACH of the following questions about your college football season ticket purchase using the scale below:

Part 1: Service Personal Values

The use of college football season tickets helps me achieve:

\begin{tabular}{|c|c|c|c|c|c|c|c|}
\hline \multirow[b]{2}{*}{ 1. more harmony in life. } & \multicolumn{2}{|c|}{$\begin{array}{l}\text { Strongly } \\
\text { Disagree }\end{array}$} & \multicolumn{3}{|c|}{$\begin{array}{l}\text { Neither Disagree } \\
\text { Nor Agree }\end{array}$} & & $\begin{array}{l}\text { Strongly } \\
\text { Agree }\end{array}$ \\
\hline & 1 & 2 & 3 & 4 & 5 & 6 & 7 \\
\hline 2. more self respect in life & 1 & 2 & 3 & 4 & 5 & 6 & 7 \\
\hline 3. more family security. & 1 & 2 & 3 & 4 & 5 & 6 & 7 \\
\hline 4. more balance in life. & 1 & 2 & 3 & 4 & 5 & 6 & 7 \\
\hline 5. more enjoyable life. & 1 & 2 & 3 & 4 & 5 & 6 & 7 \\
\hline 6. more sense of accomplishment in life & 1 & 2 & 3 & 4 & 5 & 6 & 7 \\
\hline 7. more respect from others. & 1 & 2 & 3 & 4 & 5 & 6 & 7 \\
\hline 8. the feeling that the world is more pleasant. & 1 & 2 & 3 & 4 & 5 & 6 & 7 \\
\hline more social recognition. & 1 & 2 & 3 & 4 & 5 & 6 & 7 \\
\hline 10. a higher social status. & 1 & 2 & 3 & 4 & 5 & 6 & 7 \\
\hline 11. a more stimulating and adventurous life. & 1 & 2 & 3 & 4 & 5 & 6 & 7 \\
\hline 12. a higher acceptance in my group. & 1 & 2 & 3 & 4 & 5 & 6 & 7 \\
\hline $\begin{array}{l}\text { 13. better relationships with friends, } \\
\text { co-workers, and family members. }\end{array}$ & 1 & 2 & 3 & 4 & 5 & 6 & 7 \\
\hline 14. better friendship with others. & 1 & 2 & 3 & 4 & 5 & 6 & 7 \\
\hline
\end{tabular}

Part 2: Team Identification

\begin{tabular}{|c|c|c|c|c|c|c|c|}
\hline \multirow[b]{2}{*}{$\begin{array}{l}5.1 \text { think of myself as a "real" fan of the } \\
\text { college football team. }\end{array}$} & \multicolumn{2}{|l|}{$\begin{array}{l}\text { Strongly } \\
\text { Disagree }\end{array}$} & \multicolumn{3}{|c|}{$\begin{array}{l}\text { Neither Disagree } \\
\text { Nor Agree }\end{array}$} & & $\begin{array}{l}\text { Strongly } \\
\text { Agree }\end{array}$ \\
\hline & 1 & 2 & 3 & 4 & 5 & 6 & 7 \\
\hline $\begin{array}{l}\text { 6. I would experience a loss if I had to stop being } \\
\text { a fan of the college football team }\end{array}$ & 1 & 2 & 3 & 4 & 5 & 6 & 7 \\
\hline
\end{tabular}


Part 2: Team Identification (continued)

\begin{tabular}{|c|c|c|c|c|c|c|c|}
\hline \multirow[b]{2}{*}{$\begin{array}{l}\text { 17. Being a fan of the college football team } \\
\text { is very important to me. }\end{array}$} & \multicolumn{2}{|l|}{$\begin{array}{l}\text { Strongly } \\
\text { Disagree }\end{array}$} & \multicolumn{3}{|c|}{$\begin{array}{l}\text { Neither Disagree } \\
\text { Nor Agree }\end{array}$} & \multicolumn{2}{|c|}{$\begin{array}{l}\text { Strongly } \\
\text { Agree }\end{array}$} \\
\hline & 1 & 2 & 3 & 4 & 5 & 6 & 7 \\
\hline \multicolumn{8}{|l|}{ Part 3: Customer Satisfaction } \\
\hline & \multicolumn{2}{|c|}{$\begin{array}{l}\text { Strongly } \\
\text { Disagree }\end{array}$} & \multicolumn{3}{|c|}{$\begin{array}{l}\text { Neither Disagree } \\
\text { Nor Agree }\end{array}$} & & $\begin{array}{l}\text { Strongly } \\
\text { Agree }\end{array}$ \\
\hline $\begin{array}{l}\text { 18. I am satisfied with my decision to } \\
\text { purchase college football } \\
\text { season tickets. }\end{array}$ & 1 & 2 & 3 & 4 & 5 & 6 & 7 \\
\hline $\begin{array}{l}\text { 19. I think that I did the right thing by } \\
\text { purchasing college football } \\
\text { season tickets. }\end{array}$ & 1 & 2 & 3 & 4 & 5 & 6 & 7 \\
\hline $\begin{array}{l}\text { 20. I am not happy that I purchased } \\
\text { college football season tickets }\end{array}$ & 1 & 2 & 3 & 4 & 5 & 6 & 7 \\
\hline \multicolumn{8}{|l|}{ Part 4: Consumer Behavioral Intentions } \\
\hline $\begin{aligned} & \text { Strong } \\
& \text { Disagr }\end{aligned}$ & $\begin{array}{l}\text { Strongly } \\
\text { Disagree }\end{array}$ & & \multicolumn{3}{|c|}{$\begin{array}{l}\text { Neither Disagree } \\
\text { Nor Agree }\end{array}$} & & $\begin{array}{l}\text { Strongly } \\
\text { Agree }\end{array}$ \\
\hline $\begin{array}{l}\text { 21. I plan to renew my college football } \\
\text { season tickets next year }\end{array}$ & 1 & 2 & 3 & 4 & 5 & 6 & 7 \\
\hline $\begin{array}{l}\text { 22. I will recommend my family members } \\
\text { and friends to purchase college } \\
\text { football season tickets. }\end{array}$ & 1 & 2 & 3 & 4 & 5 & 6 & 7 \\
\hline $\begin{array}{l}\text { 23. I would like to share my college } \\
\text { football attendance experience } \\
\text { with others }\end{array}$ & 1 & 2 & 3 & 4 & 5 & 6 & 7 \\
\hline $\begin{array}{l}\text { 24. I plan to purchase more college } \\
\text { football season tickets next year. }\end{array}$ & 1 & 2 & 3 & 4 & 5 & 6 & 7 \\
\hline
\end{tabular}

Please fill in the blank or check the appropriate box.

Part 5: Demographics Questions

25. How many people living in your house, apartment, or mobile home?

26. Gender (please check one):

(a) Male

(b) Female 
Please fill in the blank or check the appropriate box.

Part 5: Demographics Questions (continued)

27. Age - years old (please check one):

(a) Under 20

(b) Aged 20-34

(c) Aged 35-49

(d) Aged 50-64

(e) Aged 65 or older

28. What is your affiliation with the university?
(a) Student
(b) Alumni
(c) Employee of the University
(d) University Booster Club Member

29. How many years have you been college football season ticket holder?

30. Ethnicity (please check one):

31. Annual household income (please check one):
(a) Hispanic/Latino/Spanish Origin
(b) White
(c) Black/African American
(d) American Indian/Alaska Native
(e) Asian or Pacific Islander
(f) Others (please list)

(a) Less than US $\$ 20,000$

(b) US $\$ 20,000$ to $\$ 39,999$

(c) US $\$ 40,000$ to $\$ 59,999$

(d) US $\$ 60,000$ to $\$ 79.999$

(e) US $\$ 80,000$ to $\$ 99,999$

(f) More than $\$ 100,000$ 
Appendix C

Field Test Evaluation Form

March 1, 2011

We are conducting a study on college football season ticket holders' consumer behavior. Specifically, we are interested in the moderating impact of college football season ticket holders' team identification on the relationship between service personal values, and both consumption satisfaction perceptions and behavioral intentions. A better understanding of college football season ticket holders' service personal values and team identification level will contribute toward better understanding of college football season ticket holders' consumption behavior pattern and, hopefully, sport marketers can use college football season ticket holders' consumption behavior to formulate effective marketing strategies.

The purpose of this study is to assess college football season ticket holders' perceptions towards consumption satisfaction and behavioral intentions, and assess their service personal values and team identification level. In addition, this study is designed to investigate whether team identification level moderates the relationship between college football season ticket holders' service personal values and consumption behavior.

Your assistance is requested in helping to establish validity for this study by simply completing the enclosed questionnaire and comment form. Your participation is entirely voluntary. You may refuse to answer questions and may withdraw from completing the questionnaire at any time. You may be assured of complete confidentiality. The questionnaires will not be made available to anyone outside this study. Do NOT include your name or identification number on the survey instrument. Individual responses will not be identified or reported. Any discussion of results will be based on group data. It is estimated that the questionnaire will take 10-15 minutes to complete. Upon completion, return the questionnaire to the person who asked you to fill it out.

Feel free to contact us if you have any questions or concerns.

Sincerely,

T. Chris Greenwell

Principal Investigator

University of Louisville
Gary Tan

Key Personnel

University of Louisville 


\section{EXAMINING THE RELATIONSHIP BETWEEN COLLEGE FOOTBALL SEASON TICKET HOLDERS' SERVICE PERSONAL VALUES AND THEIR BEHAVIORAL INTENTIONS: THE MODERATING EFFECT OF TEAM IDENTIFICATION}

\section{COMMENT FORM}

Please read the enclosed survey and respond to the following statements in the space provided. Feel free to also write directly on the questionnaire. Any suggestions for improvement will be appreciated.

The purposes of this survey are to: (a) assess perceptions of student-athletes toward their conference code of ethics; (b) assess student-athletes' knowledge and understanding of their respective codes of ethics; and (c) collect demographic background information.

1. Given the purpose of this survey, do you think the questions on the survey collect the information needed? Why or why not?

2. Is the phrasing and terminology clear and easy to understand?

3. Are the directions easy to follow?

4. Is the survey attractive and neat? 
5. (a) Is the survey too long to be comfortably completed in one sitting?

(b) Approximately how long would it take you to complete it?

6. Is there any important background information that may be missing?

7. Are there any statements or categories that should be added or deleted? If so, please explain.

8. Please include any other comments relevant to the improvement of this survey.

Thank you very much for your time and assistance. 


\section{Appendix D}

\section{Modified Survey Instrument}

Please answer each of the following questions about your college football season ticket purchase using the scale below:

Part 1: Team Identification

\begin{tabular}{|c|c|c|c|c|c|c|c|}
\hline & $\begin{array}{l}\text { Strongly } \\
\text { Disagree }\end{array}$ & & \multicolumn{3}{|c|}{$\begin{array}{c}\text { Neither Disagree } \\
\text { Nor Agree }\end{array}$} & & $\begin{array}{c}\text { Strongly } \\
\text { Agree }\end{array}$ \\
\hline $\begin{array}{l}\text { 1. I think of myself as a "real" fan of the } \\
\text { college football team. }\end{array}$ & 1 & 2 & 3 & 4 & 5 & 6 & 7 \\
\hline $\begin{array}{l}\text { I would experience a loss if I had to stop being } \\
\text { a fan of the college football team }\end{array}$ & 1 & 2 & 3 & 4 & 5 & 6 & 7 \\
\hline $\begin{array}{l}\text { Being a fan of the college football team } \\
\text { is very important to me. }\end{array}$ & 1 & 2 & 3 & 4 & 5 & 6 & 7 \\
\hline
\end{tabular}

Part2: Customer Satisfaction

$$
\text { Strongly }
$$$$
\text { Neither Disagree }
$$$$
\text { Nor Agree }
$$

Strongly Agree

$\begin{aligned} & \text { 4. I am satisfied with my decision to } \\ & \text { purchase college football } \\ & \text { season tickets. }\end{aligned}$
$\begin{aligned} & \text { 5. I think that I did the right thing by } \\ & \begin{array}{c}\text { purchasing college football } \\ \text { season tickets. }\end{array}\end{aligned}$
$\begin{aligned} & \text { f } \\ & \text { 6. I am not happy that I purchased } \\ & \text { college football season tickets }\end{aligned}$

Part 3: Consumer Behavioral Intentions

Strongly

Disagree

7. I plan to renew my college football season tickets next year

8. I will recommend my family members and friends to purchase college football season tickets.

\section{Neither Disagree \\ Nor Agree}

Strongly Agree

$\begin{array}{llllllll}1 & 2 & 3 & 4 & 5 & 6 & 7\end{array}$

1

2

3

4

5

6

7 
Part 3: Consumer Behavioral Intentions (Continued)

Strongly

Disagree
Neither Disagree

Nor Agree

2

9. I would like to share my college football 1 game spectating experience with others

10. I plan to purchase more college football 1 season tickets next year.

\section{Part 4: Service Personal Values}

The use of college football season tickets helps me achieve:

\begin{tabular}{|c|c|c|c|c|c|c|c|}
\hline & \multicolumn{2}{|c|}{$\begin{array}{l}\text { Strongly } \\
\text { Disagree }\end{array}$} & \multicolumn{3}{|c|}{$\begin{array}{c}\text { Neither Disagree } \\
\text { Nor Agree }\end{array}$} & & $\begin{array}{l}\text { Strongly } \\
\text { Agree }\end{array}$ \\
\hline 1. more balance in life. & 1 & 2 & 3 & 4 & 5 & 6 & 7 \\
\hline 12. more enjoyable life. & 1 & 2 & 3 & 4 & 5 & 6 & 7 \\
\hline 3. more sense of accomplishment in life. & 1 & 2 & 3 & 4 & 5 & 6 & 7 \\
\hline 14. more respect from others. & 1 & 2 & 3 & 4 & 5 & 6 & 7 \\
\hline 5. more social recognition. & 1 & 2 & 3 & 4 & 5 & 6 & 7 \\
\hline 16. a more stimulating and adventurous life. & 1 & 2 & 3 & 4 & 5 & 6 & 7 \\
\hline 17. a higher acceptance in my social group. & 1 & 2 & 3 & 4 & 5 & 6 & 7 \\
\hline $\begin{array}{l}\text { 18. better relationships with friends, } \\
\text { co-workers, and family members. }\end{array}$ & 1 & 2 & 3 & 4 & 5 & 6 & 7 \\
\hline 19. better friendship with others. & 1 & 2 & 3 & 4 & 5 & 6 & 7 \\
\hline
\end{tabular}

Please fill in the blank or check the appropriate box.

Part 5: Demographics Questions

20. How many people living in your household?

21. Gender (please check one):

(a) Male

(b) Female

22. What is your affiliation with the university? (please check all that applies)
Strongly

Agree

7

7 (a) Student

(b) Alumni

(c) Employee of the University

(d) University Booster Club Member

(e) Others (please list) 
Please fill in the blank or check the appropriate box.

Part 5: Demographics Questions (continued)

24. Ethnicity (please check all that applies):

(a) Hispanic/Latino/Spanish Origin

(b) White

(c) Black/African American

(d) American Indian/Alaska Native

(e) Asian or Pacific Islander

(f) Others (please list)

25. Annual household income (please check one):
(a) Less than $\$ 20,000$
(b) $\$ 20,000$ to $\$ 39,999$
(c) $\$ 40,000$ to $\$ 59,999$
(d) $\$ 60,000$ to $\$ 79.999$
(e) $\$ 80,000$ to $\$ 99,999$
(f) More than $\$ 100,000$ 


\section{CURRICULUM VITAE}

\section{G A R Y P E N G - L I A N G T A N \\ $10750 \mathrm{SW} 11$ th St, H101, Miami FL 33174 \\ (502) 445-2684 • gtan(a)fiu.edu}

\section{EDUCATION}

University of Louisville

Ph.D. in Educational Leadership and Organizational Development

Projected May, 2011

Central Michigan University

December, 2006

M.S. in Administration

Central Michigan University

May, 2003

M. A. in Economics

Central Michigan University

B.S. in Business Administration (Economics major and Finance minor)

August, 2001

\section{PROFESSIONAL EXPERIENCE}

Florida International University, Housing \& Residential Life, Miami FL

Residence Life Coordinator, University Park Apartments

2009 - Present

- Supervising daily operations of ten apartment buildings with more than 535 residents (i.e., ranging from freshmen to upperclassmen, transfer students, and graduate students)

- Supervising a Senior Secretary, a graduate Assistant Residence Life Coordinator, ten Resident Assistants, and four maintenance and custodial personnel.

- Serving as Residential Life Office hearing officer - conducting student conduct information session, administrative hearing, and case outcomes meeting

- Creating and implementing Resident Assistant training materials and initiatives

- Participating in assessment and student services planning of the residential housing program

- Managing programming and office supplies budget in excess of $\$ 6500$ per academic year.

University of Louisville, Housing \& Residence Life, Louisville KY

Graduate Residence Life Coordinator - Apartments

- Synchronized the daily operations of two apartment buildings (i.e., MDA \& UTA) with 170 apartments (housing 300 upperclassmen, graduate students, married, and professional students)

- Responded to crisis situations and performing on-call rotation duties

- Communicated organization mission statement and expectations to supervisees and residents

- Coordinated short term housing assignment for medical rotation students and university guests 
- Planned and monitored community and staff development budget

- Recruited, trained, supervised, and evaluated seven Assistant Apartment Managers and 20 desk assistants and initiating customer service programs for apartment residents

University of Louisville, Housing \& Residence Life, Louisville KY

Graduate Apartment Manager, Medical-Dental Apartments (MDA) 2007 - 2008

- Enforced university and housing office policies, holding formal student conduct, decision making workshops, and conflict mediation meetings with residents and supervisees

- Designed and implemented community and staff development programs

- Directed building transition (from residence hall to departmental offices) project

- Counseled residents and supervisees on issues related to personal and professional development

- Resolved building maintenance problems with physical plant office

- Selected, trained, and managed two Assistant Apartment Managers and eight Desk Assistants and conducted resident assistant/assistant apartment manager training and evaluation

VG Racing Research, Inc., Los Angeles CA

Assistant Director for Marketing Services

$2003-2004$

- Conducted SWOT analysis for new performance auto products

- Served as primary contact person for international business division

- Positioned and priced more than 200 new performance auto parts and generated total sales of $\$ 2.2$ million during tenure

- Instigated three major customer satisfaction initiatives

- Recruited and trained more than 50 new sales representatives and supervised staff members of four sales managers and 25 sales representatives

- Developed, administered, and analyzed staff job satisfaction survey.

\section{PARAPROFESSIONAL EXPERIENCE}

Professional Golf Association (PGA), Ryder Cup, Louisville KY

Corporate Hospitality Intern

- Served as primary liaison between corporate client and the PGA, caterer, transportation provider, and other vendors

- Resolved corporate event planner customer service concerns and ensured all corporate guests have the ultimate Ryder Cup experience

- Provided operational support for PGA corporate hospitality professional staff during and following the event

- Organized and maintained various Business Centers operations

University of Louisville, Housing and Residence Life Office, Louisville KY Summer Conference Graduate Intern

Summer 2008

- Monitored summer conference expenses account

- Organized summer conference assistant resume workshop

- Handled summer conference guests' internet access accounts

- Gathered and examined summer conference assistants' training satisfaction data 
Central Michigan University, Housing and Residence Life Office, Mount Pleasant MI Computer Center and Front Desk Operations Manager $2001-2003$

- Recruited, trained, scheduled, and evaluated computer center and front desk assistants

- Processed computer center and front desk staff payroll documents

- Generated semester computer center utilization report

\section{PROFESSIONAL DEVELOPMENT AND COMMIT'TEE INVOLVEMENT}

Florida International University, Division of Student Affairs

Participant - New Professional Group

- Attended monthly two-hour meeting (i.e., from Fall 2010 to Spring 2011) discussing topics related to new professional within the Division of Student Affairs

- Developed professional networking with other new professionals within the Division of Student Affairs

- Participated in the common reading (i.e., "Beginning your journey: A guide for new professionals in Student Affairs" by Amey and Rissor, 2009) discussion

- Shadowed Counseling and Psychological Services Budget Manager and Associate Director of Housing Office to learn about departmental budgeting process

Southeastern Association of Housing Officers, Regional Entry Level Institute

Participant

Summer 2010

- Selected as one of the thirty two members to participate in Southeastern Association of Housing Officers' (SEAHO) $7^{\text {th }}$ Regional Entry Level Institute (RELI)

- Participated in intensive training sessions on topics related to supervision, personal and professional balance, risk management, professional development, mentoring, budgeting, facilities management, and professional ethics.

- Engaged in one-on-one professional career planning discussion with faculty member, Dr. Ralphel Smith.

- Read the common reading (i.e., "Grown-Up Leadership" by Bailey and Bailey, 2005) and involved in group discussion.

\section{Association of College and University Housing Officers - International}

Member - Research Committee

Summer 2010 - Present

- Provided insights, guidance, and expertise in the formulation and implementation of the Association of College and University Housing Officers - International (ACUHO-I) research strategy

- Formulated research proposals related university housing customer service initiatives and residents retention analysis

- Acted as liaison between Research Committee and researcher, providing constructive feedback for research proposals submitted to the Research Committee

- Identified critical issues and research opportunities in university housing 


\section{PROFESSIONAL DEVELOPMENT AND COMMITTEE INVOLVEMENT (continued)}

University of Louisville, College of Education and Human Development

Participant - Future Faculty Program

Fall 2007 - Spring 2008

- Attended monthly (i.e., from Fall 2008 to Spring 2009) three-hour meeting discussing topics related to new faculty in the field of education

- Developed personal curriculum vitae, research interests statement, and teaching philosophy

- Shadowed Dr. Mary Hums in International Sports (SPAD 661) and served as guest lecturer on the topic "Sports in Malaysia"

- Created professional service plan collectively with faculty mentor, Dr. Mary Hums

\section{CONFERENCE PRESENTATIONS}

Schwarz, A., \& Tan, G. P. (2011, February). The multi-stage resident assistant centered re-hiring process. Presented at the Southeastern Association of Housing Officers annual meeting, Mobile, AL.

Tan, G. P. (2011, February). Assessing the relationship between student housing needs and demographic profiles. Presented at the Southeastern Association of Housing Officers annual meeting, Mobile, AL.

Weaver-Douglas, J. M.., et al. (2011, February). RELIve the experience: Exploring SEAHO's premier entry level institute. Presented at the Southeastern Association of Housing Officers annual meeting, Mobile, AL.

Smith, S. J., \& Tan, G. P. (2006, June). Examining the labor market for sport management doctoral faculty (2000 - 2004) from the labor economics perspective. Presented at the North America Society for Sport Management annual meeting, Kansas City, MO.

Thompson, P. B., Tan, G. P., \& Olorunshola, O. (2005, March). The connection between crude oil, refinery, wholesale, and Midwest retail gasoline price, 1997 - 2004. Presented at the Midwest Economic Association annual meeting, Milwaukee, WI 
Florida International University, Undergraduate Education

Lecturer - First-Year Experience Seminar (SLS 1501)

- Created course syllabus and course grading system

- Conducted student-centered lecture sessions and facilitated common reading discussion

- Collaborated with other Student Affairs departments exposing students to university services

- Developed assessment tools to measure students' knowledge regarding university resources

Florida International University, Undergraduate Education $\quad$ Spring 2010 - Present

Instructor - Resident Assistant (RA) Class

- Developed teaching plan for $20 \mathrm{RA}$ candidates

- Discussed issues (e.g., related to RA positions, multicultural competency, globalization awareness)

- Created assessment scale for participants' class involvement

- Provided constructive feedback for the participants

University of Louisville, Sport Administration Program

Summer 2009

Guest Lecturer - Sport Marketing (SPAD 683)

- Developed teaching plan for topic related sport customer service.

- Engaged students in discussion on issues related to sport consumer behavior

- Advised students on questions related to final exam and invigilated the course final exam

- Provided feedback on students' class projects discussion

University of Louisville, Educational Leadership Program

Guest Lecturer - Principles of Sport Administration (SPAD 281) Spring 2009

- Developed lecture plan for issues related to sport economics

- Facilitated discussion among students on issues surrounding professional sport economics

- Created quiz to assess students understanding of sport economics

- Responded to students questions related to the relationship between sport marketing and sport economics

University of Louisville, Educational Leadership Program

Invited Lecturer - Advanced Organizational Theory (ELFH 715) Spring 2008

- Planned lecture session for issues related to organization power and politics

- Mediated doctoral students discussion on issues related to organization power distribution

- Discussed issues related departmental expectations for doctoral students

- Tutored doctoral students on subjects related to comprehensive exams and dissertations 


\section{UNIVERSITY AND DEPARTMENTAL COMMITTEE INVOLVEMENT}

Florida International University, Housing and Residential Life Office

Chair - Diversity Committee (Different Individual Valuing Equality)

Fall 2010

- Created resources (e.g., articles, packaged programs, bulletin boards, internet resources, contacts for campus resources, etc.) on various aspects of diversity

- Assisted in developing training activities that address specific populations as well as general diversity training

- Served as resources for other staff members when developing diversity programs

Florida International University, Housing and Residential Life Office

Member - Resident Assistant (RA) Selection Committee

Fall 2010

- Planned the timeline for current and new RA selection process (i.e., information session, tabling, RA class materials, and interview process)

- Developed the RA job descriptions

- Created RA class participants feedback form

Florida International University, Housing and Residential Life Office Member - Professional Staff Training Committee

Summer 2010

- Planned training sessions for Residence Life Coordinator (RLC) and graduate Assistant Residence Life Coordinator (i.e., Professional Staff)

- Developed Professional Staff training feedback form

- Analyzed Professional Staff training feedback and generated suggestions for future training

Florida International University, Housing and Residential Life Office Member - RA Performance Discussion Committee Summer 2010

- Transformed RA performance appraisal into RA performance discussion following Human Resource Office guidelines

- Created performance discussion topics based on RA job description

- Facilitated the focus group discussion with returning RAs

Florida International University, Housing and Residential Life Office

Member - Residence Life Coordinator (RLC) Search Committee

- Reviewed all the application files and made recommendations of candidates eligible for phone interviews to Director of Residential Life

- Conducted phone interviews with selected RLC candidates

- Served as host for the RLC candidates who are invited for on-campus interviews 


\section{UNIVERSITY AND DEPARTMENTAL COMMITTEE INVOLVEMENT (continued)}

Florida International University, Housing and Residential Life Office

Member - RA Training Committee

Spring 2010

- Planned the overall training session for 72 RAs (e.g., training topics, schedules, collaboration with topic experts on campus, and meals)

- Created the two-days training modules for new RAs (i.e., Camp RA)

- Developed the in-hall training guidelines for the professional residential life staff

Florida International University, Housing and Residential Life Office

Delegate Advisor - Florida RA Seminar (FRAS)

Spring 2010

- Lead a group of 10 RAs to FRAS and created the staff roll-call program

- Participated in the advisor training sessions

- Monitored RAs well-being during the seminar at Pensacola, FL

Florida International University, Housing and Residential Life Office

Member - On-Campus Housing Student Services Assessment

Fall 2009

- Developed the survey questionnaire to assess student services satisfaction

- Implemented the survey questionnaire using online survey software (i.e., Qualtrics)

- Analyzed the survey results and proposed service improvement initiatives to the Housing and Residential Life Office senior staff

University of Louisville, Housing and Residential Life Office

Member - Departmental Budget Planning Committee

Fall 2008

- Reviewed the department's $\$ 8$ million budget and suggested areas for budget improvement

- Developed the hall improvement plan (i.e., $\$ 1000$ is provided to each residential hall or apartment complex)

- Formulated the 2009/2010 academic year budget and prepared a proposal for Director of Housing presenting to the Resident Student Association

University of Louisville, Housing and Residential Life Office

Member - RA Training Committee

Spring 2008

- Streamlined the RA training schedules to optimize RA learning experience

- Created the RA training satisfaction assessment

- Analyzed the RA training satisfaction assessment and developed a report containing future RA training quality enhancement initiatives 


\section{RESEARCH IN PROGRESS}

Tan, G. P. A dynamic residence life staff training conceptual framework focusing on personal values, individual strengths, and transferable skills.

Tan, G. P. 'The relationship between residents' service personal values, satisfaction, and behavioral intentions: An implication for housing and residence life administrators.

Tan, G. P., Hirschy, A. S., \& Keedy J. L. The influence of student cognitive development on student worker empowerment initiatives.

\section{GRANT}

\section{Funded}

Thompson, P. B., \& Tan, G. P. (2005). Midwest retail gasoline price asymmetry analysis, 1992 2005. Funded by the Central Michigan University Economics Department for year 2005 in the amount of $\$ 1,300.00$.

\section{Unfunded}

Smith, S. J., \& Tan, G. P. (2006). Examining the labor market for sport management doctoral faculty $(2000$ - 2004). Submitted to Central Michigan University Graduate School for year 2006 in the amount of $\$ 600.00$.

\section{PROFESSIONAL MEMBERSHIPS}

American College Personnel Association (Member) Association of College \& University Housing Officers - International (Member)

North America Society of Sport Management (Member) 


\section{PROFESSIONAL REFERENCES FOR GARY P. TAN}

T. Chris Greenwell, Ph.D. - Associate Professor Health and Sport Sciences, University of Louisville HP/Studio Arts, Room 103, Louisville KY 40292 (502) 852-0555

tcgreenwell@louisville.edu

Mary Hums, Ph.D. - Professor

Health and Sport Sciences, University of Louisville HP/Studio Arts, Room 107, Louisville KY 40292

(502) 852-5908

mhums@louisville.edu

Anita Moorman, J.D. - Associate Professor

Health and Sport Sciences, University of Louisville

HP/Studio Arts, Room 102, Louisville KY 40292

(502) 852-5908

amm@louisville.edu

John Keedy, Ph.D. - Professor

Leadership, Foundations, and Human Resource Education, University of Louisville Education Building, Room 336, Louisville KY 40292

(502) 852-0619

keedy@louisville.edu

Amy S. Hirschy, Ph.D. - Assistant Professor

Educational Counseling and Psychology, University of Louisville

Education Building, Room 325, Louisville KY 40292

(502) 852-0625

amy.hirschy@louisville.edu 